Portland State University

PDXScholar

\title{
An Experimental Investigation of Unbraced Reinforced Concrete Frames
}

Nourollah Samiee Nejad

Portland State University

Follow this and additional works at: https://pdxscholar.library.pdx.edu/open_access_etds

Part of the Engineering Science and Materials Commons Let us know how access to this document benefits you.

\section{Recommended Citation}

Nejad, Nourollah Samiee, "An Experimental Investigation of Unbraced Reinforced Concrete Frames" (1977). Dissertations and Theses. Paper 2566.

https://doi.org/10.15760/etd.2562

This Thesis is brought to you for free and open access. It has been accepted for inclusion in Dissertations and Theses by an authorized administrator of PDXScholar. Please contact us if we can make this document more accessible: pdxscholar@pdx.edu. 
AN ABSTRACT OF THE THESIS OF Nourollah Samiee Nejad for the Master of Science in Applied Science presented May 20, 1977.

Title: An Experimental Investigation of Unbraced Reinforced Concrete Frames

APPROVED BY MEMBERS OF THE THESIS COMMTTEE:



Wendelin H. Mueller, III



The main objective of this investigation is to study experimentally the behavior of rectangular reinforced concrete frames subject to a combination of low column loads, beam loads, and lateral load. The analytical tool used in this investigation is a computer program which is a generalized computational method for non linear force deformation relationship and secondary forces due to displacement of the joints during loading.

In the experimental portion of this investigation, two rectangular frames, one design by the U1timate Strength Design method and the other 
by a Limit Design method were prepared and tested to failure with short time loading.

Physical tests indicate that frames under the action of low gravity loads and lateral load became unstable after the formation of two hinges in the beams. 
AN EXPERIMENTAL INVESTIGATION OF

UNBRACED REINFORCED CONCRETE FRAMES

by

Nourollah Samiee Nejad

A thesis submitted in partial fulfillment of the

requirements for the degree of

\author{
MASTER OF SCIENCE \\ in \\ APPLIED SCIENCE
}

Portland State UnIversity

1977 
TO THE OFFICE OF GRADUATE STUDIES AND RESEARCH:

The members of the Committee approve the thesis of Nourollah Samiee Nejad presented May $2 Q 1977$.

TO MY PARENTS

Mohamad-Hossien Samiee Nejad

and

Khojasteh Samiee Nejad 


\section{ACKNOWLEDGMENTS}

I am deeply grateful to my advisor, Dr. F. N. Rad, for his guidance, patience, encouragement and invaluable suggestions throughout all phases of my research work. I would also like to thank members of my thesis committee, Drs. Mueller, Terraglio, and Gold for their helpful comments. Special appreciation and thanks are due to Messrs. Tom Gavin, Steve Speer and Steve Rinella for their technical assistance throughout the experiments. I also wish to thank Mr. Mark Borquist for his assistance in preparing of the figures. Finally, special thanks are due Donna Mikulic for typing this thesis. 
TABLE OF CONTENTS

PAGE

ACKNOWLEDGEMENTS. . . . . . . . . . . . . . . . . . . . . . . i i

LIST OF TABLES. ............................. vid

LIST OF FIGURES. ............................ vili

CHAPTER

I INTRODUCTION. .......................... 1

1.1 Genera1............................. 1

1.2 Reinforced Concrete Behavior Beyond the Elastic Stage........................ 1

1.3 Objective of this Investigation.............. 3

II ANALYTICAL APPROACH. ..................... 4

2.1 Genera1............................. 4

2.2 General Nonlinear Program NøNFIX7............ 4

2.3 Frame Selection....................... 6

a) General........................... 6

b) Frame USD-2........................... 6

c) Frame Analysis and Design of





e) Frame Analysis and Design of



III PHYSICAL TESTS......................... 24

3.1 General.............................. 24

3.2 Principle Properties of Frames................ 24

3.3 Materials............................ 26

3.4 Specimen Formwork...................... 26 
3.5 Specimen Fabrication, Detail, Casting,



3.6 Instrumentation...................... 30

a) General........................... 30

b) Loading Instrumentation................. 30

c) Concrete Strain Measurements............... 32

d) Corner Rotation Measurements.............. 32

e) Lateral Deflection Measurement............ 36

3.7 Loading System Components................ 36

a) General.......................... 36

b) Reaction Device and Sway Adjustment System........................... 42

c) Column Load Device................... 42

d) Beam Load Device.................... 46

e) Lateral Load Device.................. 46

IV Test Result and Predicted Behavior.............. 52

4.1 General Approach..................... 52

a) Load vs. Moment................... 52

b) Lateral Force vs. Components of Moment........ 53



d) Load vs. Corner Rotations............... 53

e) Load vs. Lateral Deflection............... 54

4.2 Frame UsD $-2 \ldots \ldots \ldots \ldots \ldots \ldots \ldots \ldots \ldots \ldots \ldots \ldots \ldots \ldots$

a) General......................... 54

b) Load vs. Moment................... 55

c) Lateral Load vs. Components of Moment........ 56

d) Lateral Load vs. $\delta \ldots \ldots \ldots \ldots \ldots \ldots \ldots \ldots \ldots \ldots$

e) Corner Rotations..................... 56

f) Load vs. Lateral Deflection.............. 56

4.3 Frame $L D-2 \ldots \ldots \ldots \ldots \ldots \ldots \ldots \ldots \ldots \ldots \ldots \ldots \ldots \ldots \ldots \ldots \ldots$

a) General..........................66 66

b) Load vs. Moment...................... 66

c) Lateral Load vs. Components of Moment........ 67

d) Lateral Load vs. $\delta \ldots \ldots \ldots \ldots \ldots \ldots \ldots \ldots \ldots \ldots \ldots 67$

e) Corner Rotations..................... 68

f) Load vs. Lateral Deflection.............. 68

4.4 Comparison of Trame USD-2 and LD-2.......... 77 
V SUMMARY, CONCLUSIONS, AND RECOMMENDATIONS........... 79 REFERENCES.................................. 81 


\section{LIST OF TABLES}

TABLE

PAGE

2.1 Bill of Reinforcement, Frame USD-2............ 14

2.2 Bill of Reinforcement, Frame $L D-2 \ldots \ldots \ldots \ldots \ldots \ldots \ldots \ldots$

3.1 Principle Properties of Frames................. 24

3.2 Measured Overall Geometry of Frames.............. 31 


\section{LIST OF FIGURES}

FIGURE

PAGE

2.1 Multistory Unbraced Frame.................. 5

2.2 Panel and Model Frame..................... 5

2.3 Service Loads and Loading Conditions............. 7

2.4 Moment Diagram, Frame USD-2................ 8

2.5 Frame USD-2 Detailing.................... 13

$2.6 \quad$ Reinforcing Detail...................... 14

2.7 Cross Sectional Dimensions.................. 15

2.8 Beam Moment Dlagram..................... 17

2.9 Frame LD-2 Detalling..................... 21

2.10 Reinforclng Detail Frame LD-2................ 22

2.11 Cross Sectional Dimensions of Beam and Column........ 23



3.2 Load Components of Test Frames................ 25

3.3 Schematic Diagram of the Form................ 28

3.4 Form Preparation Before Placing Beam and Column Cages............................. 28



3.6 Beam Cage Assembly....................... 29

3.7 Beam and Column Curvature Meters............... 33

Location of Curvature Meters, Rotation
Dials and Lateral Deflection Dial.............. 34

3.9 Curvature Meters in Position.................. 34

3.10 Corner Rotation Measurement System.............. 35 
3.11 Lateral Deflection Device................... 37

3.12 Schematic Diagram of Frame and Loading System........ 38

3.13 Detall of Concrete Reaction Beam................. 39

3.14 Overall view of Test Setup................... 40

$3.15 \quad$ Roller Nest............................. 40

$3.16 \quad$ Roller Nest System...................... 41

3.17 The Reaction Device....................... 43

3.18 Sway Adjustment System.................... 43

3.19 Bearing Head........................... 44

3.20 Column Bearing Head...................... 45

3.21 Column Head........................... 45

3.22 Detail of Wheel stand .................... 47

3.23 Elevation Diagram of Support Frame.............. 47

3.24 Column Heads Suspension System................. 48

3.25 Beam Head............................. 49

3.26 Lateral Load Assembly...................... 50

4.1 Axial Load-Moment Relationship, Frame USD-2......... 58

4.2 Lateral Force Moment Relationship, Frame USD-2....... 59

4.3 Components of Moment in Left Column Frame USD-2.......60

4.4 Lateral Force- $\delta$ Relationship, Frame USD-2.......... 61

4.5 Load-Corner Rotations, Frame USD-2.............. 62

4.6 Load-Lateral Deflection, Frame USD-2............. 63

4.7 Two Views of Frame USD-2 After Testing.............. 64

4.8 Two Views of Frame USD-2 After Testing............. 65

4.9 Axial Load-Moment Relationship, Frame LD-2......... 69

4.10 Lateral Force-Moment Relationship; Frame LD-2........ 70 
4.11 Components of the Moment in Left Column,



4.12 Lateral Force- $\delta$ Relationship, Frame LD-2........... 72

4.13 Corner Rotations, Frame LD-2................. 73

4.14 Load-Lateral Deflection, Frame LD-2.............. 74

4.15 Two Views of Frame LD-2 After Fallure.............. 75

4.16 Two Views of Cracks, Frame LD-2................ 76

4.17 Lateral Force vs. Lateral Deflection, Frames

USD -2 and $L D-2 \ldots \ldots \ldots \ldots \ldots \ldots \ldots \ldots \ldots \ldots \ldots \ldots$ 


\section{CHAPTER I}

\section{INTRODUCTION}

\subsection{GENERAL}

Although some of the early investigators of reinforced concrete favored design based on ultimate strength theories, working stress design (elastic theory) method was long the standard design procedure. In 1956, the ACI code authorized design based on ultimate strength. As compared to working stress design, ultimate strength design theory results in a more uniform factor of safety, a greater saving of material, and a more consistant design procedure. In 1964, the European Concrete Committee introduced the concept of limit state design (1).Mainly limit design method aims to satisfy three conditions: (1) limit equilibrium, (2) rotational compatibility, (3) serviceability.

This method of design takes the elastic moment pattern method (assumed by working stress and ultimate strength design methods) a stage further and allows moment redistribution.

\subsection{REINFORCED CONCRETE BEHAVIOR BEYOND THE ELASTIC STAGE}

To understand the behavior of any structure, behavior of its components such as beams and columns, and the materials used in the structure must be well understood. There has been a large number of investigations both analytically and experimentally on the behavior of reinforced concrete members and frames in recent years and a few are summarized below: 
In 1961 a report on limit design was published by the Institution Research Committee on U1timate Load Design. In this report, the fundamental theory and application of limit design were reviewed and a design method suggested. In this method, positions of plastic hinges and the values of rotation at hinges in a structure are obtained by a trial and adjustment procedure (2).

Limit design theories for reinforced concrete statically indeterminate structures require a knowledge of rotation capacity of hinging regions. Results of thirty-seven tests of double reinforced beams (3) showed that maximum concrete compressive strain was very much in excess of the usually assumed value of .003 . Consequent1y, the curvature at ultimate strength can also be very much greater than the value calculated on the assumption that the maximum concrete compressive strain is IImited to .003 . So the inelastic rotation occuring in the hinging regions was considerably greater than might be expected.

In 1968, ACI-ASCE Committee 428 Limit Design, submitted a report on "Mode1 Code Clauses" (4) based on recent developments on nonlinear behavior of reinforced concrete structures. The suggested model clauses defined envelopes, or upper and lower limits, rather than a single method of design.

There also has been extensive research on the strength of long reinforced concrete columns in recent years $(5,6)$. Some investigations have particularly focused on framed columns. In unbraced frames, moments due to lateral deflection of frame may become very significant. In a recent investigation (7), the behavior of single story two column reinforced concrete frames under combined loading was studied. The re- 
sults indicated that the frames under the action of large gravity loals and lateral load become unstable after the formation of two hinges at leeward joints, either in the ends of column or the adjacent beam.

\subsection{OBJECTIVES OF THIS INVESTIGATION}

The main objective of this investigation was to study experimentally the behavior of rectangular reinforced concrete frames, subjected to a combination of low column loads, beam loads, and latera1 loads.

The main portion of this investigation may be outlined as follows:

1) To describe the design and loading condition of the test frames, discussed in Chapter II.

2) To describe the design and fabrication of the loading system, discussed in Chapter III.

3) To describe the physical test behavior of two frames and the predicted behaviors by a computer analysis. This portion is explained in Chapter IV.

Chapter $\mathrm{V}$ contains a summary and conclusions of this investigation. 


\section{CHAPTER II}

\section{ANALYTICAL APPROACH}

\subsection{GENERAL}

The main purpose of this investigation was to determine physical behavior of two unbraced rectangular reinforced concrete frames, one designed by the ultimate strength design method and the other by a limit design method.

An unbraced multistory structure is shown in Fig. 2.1. One portion of this structure (one story, one bay) as shown in Fig. $2.2(\mathrm{a}, \mathrm{b})$ represents the behavior of each panel. This panel is acted upon by column loads, floor loads shown as two concentrated loads (Q) at beam third points, and wind (or earthquake) load. Since this frame is antisymmetrical with respect to a horizontal axis through the mid height of the column, only the top half of the frame is selected for analytical and experimental work in this investigation.

\subsection{GENERAL NONLINEAR PROGRAM NØNFIX7}

The main analytical tool used in this investigation was computer


"NØNFIX5" developed by Gunnin (8). Program NONFIX7 is a generalized computational method for a nonlinear force-deformation relationship and secondary forces due to displacement of the joints during loading. The thrust-moment-curvature relationships for individual members are constructed using a subroutine which assumes Hognestad (9) stress-strain 




Figure 2.1 Multistory unbraced frame


Figure 2.2 Panel and model frame 
curve for steel in tension and compression. A complete description of this computer program can be found in Ref. (7) and Ref. (8).

\subsection{FRAME SELECTION}

a) General - Several test frames were analyzed using a nonlinear computer program and a model study. A recent model study (7) indicated that as the number of stories increase, thus increasing column thrusts, a condition of frame stability failure may result. Computer analyses(11) indicated that the number of stories should not go above 6 or 7 , if limit design is to be used for design of unbraced concrete frames. Accordingly, test frames representing the lowest level of a seven story structure were selected. Figure 2.1 shows a seven story structure with floor loads and lateral loads. The relationships $Q / T=1 /(2 n-1)$, and $Q / P=1 /(2 n-2)$ exist between gravity loads, where $Q$ is the beam load at third point, $T$ is column thrust, $P$ is column load (applied at top), $\mathrm{n}$ is number of stories. Based on the above relationship, for $\mathrm{n}=7$, a $Q / P$ of 0.083 was selected for the test frames. Frames USD-2 and LD-2 were designed by Gavin (11).

b) Frame USD-2 - The assumed service loads are shown in Fig. 2.3. The ACI 318-7I (10) code equations $9-1$ and 9-2 were applied to determine the factored loads. Based on these loads frame USD-2 was designed by the Ultimate Strength Design method using ACI 318-71 provisions. Capacity reduction factor $(\emptyset)$ was assumed as 1.0 , and the columns were designed such that their capacities were slightly greater than the beam, so the hinges would form in the beam. Beam moment diagram including $\mathrm{P}-\Delta$ moments, for both loading conditions is shown in Fig. 2.4. 

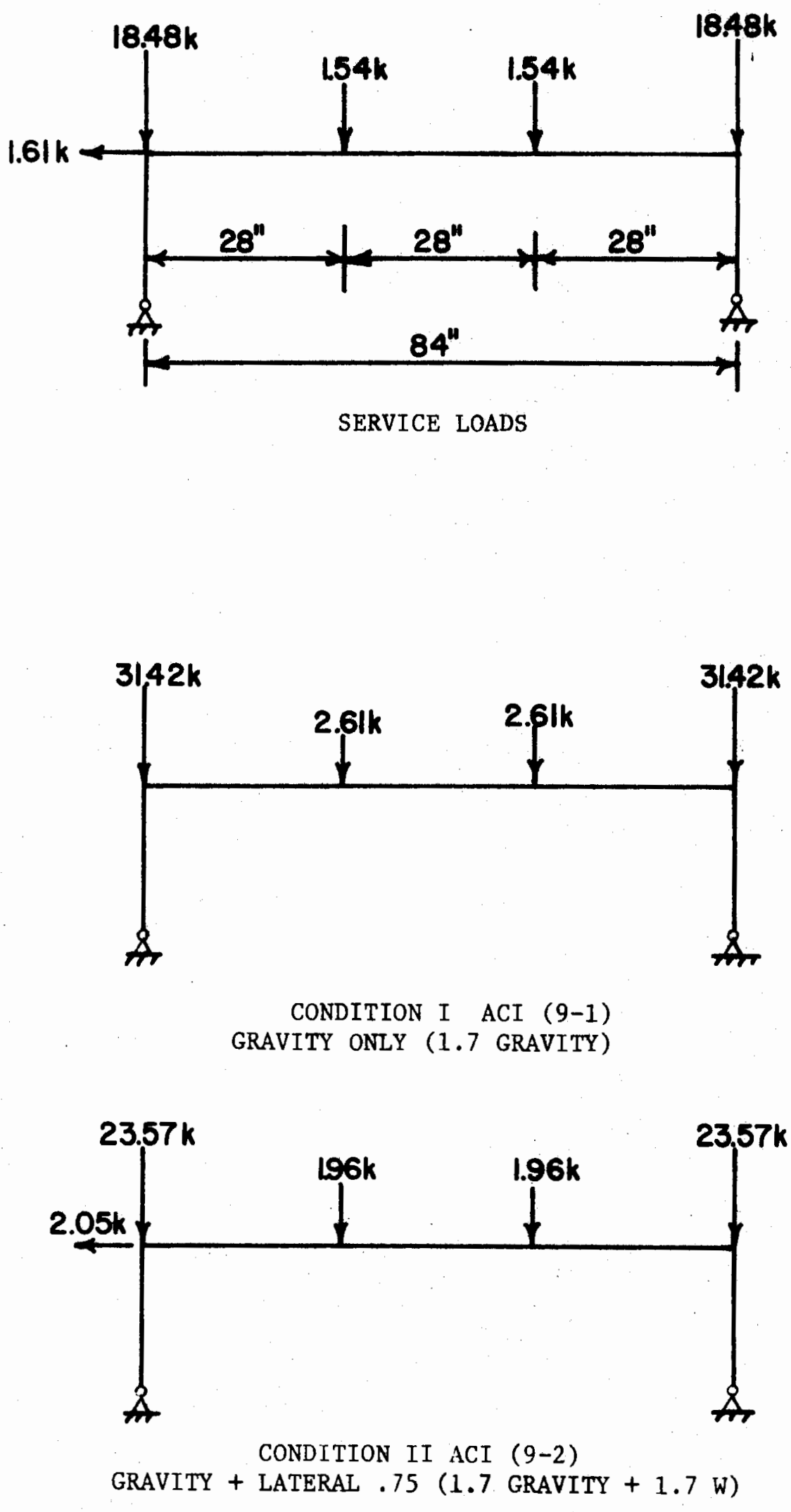

Figure 2.3 Service loads and loading conditions 




Figure 2.4 Moment diagram, frame USD-2 
c) Frame analysis and design of frame USD-2 - Brief design procedure is given below, but a more complete analysis and design of frames may be found in Ref. 11 .

Column Design:

$$
\begin{aligned}
& \text { Try } b=6.00 \text { in } h=4.00 \text { in } 4 \text { 非 bars } \\
& \mathrm{f}_{c}^{\prime}=4000 \mathrm{psi} \quad \mathrm{f}_{\mathrm{y}}=60.9 \mathrm{ksi}
\end{aligned}
$$

Condition I (Gravity)

$$
\mathrm{P}_{\mathrm{u}}=34.03 \mathrm{k}
$$

Column base shear $=1.88 \mathrm{k}$

$$
\begin{aligned}
& \text { (d) face } M_{u}=18.75^{\prime \prime} \times 1.88=35.3 \mathrm{k} \text {-in } \\
& d^{\prime}=.105+.1875+.4573=.75 \mathrm{in} \\
& \gamma=\frac{h_{-2} d^{\prime}}{h}=\frac{4.00-(2)(.75)}{4}=.63
\end{aligned}
$$

Flexural stiffness of beam and column from $\mathrm{P}-\mathrm{M}-\emptyset$ plots (not shown):

$$
\begin{aligned}
\beta_{d}=0 \quad E I_{c} & =51000 \mathrm{k}-i n^{2} \\
E I_{b} & =51800 \mathrm{k}-i n^{2}
\end{aligned}
$$

Determine $k$ :

$$
\begin{aligned}
& \psi_{B}=\frac{E I_{c} / L_{c}}{E I_{b} / L_{b}}=\frac{51000 / 21}{51800 / 84}=3.94 \\
& \psi_{A}=\infty
\end{aligned}
$$

From Jackson and Moreland's nomograph (12)

$$
\begin{aligned}
& \mathrm{K}=3.2 \\
& \mathrm{P}_{\mathrm{c}}=\frac{\pi^{2} \mathrm{EI} \mathrm{c}}{(\mathrm{K} l \mathrm{u})^{2}}=\frac{\pi^{2} \times 51000}{(3.2 \times 18.75)^{2}}=139.8 \mathrm{k}
\end{aligned}
$$




$$
\begin{aligned}
& \delta=\frac{\mathrm{C}_{\mathrm{m}}}{1-\mathrm{P}_{\mathrm{u}} / \mathrm{P}_{\mathrm{c}}}=\frac{1.0}{1-34.03 / 139.8}=1.32 \\
& M_{c}=\delta M_{2}=1.32 \times 35.6=46.6
\end{aligned}
$$

Analysis:

$$
\begin{aligned}
& \delta \mathrm{e} / \mathrm{h}=\frac{1.32 \times 46.6}{34.03 \times 4.0}=.452 \\
& \mathrm{~m}=\frac{\mathrm{f}_{\mathrm{y}}}{.85 \mathrm{f}_{\mathrm{c}}}=\frac{60.9}{(.85)(4)}=17.7 \\
& \rho_{\mathrm{t}} \mathrm{m}=.0183 \times 17.7=.324
\end{aligned}
$$

From ACI SP-17A "Ultimate Strength Design Handbook" (13)

$$
\text { Capacity } \mathrm{K}=.29
$$

For $\emptyset=1 \quad K=\frac{.29}{.7}=.41$

Required $K=\frac{P_{u}}{f_{c}^{\prime} b t}=\frac{34.03}{(4)(6)(4)}=.35<.41 \quad$ OK

Condition II (Gravity + Lateral)

$P_{u}=26.04 \mathrm{k}$

$\mathrm{M}_{\mathrm{u}}=18.75 \times 2.44=45.8 \mathrm{k}-\mathrm{in}$

$E I_{c}=49600 \mathrm{k}-\mathrm{in}^{2}$

$E I_{b}=51800 k-i n^{2}$

$\psi_{B}=\frac{E I_{c} / L_{c}}{E I_{b} / L_{b}}=\frac{49600 / 21}{51800 / 84}=3.83$

$\psi_{\mathrm{A}}=\infty$

$K=3.2$ 
Moment magnifiers $(\delta)$ :

$P_{c}=\frac{\pi^{2} E I c}{(K 1 u)^{2}}=\frac{\pi^{2} \times 49600}{(3.2 \times 18.75)^{2}}=136.00 \mathrm{k}$

$\delta=\frac{C_{m}}{1-P_{u} / P_{c}}=\frac{1.0}{1=26.04 / 136}=1.24$

$\delta M=1.24 \times 45.8=56.7$

$\rho_{t} m=.324, \quad \delta \mathrm{e} / \mathrm{h}=.545$

From ACI SP-17A "Ultimate Strength Design Handbook" (13)

Capacity $\mathrm{K}=\frac{.24}{.7}=.34$

Required $\mathrm{K}=\frac{\mathrm{P}_{\mathrm{u}}}{\mathrm{f}_{\mathrm{c}}^{\mathrm{bt}}}=\frac{26.04}{(4)(6)(4)}=.271<.34 \quad$ OK

Previous trial and exrors and $P-M-\emptyset$ plots are not shown.

Beam design:

Draw moment diagram considering joint block statics.

Negative moment e critical section $=57.4 \mathrm{k}$-in

Try: $b=6.00^{\prime \prime} \quad h=4.5^{\prime \prime}, f_{c}^{\prime}=4.00 \mathrm{ks}, 2$ 非 3 bars

$f_{y}=77.3 \mathrm{kis}$

Analysis :

$d=3.75$ (previous trial \& error not shown)

$\mathrm{T}=A_{s} f_{y}=2(.11)(77.3)=17.0 \mathrm{~K}$

$\mathrm{C}=\mathrm{T}$

$.85 \mathrm{f}_{\mathrm{c}} \mathrm{a} \times \mathrm{b}=17 ; \mathrm{a}=.833$ in 
$M=T(d-a / 2)=57.3 \mathrm{k}-$ in $\quad$ OK

Positive moment e critical section $=37.3 \mathrm{k}-$ in

Try: $b=6.00^{\prime \prime} \quad h=4.00^{\prime \prime} \quad d=3.43^{\prime \prime}$ (after trial \& error) $f_{c}^{\prime}=4.00 \mathrm{ksi} \quad f_{y}=54.1 \mathrm{ksi}$

Analysis :

$T=A_{s} f_{y}=(.22)(54.1)=11.9 \mathrm{k}$

$\mathrm{C}=\mathrm{T}$

$.85 \mathrm{f}_{c}^{\prime} a b=11.9 \mathrm{k} ; \mathrm{a}=.583 \mathrm{ln}$

$M=T(d-a / 2)=37.3 \mathrm{k}-$ in $\quad$ OK

Check shear:

$v_{u}=v_{u} / \emptyset b_{w} d=\frac{2890}{(1.0)(6)(3.79)}=127.1 \mathrm{psi}$

$v_{c}=2 \sqrt{f_{c}^{\prime}}=2 \sqrt{4000}=126.5 \mathrm{psi}$

$v_{s}=127.1-126.5=.60 \mathrm{psi}$

Use $\# 12$ gage wire st1rrups $0 \mathrm{~d} / 2=3.79 / 2=1.90$ in spacing. No stirrups required in midspan section.

The envelope moment diagram with detailing of the frame is shown in Fig. 2.5. Complete reinforcing detail of frame USD-2 is presented in Fig. 2.6 and bill of reinforcing is 1isted in Table 2.1. Cross sectional dimensions of the beam and column are shown in Fig. 2.7. 




DETAILING OF FRAME USD-2

Figure 2.5 Frame IISD-2 detailing 




Table 2.1 Bill of reinforcing frame USD-2

\begin{tabular}{|c|c|c|c|c|c|}
\hline BAR & NO. BARS & SIZE & $f_{y}$ ksi & DIM. "A" & LENGTH \\
\hline$U-1$ & 2 & 3 & 77.3 & $2^{\prime}-2^{\prime \prime}$ & $2^{\prime}-8^{\prime \prime}$ \\
\hline$U-2$ & 2 & 3 & 77.3 & $3^{\prime}-2^{\prime \prime}$ & $3^{\prime}-8^{\prime \prime}$ \\
\hline$U-3$ & 1 & 3 & 54.1 & - & $5^{\prime}-7^{\prime \prime}$ \\
\hline$U-4$ & 1 & 3 & 54.1 & $8^{\prime}-6^{\prime \prime}$ & $9^{\prime}-6^{\prime \prime}$ \\
\hline$U-5$ & 8 & 3 & 60.9 & & $4^{\prime}-1 k^{\prime \prime}$ \\
\hline
\end{tabular}

Figure 2.6 Reinforcing detail 

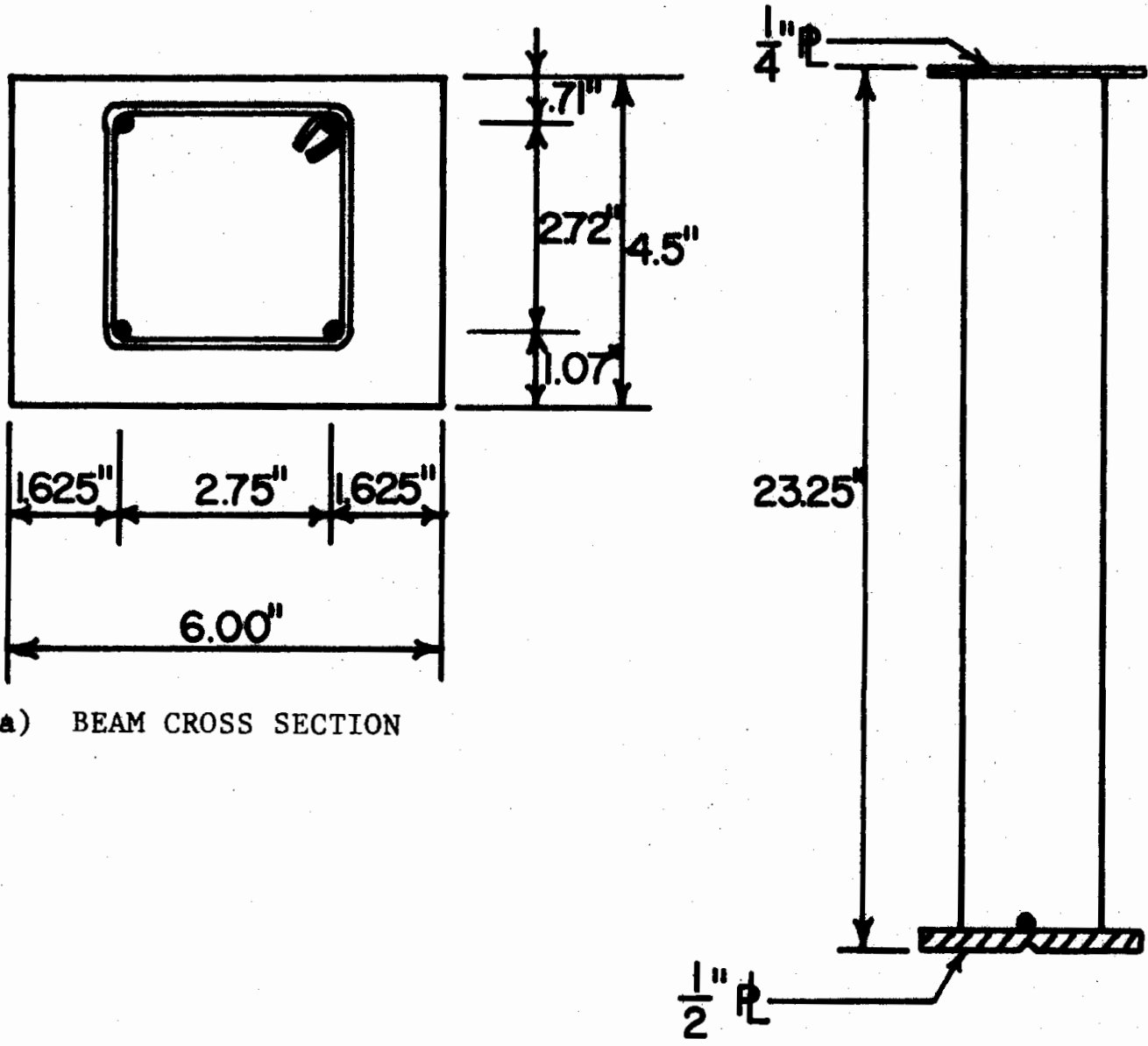

a) BEAM CROSS SECTION

c) COLUMN CAGE
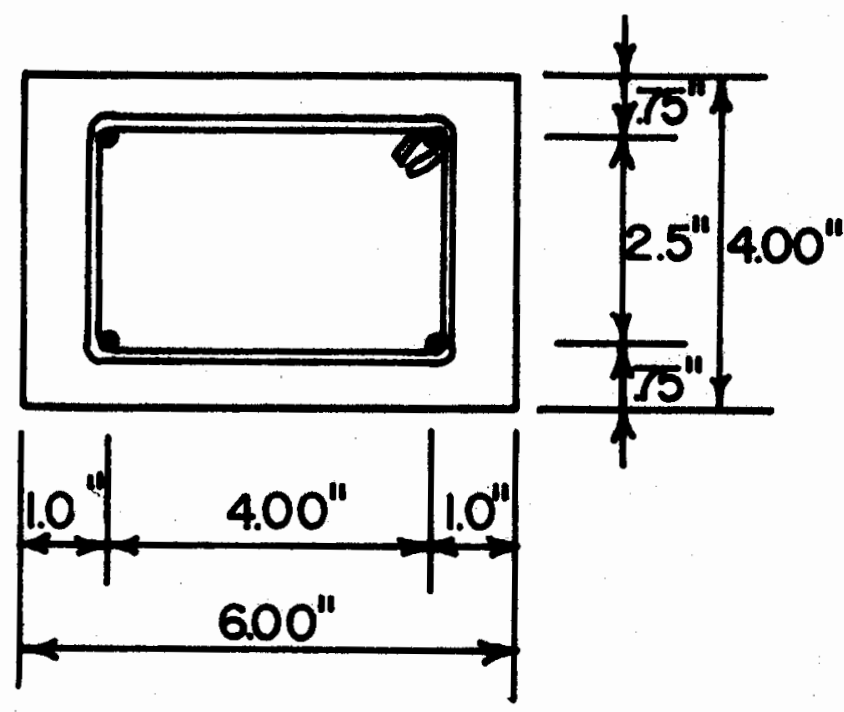

b) COLUMN CROSS SECTION

Figure 2.7 Cross sectional dimensions 
d) Frame LD-2 - Frame LD-2 was designed based on the mechanism method. To account for $P-\Delta$ moments an estimate of the failure load was determined using Merchant-Rankin formula modified by Wood (14) as: $1 / \lambda f=1 / \lambda_{p}+1 / \lambda c$; where $\lambda f$ is the collapse load factor of a partially plastic multi-story structure, $\lambda p$ is the 1dealized rigidplastic collapse load factor, and $\lambda c$ is the elastic critical load factor. To achieve a design $M_{P}$, the plastic collapse load factor was increased to account for the $\mathrm{P}-\Delta$ moments. The two loading conditions for the frame LD-2 are shown in Fig. 2.3. The beam moment diagram with $\mathrm{P}-\Delta$ moment included are drawn for both loading conditions in Fig. 2.8.

e) Frame analysis and design of frame LD-2

Column design:

Try columns $b=6.00$ in $h=3.75$ in 4 非 3 bars

$$
\mathrm{f}_{\mathrm{c}}^{\prime}=4000 \mathrm{psi} \quad \mathrm{f}_{\mathrm{y}}=59.1 \mathrm{ksi}
$$

Condition I (Gravity)

Flexural stiffness of beam and column from $P-M-\emptyset$ polts (not

shown):

$$
\begin{aligned}
\beta_{d}=0 \quad E I_{c} & =41900 \mathrm{k}-i n^{2} \\
E I_{b} & =48700 \mathrm{k}-i n^{2}
\end{aligned}
$$

Determine $\mathrm{K}$

$$
\begin{aligned}
& \psi_{B}=\frac{E I_{C} / L_{C}}{E I_{b} / L_{b}}=\frac{41900 / 21}{48700 / 84}=3.44 \\
& \psi_{A}=\infty \\
& K=3.0
\end{aligned}
$$




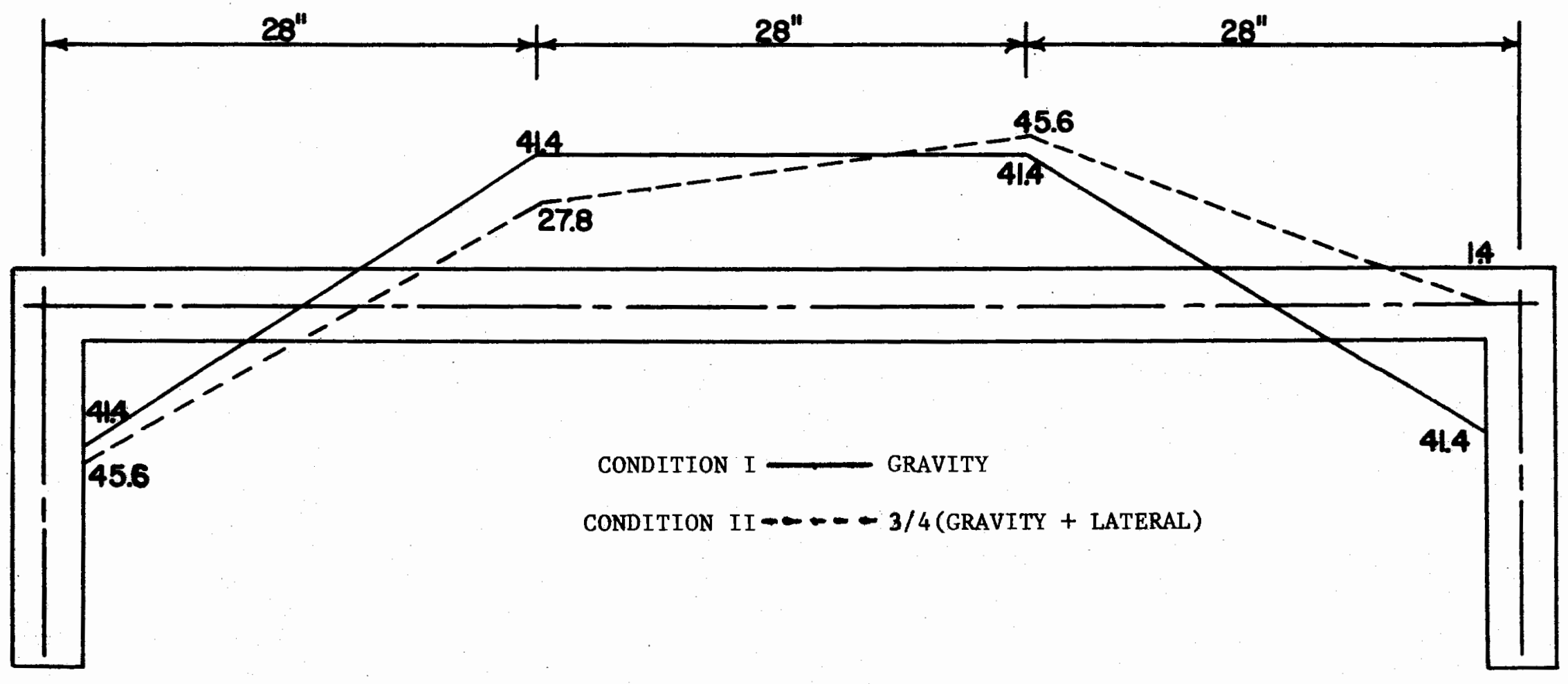

Figure 2.8 Beam moment diagram frame LD-2 


$$
\begin{aligned}
& P_{c}=\frac{\pi^{2} I_{c}}{(K I u)^{2}}=\frac{(\pi)^{2}(41900)}{(3 \times 18.75)^{2}}=130.7 \mathrm{k} \\
& \lambda_{E}=\frac{\text { Critical Load }}{\text { Service Load }} \\
& \lambda_{E}=\frac{130.7}{18.48+1.54}=6.53 \\
& \lambda_{P}=\frac{.9 \lambda_{F} \lambda_{E}}{\lambda_{E}{ }^{-\lambda_{F}}}=\frac{(.9)(1.7)(6.53)}{6.53-1.7}=2.07
\end{aligned}
$$

Required $\mathrm{M}_{\mathrm{P}}$ :

$M_{P}=\frac{P_{a} L_{b}}{7.77}$ from mechantsm analysis (not shown)

$M_{\mathrm{P}}=\frac{(2.07)(18.48)(84)}{77.7}$

Required $\quad \mathrm{M}_{\mathrm{P}}=41.4$

Equivalent $(\delta)$

$\delta=\frac{41.4}{34}=1.22$

Condition II (Gravity + Lateral)

$$
\begin{aligned}
& E I_{c}=42400 \mathrm{k}-1 \mathrm{n}^{2} \\
& E I_{b}=48700 \mathrm{k}-1 \mathrm{n}^{2}
\end{aligned}
$$

Determine $\mathrm{K}$

$$
\psi_{B}=\frac{E I_{c} / I_{c}}{E I_{b} / L_{b}}=\frac{42400 / 21}{48700 / 84}=3.48
$$

$$
\begin{aligned}
& \psi_{A}=\infty \\
& K=3.1 \\
& P_{C}=\frac{\pi^{2} E I}{(K I u)^{2}}=\frac{\pi^{2} \times 42400}{(3.1)(18.75)^{2}}=123.9 \mathrm{k}
\end{aligned}
$$




$$
\begin{aligned}
& \lambda_{\mathbf{E}}=\frac{\text { Critical Load }}{\text { Service Load }} \\
& \lambda_{E}=\frac{123.9}{15.32}=8.09 \\
& \lambda_{P}=\frac{.9 \lambda_{F} \lambda_{E}}{\lambda_{E}-\lambda_{F}}=\frac{(.9)(1.7)(8.09)}{8.09-1.7}=1.94
\end{aligned}
$$

Required $\mathrm{M}_{\mathrm{P}}$

$M_{P}=\frac{P_{u} L_{b}}{49.5} \quad$ from mechanism analysis (not shown)

$$
\mathrm{M}_{\mathrm{P}}=45.6
$$

Equivalent $(\delta)$

$$
\delta=\frac{45.6}{40}=1.14
$$

Beam Design:

Required $M_{p}=45.6 \mathrm{k}$-in (negative \& positive)

$$
\text { Try: } \begin{aligned}
b & =6.00 \text { in } h=4.5 \text { in } 2 \# 3 \text { bars } \quad f_{c}^{\prime}=4000 \text { psi } \\
f_{y} & =60.9
\end{aligned}
$$

Analysis:

$$
\begin{aligned}
& d=3.73 \text { (previous trial \& error not shown) } \\
& T=A_{s} f_{y} \\
&=(2)(.11)(60.9)=13.4 \mathrm{k} \\
& C=T \\
& .85 f_{c}^{\prime} a b=13.4 \mathrm{k} \\
& \mathrm{a}=13.4 /(.85)(4)(6)=.6571 \mathrm{n} \\
& M=T(d-a / 2) \\
&=13.4(3 / 73-.657 / 2)
\end{aligned}
$$


$M=45.6 \mathrm{k}-$ in ok

Check shear

$$
\begin{aligned}
\emptyset=1.0 \quad v_{u} & =v_{u} / 6 b_{w} d \\
v_{u} & =3170 /(1.0)(6)(3.73)=141.6 \mathrm{psi} \\
v_{c} & =2 \sqrt{f_{c}^{\prime}}=2 \sqrt{4000}=126.5 \mathrm{psi} \\
v_{s} & =141.6-126.5=15.1 \mathrm{psi}
\end{aligned}
$$

use \#12 GA stirrups a $d / 2=3.73 / 2=1.87 \mathrm{in}$.

No stirrups required in mid span region

Detalling of the frame is shown in Fig. 2.9. Table 2.2 shows the b111 of reinforcing and the complete reinforcing detail is shown in Fig. 2.10. Nominal cross sections for beam and column are shown in Fig. 2.11. 


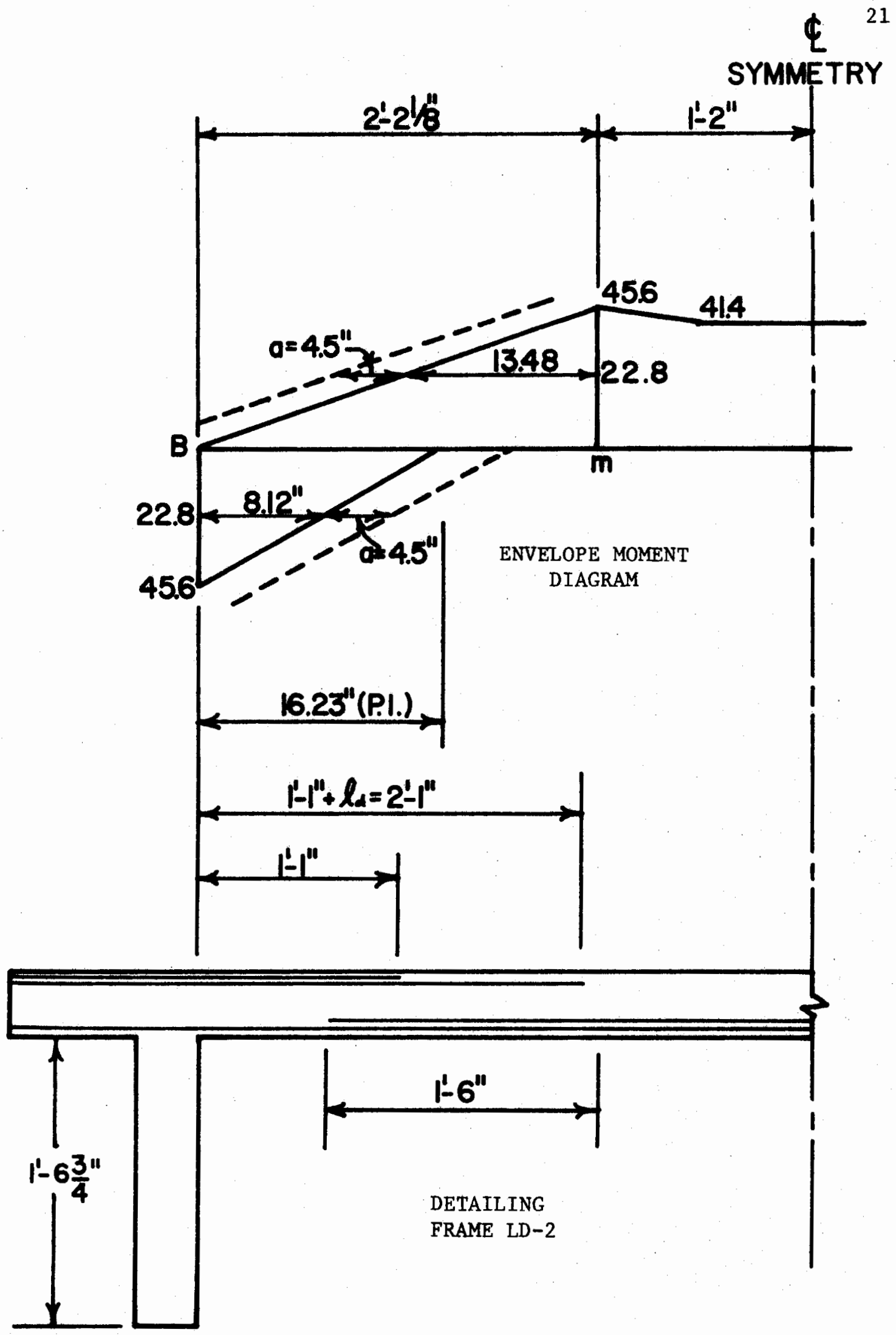

Figure 2.9 Frame LD-2 detailing 




Table 2.2 Bill of reinforcing frame $L D-2$

\begin{tabular}{|c|c|c|c|c|c|}
\hline BAR & NO.BARS & SIZE & fy ksi & DIM "A' & LENGTH \\
\hline$U-1$ & 2 & 3 & 60.9 & $2^{\prime}-0^{\prime \prime}$ & $2^{\prime}-6^{\prime \prime}$ \\
\hline$U-2$ & 2 & 3 & 60.9 & $3^{\prime}-0^{\prime \prime}$ & $3^{\prime}-6^{\prime \prime}$ \\
\hline$U-3$ & 1 & 3 & 60.9 & & $5^{\prime}-4^{\prime \prime}$ \\
\hline$U-4$ & 1 & 3 & 60.9 & $8^{\prime}-6^{\prime \prime}$ & $9^{\prime}-6^{\prime \prime}$ \\
\hline$U-5$ & 8 & 3 & 59.1 & - & $4^{\prime}-11 / 4^{\prime \prime}$ \\
\hline
\end{tabular}

Figure 2.10 Reinforcing detail frame LD-2 

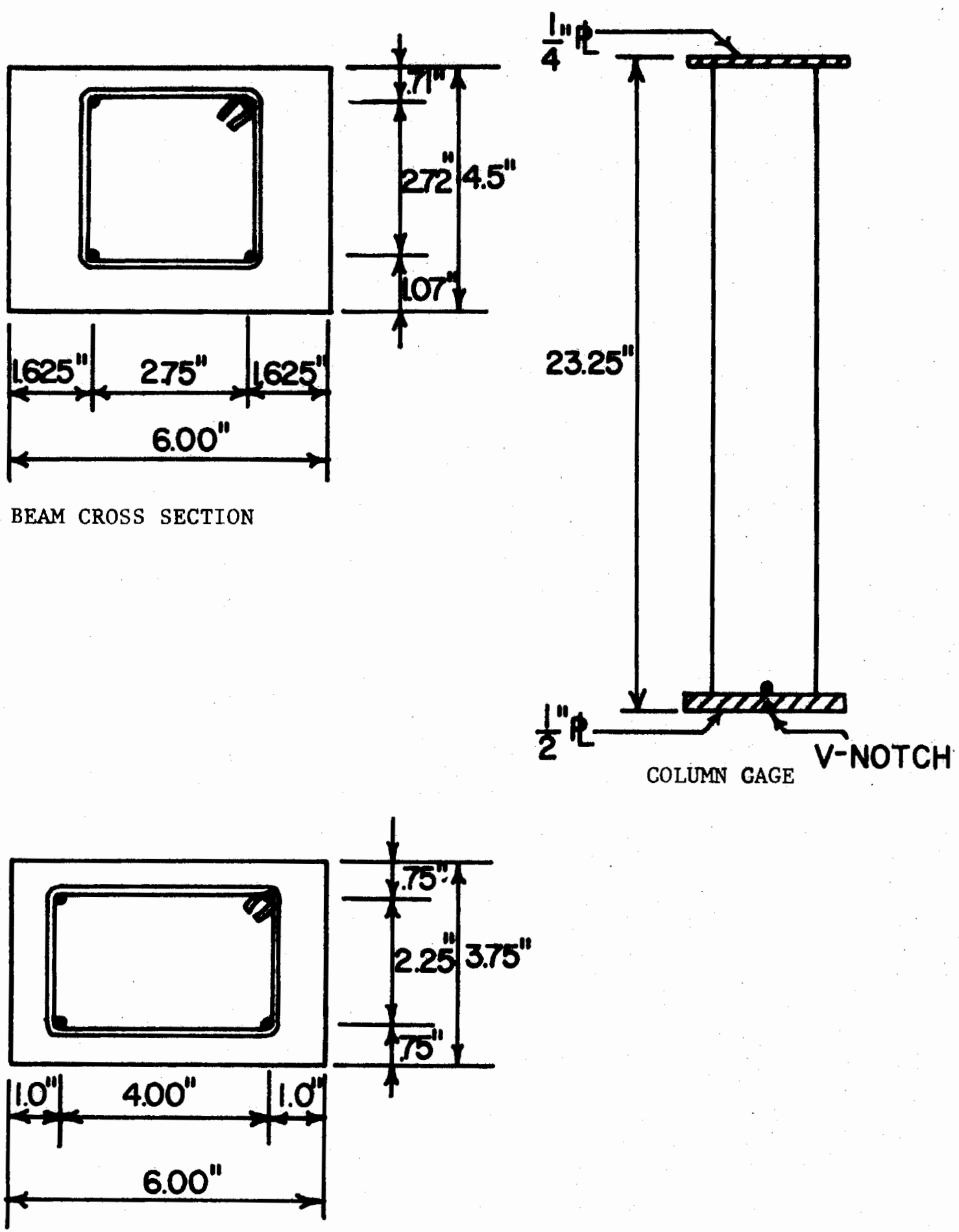

COLUMN CROSS SECTION

Figure 2.11 Cross sectional dimensions of beam and column 


\section{CHAPTER III}

\section{PHYSICAL TESTS}

\subsection{GENERAL}

As the experimental part of this investigation two frames, designated as USD-2 and LD-2 were prepared and tested to failure with short time loading in horizontal position. Frames USD-2 and LD-2 are shown schematically in Fig. 3.1. These frames were symetrical with respect to the vertical axis through beam mid-span. The load components are shown in Fig. 3.2. Preparation of the specimens, instrumentation, loading and testing were done in the concrete laboratory, Portland State University.

\subsection{PRINCIPAL PROPERTIES OF FRAMES}

The principal properties of the two frames, measured after frames were cast, are listed in Table 3.1. The quantity $\rho_{t}$ is defined as the total reinforcement/gross area.

TABLE 3.1 PRINCIPLE PROPERTIES OF THE FRAME

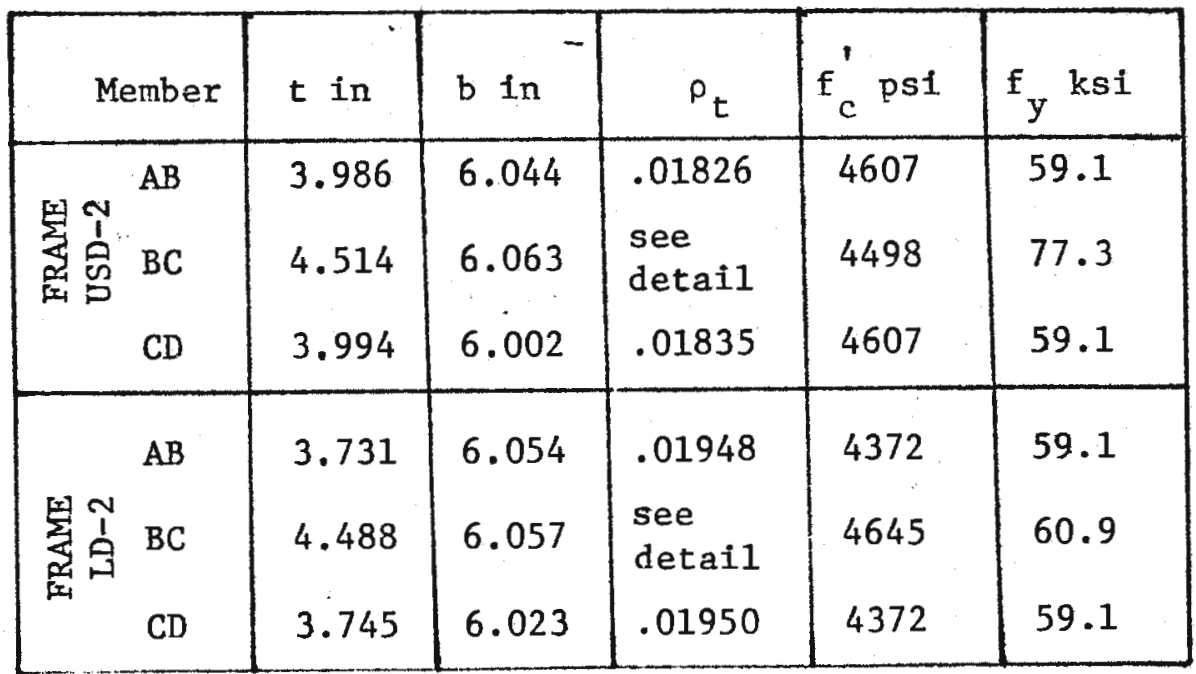



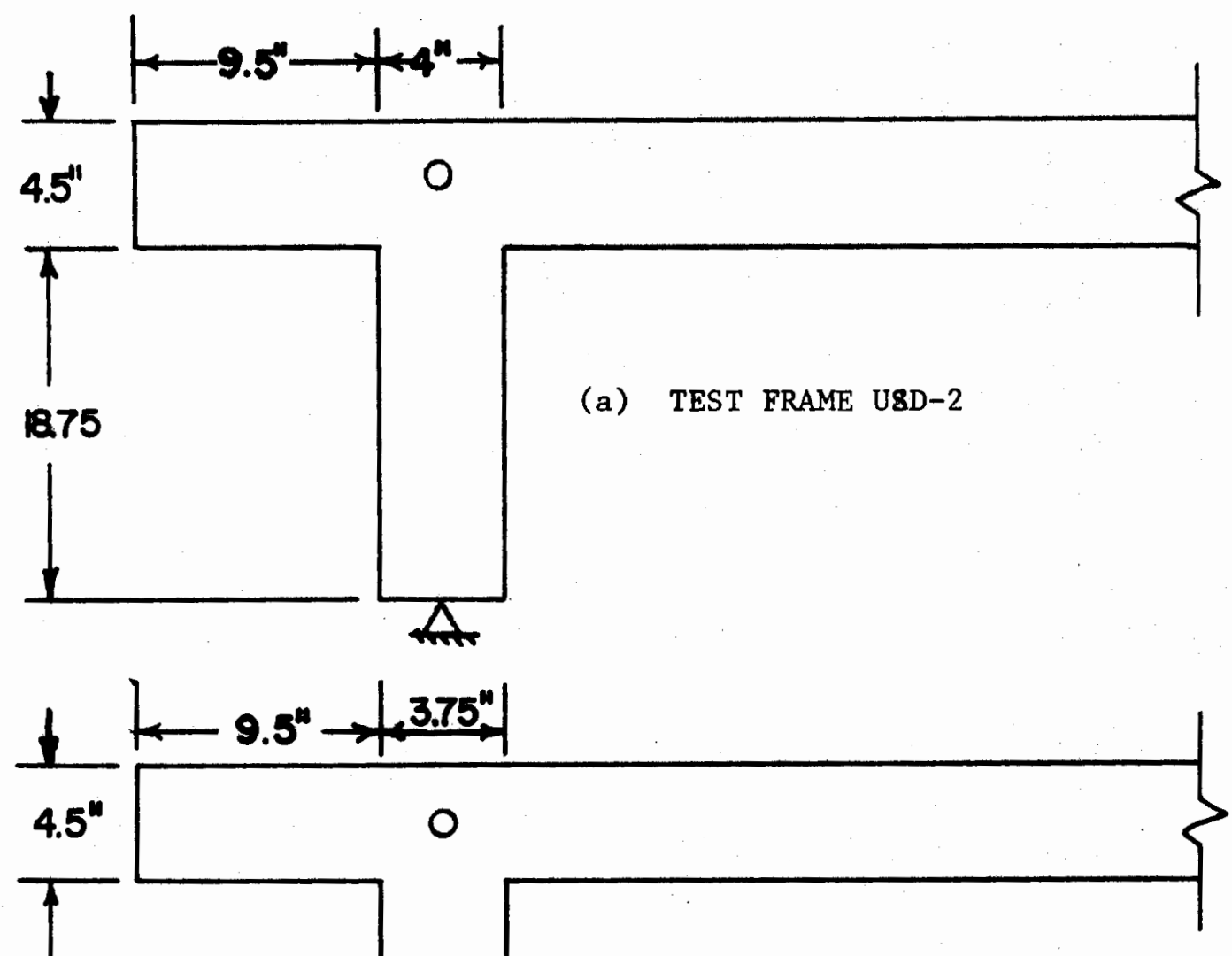

(b) TEST FRAME LD-2

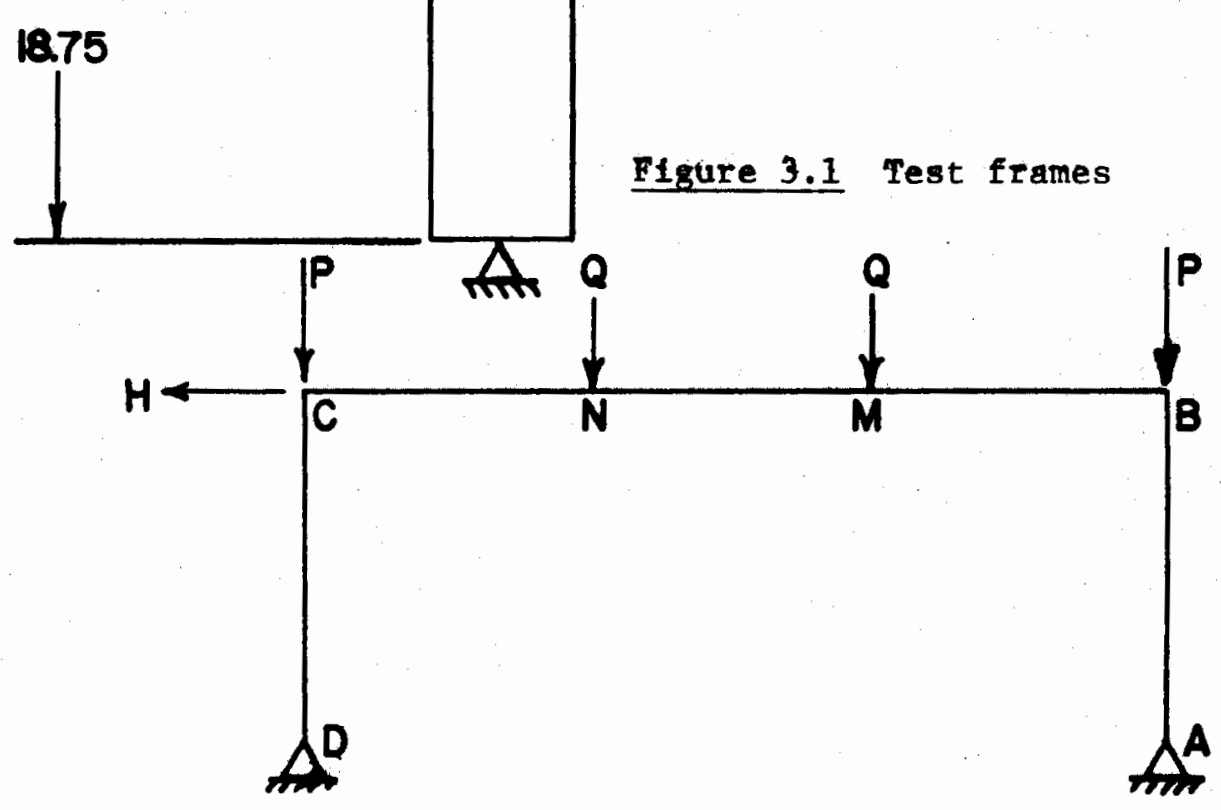

F1gure 3.2 Load componénts of test frames 


\subsection{MATERIALS}

a) Reinforcing steel - different sizes of intermediate grade steel were used in the frames. The relnforcing bars in all columns and beams were $\# 3$ bars. The tension yield strength of the reinforcing steel was obtained from test coupons which were cut from bar stocks and tested by the Material Testing System hydraulic machine at Portland State University

b) Concrete - the concrete mixture was designed to provide an average compressive strength of 4000 psi at six days. The cement used was Type III (high early strength), the fine aggregate was Willamette River basin sand and the coarse aggregate was graded pea grave1 of $3 / 8$ in. maximum size.

\subsection{SPECIMEN FORMWORK}

The forms used consisted of 10 inch steel channels welded together, used as the base, and 6-inch steel channels for the sides. Base channels were laid on $2 \times 4$ lumber grillage and were levelled in both directions using a hand level. Raising the forms by $2 \times 4$ sections facilitated erection and removal of the side channels. The center line of the frame was scribe marked on the base channels and accurate dimensions of the frame at the base were maintained by adjusting the position of the side channels. In order to adjust the side channel to proper positions, 18 pieces of 4 inch angles were welded to the base channels at frequent intervals. A bolt was welded to side channels at these intervals and through a drilled hold in angles with two nuts at each side. Proper dimensions at the top surface were then maintained by adjusting the 
positions of the nuts. Schematic diagram and a photograph of the forms are shown in Fig. 3.3 and 3.4 .

\subsection{SPECIMEN FABRICATION, DETAILS, CASTTNG AND CURING}

Both frames USD-2 and $\mathrm{LD}-2$ were reinforced with $\# 3$ bars. Nomina1 cross sections of the beams and columns are shown in Fig. 2.7 and 2.11. Both frames had a beam cross section of 6.00 in. wide by 4.5 in. deep. Columns in frame USD-2 were $4.00 \mathrm{in.} \mathrm{deep} \mathrm{by} 6$ in. wide, and frame LD-2 columns were 3.75 in. deep by $6.00 \mathrm{in.} \mathrm{wide.}$

A typical column cage contained two plates at top and bottom with planar dimensions same as column cross sections. Reinforcing bars were welded to these plates at predrilled hold location and reinforcing bars were tied by $\# 12$ gage wire ties and $4.00 \mathrm{in}$. intervals. Fig. 3.5 shows a typical column cage.

For assembling the beam cage, rebars were cut allowing $10.00 \mathrm{in}$. at one end, and bent into a $180^{\circ}$ hook using a bar bending jig. The one continuous bar in each beam was hooked at both ends. Beam cages were assembled by placing the bars on wooden supports, and tied with \#12 gage wire stirrups at 1.9 inch intervals where stirrups were required by design. Fig. 3.6 shows a typical beam cage.

To obtain the same concrete cover as in design, small steel chairs were tied to the beam cage on three faces, at frequent intervals. Once the cages were ready the form was oiled and cages were placed in the form. A $7 / 8$ in. (0.D.) $\times 6$ in. steel pipe was inserted through the cage and the base channel at the intersection of beam and leeward column center 1ines. This pipe was used for application of the lateral load. Concrete was then poured to the level of the form and a small vibrator 


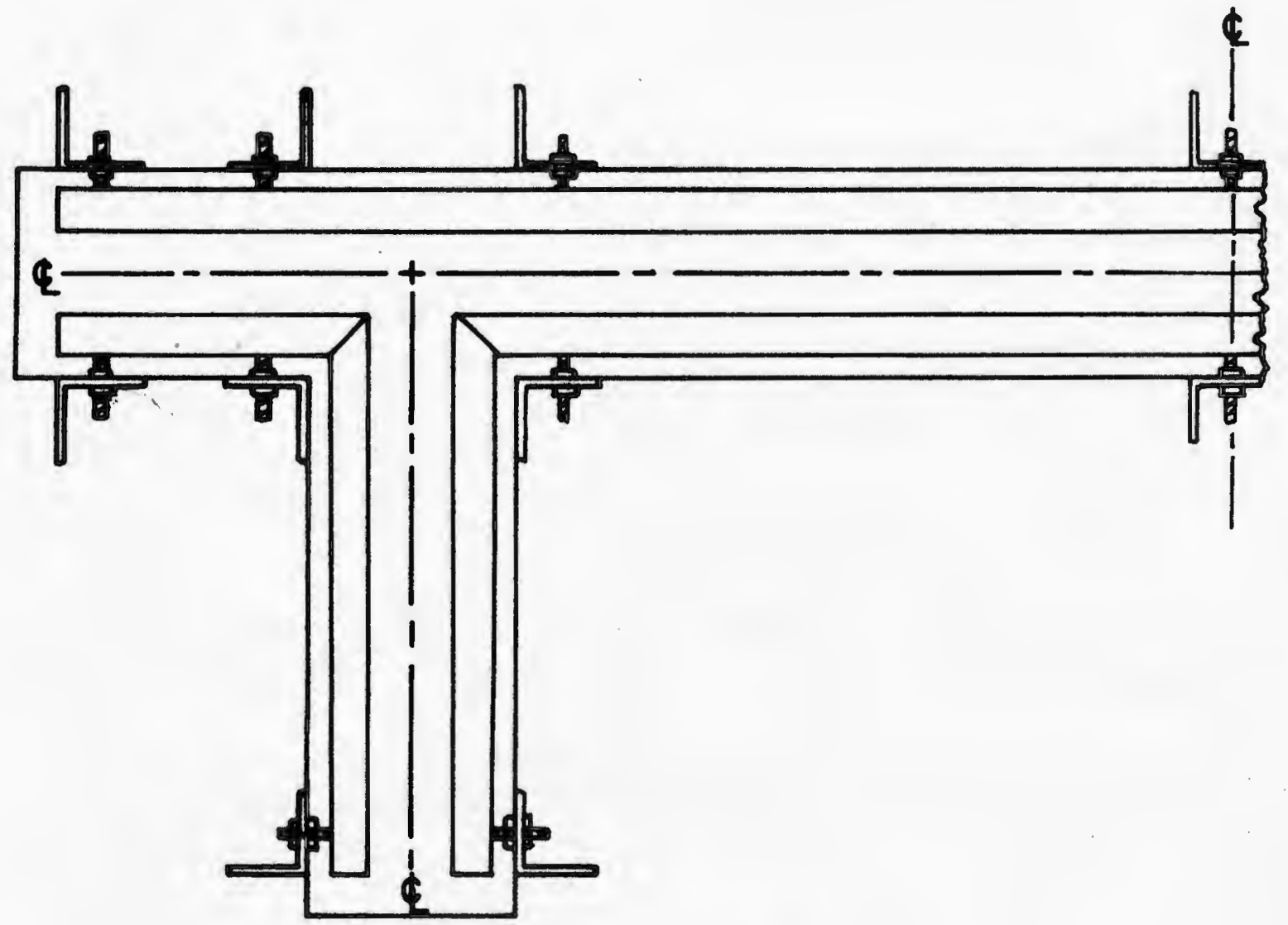

Figure 3.3. Schematic diagram of the form

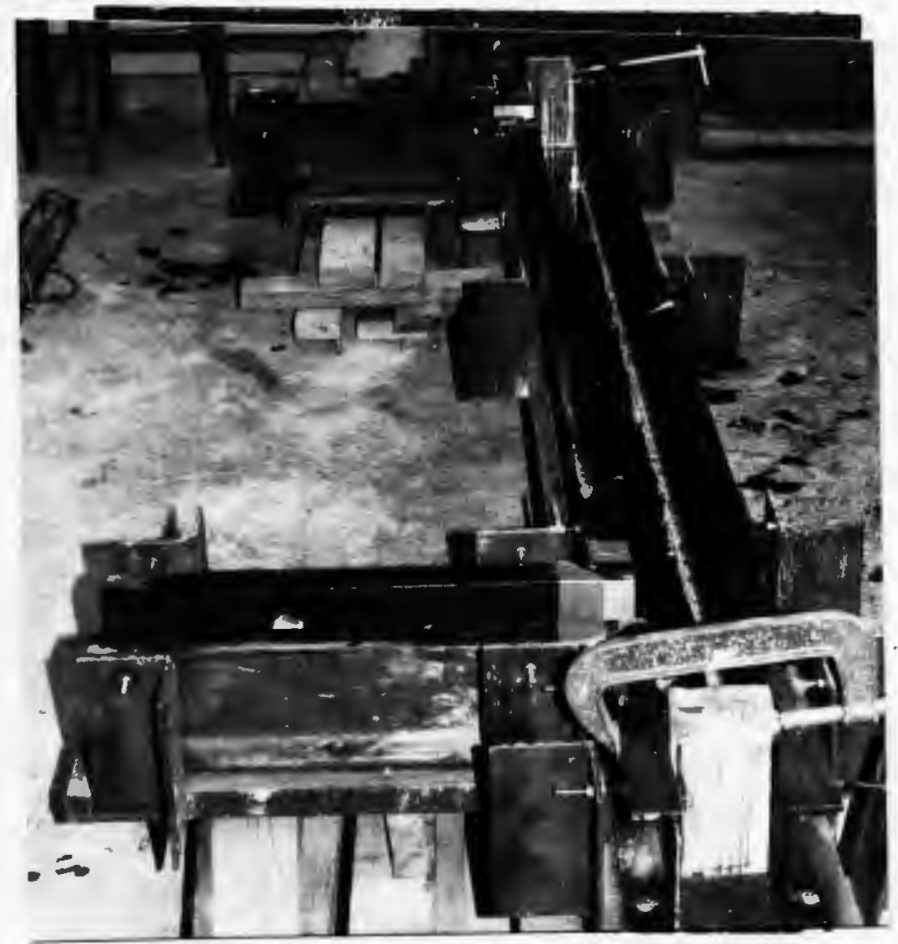

Eigure 3.4. Form preparation before placing beam and column cages 


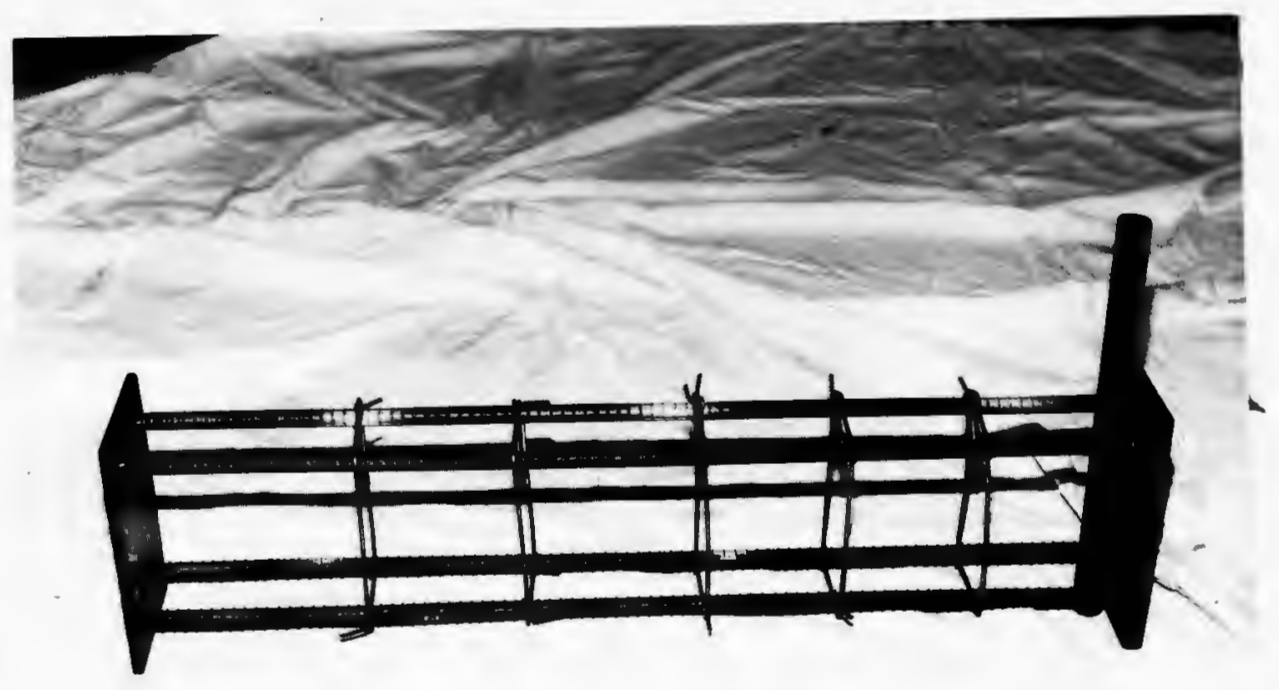

FIgure 3.5. Column cage assembly

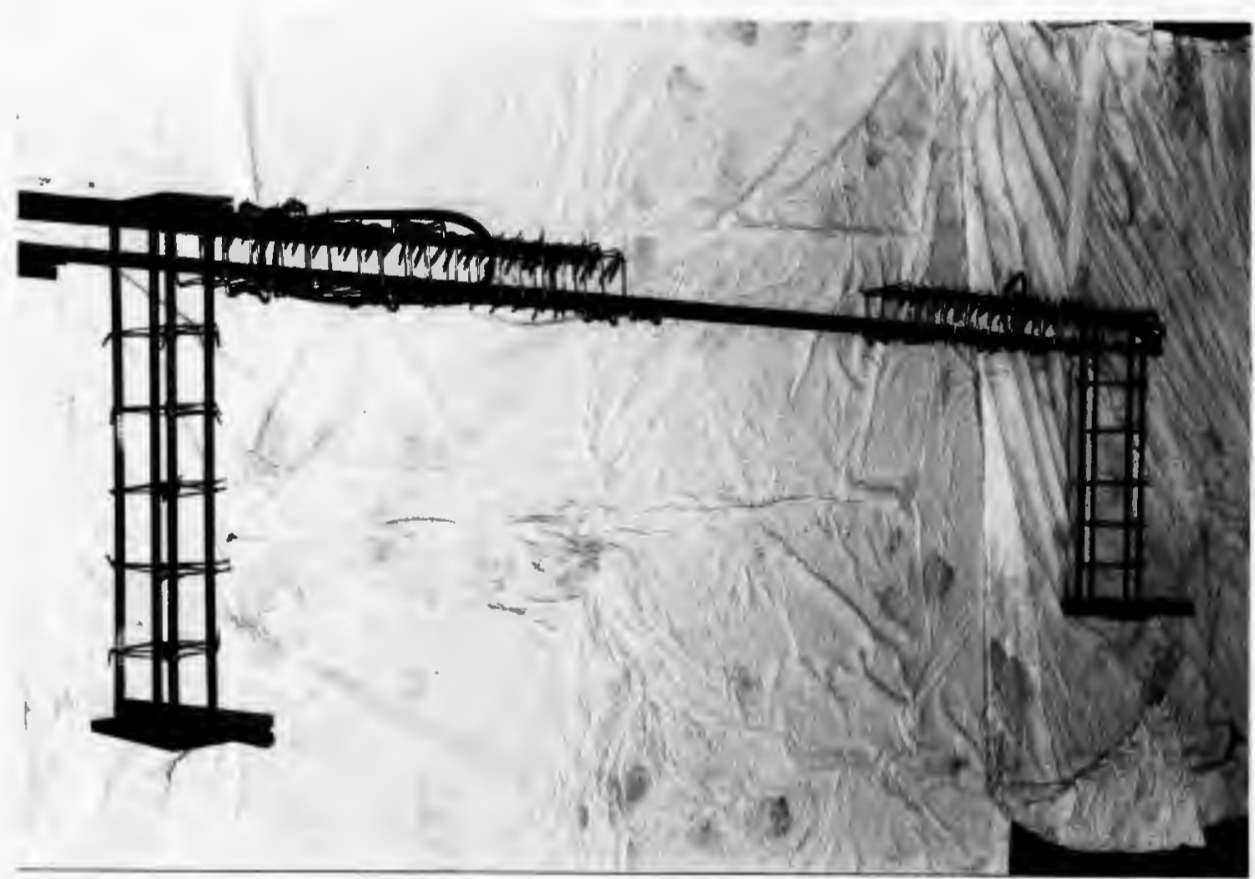

Figure 3.6. Beam cage assemb1y 
was used while casting. Concrete on top was screeded and then covered with damp burlap.

Twenty-four hours later the form was removed and the frame was lifted and placed over water saturated curing mats where the frame was cured wet for about four days; then lifted and transferred to the test bed and prepared for measurement and instrumentation. Table 3.2 shows the overall geometrical dimensions of each frame as measured after casting.

\subsection{INSTRUMENTATION}

a) General - In the experimental frame tests the following measurements were taken:

1) Column axial loads $P$, Beam loads $Q$ and sway load H

2) Latera1 deflection

3) Concrete surface strains at various stations (to estimate the bending moment at mid point of each station).

b) Loading instrumentation - A loading sequence consistent with the ACI 318-71 building code (10) requires that lateral loads should be applied on 75 percent of the vertical loads. Thus the column and beam loads were incrementally applied, until the design gravity loads were reached. The lateral load was then applied until frame failure. The system used for the application of the column loads consisted of 30 ton capacity hydraulic rams and a pump equipped with pressure gages in range of 0-10000 psi. Since the column axial loads were the same for both columns, pressure hoses from the column rams were connected to a manifold, and only one pump was used to apply both column loads. 
TABLE 3.2 MEASURED OVERALL GEOMETRY OF FRAMES

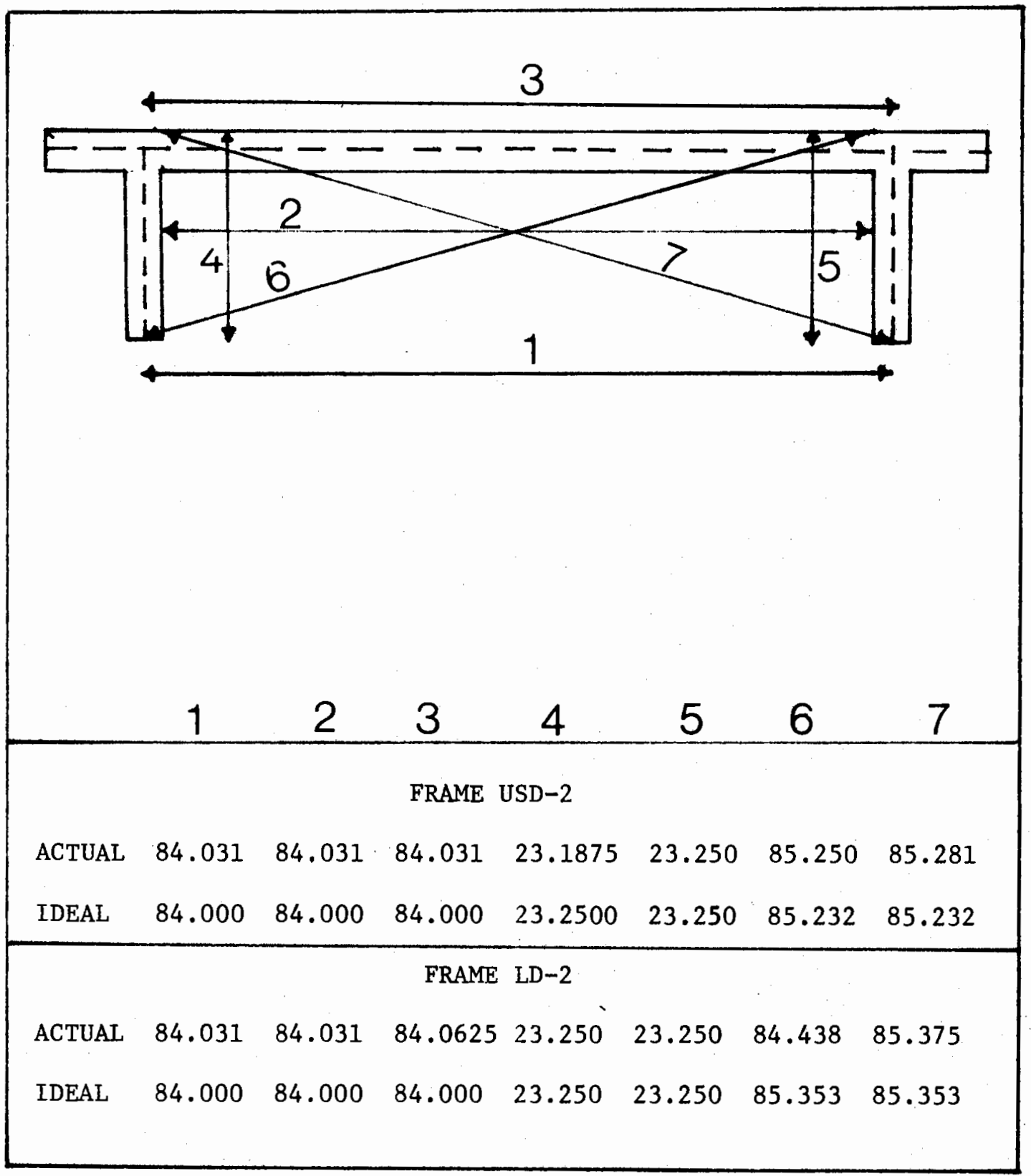


Beam loads (Q) were applied using a 20 ton hydraulic ram and lateral load was applied by a 12-ton ram. Column loads, beam loads and lateral load devices are described in section $3.7 \mathrm{c}$, d and e.

A11 gravity loads were measured by 10,000 psi capacity pressure transducers. The lateral load was measured using a 10-kip capacity load ce11, and monitored by pressure transducer. Pressure transducers and load cell were calibrated using MTS hydraulic testing machine.

c) Concrete strain measurements - Curvature meters were used for measuring concrete surface strains at different stations along the members. Average curvatures were determined by summing the changes in dial readings on two sides and dividing it by the transverse distance between dials.

The schematic diagram of curvature meters are shown in Fig. 3.7. Positions of curvature meters on the frame are shown in Fig. 3.8 and a photograph of curvature meters is shown in Fig. 3.9.

d) Corner rotation measurements - Angular rotations were measured at corners $A$ and $D$ by using a dial gage system shown in Fig. 3.10. This system consisted of a $3 / 4 \emptyset \times 9$ in. long steel solid bar welded at center of base plates of the column cages cast in concrete; and a $1 \times 1 \times 18$ in. angle (arm) welded to a 1 in $\emptyset$ (O.D.) $\times 3$ in. plpe that slipped over the $3 / 4 \emptyset$ solid bar, as shown in Fig. 3.10 .

Rotation of the arm was measured by a one inch travel dial gage (LC-8) and by applying the relationship $\theta=\Delta$ (D.R.)/L (where $\Delta D . R$. is the change in dial reading, and $L$ is the length from center of the pipe to the point of contact of dial gage). This system is applicable 


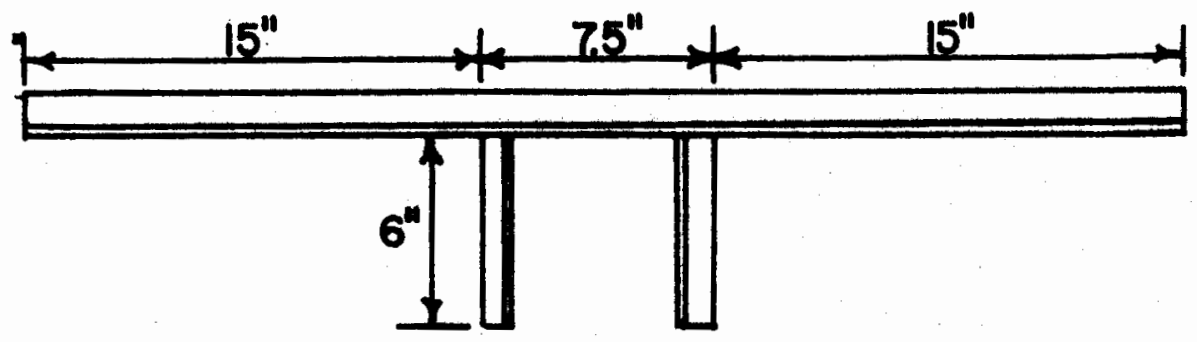

(a) COLUMN CURVATURE METER

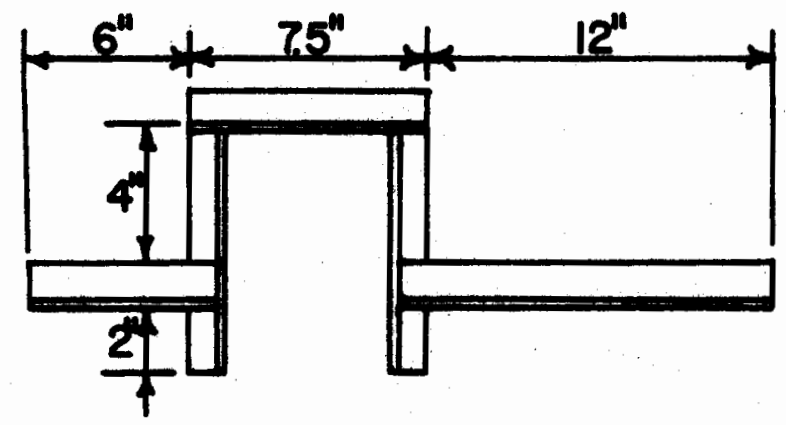

(b) BEAM CURVATURE METER AT CENTER

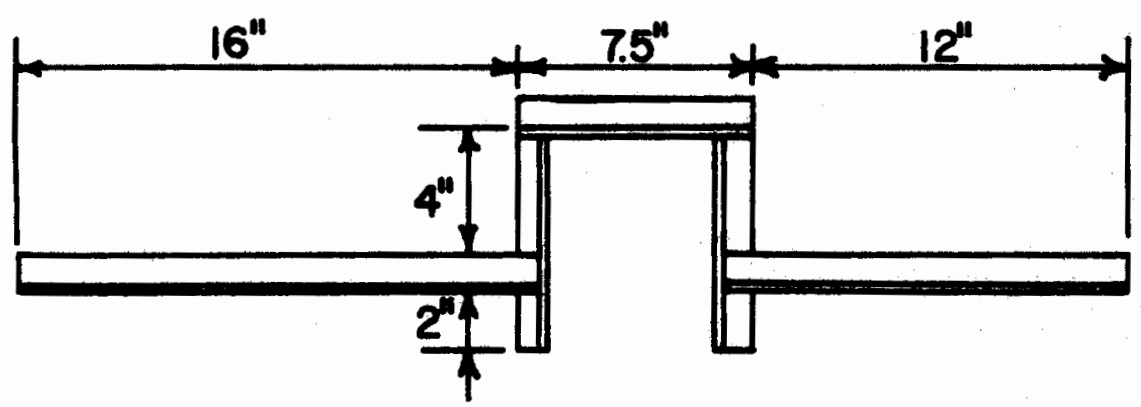

(c) BEAM CURVATURE METER AT CORNER B \& C

Figure 3.7. Beam and column curvature meters 


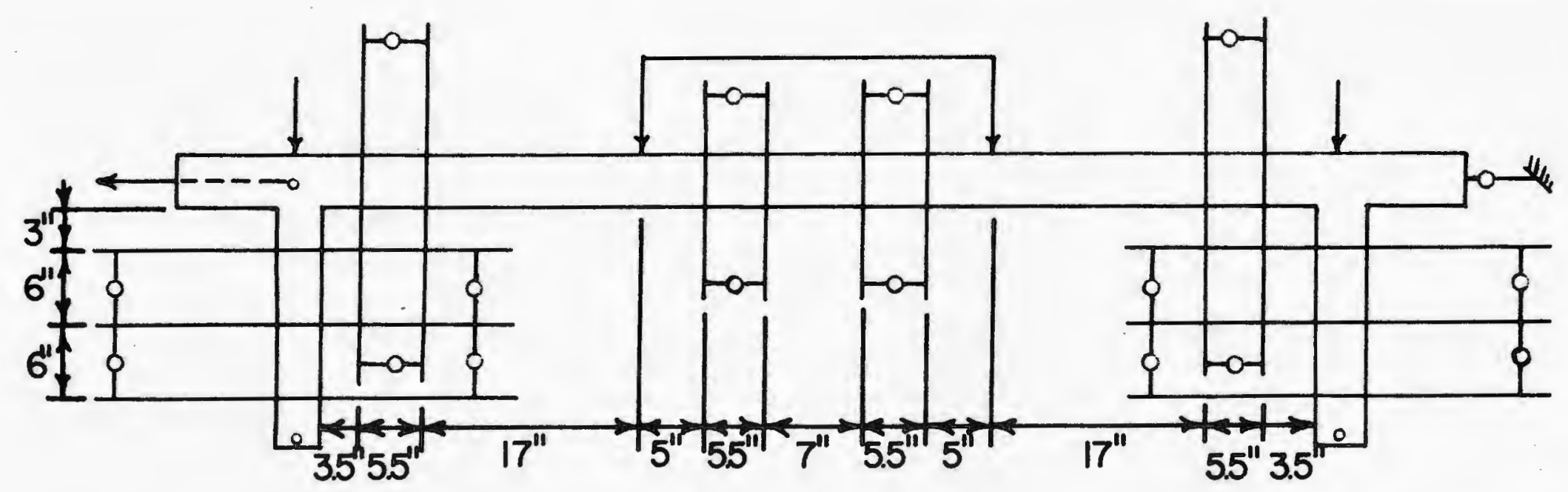

Figure 3.8. Location of curvature meters, rotation dials and lateral deflection dial

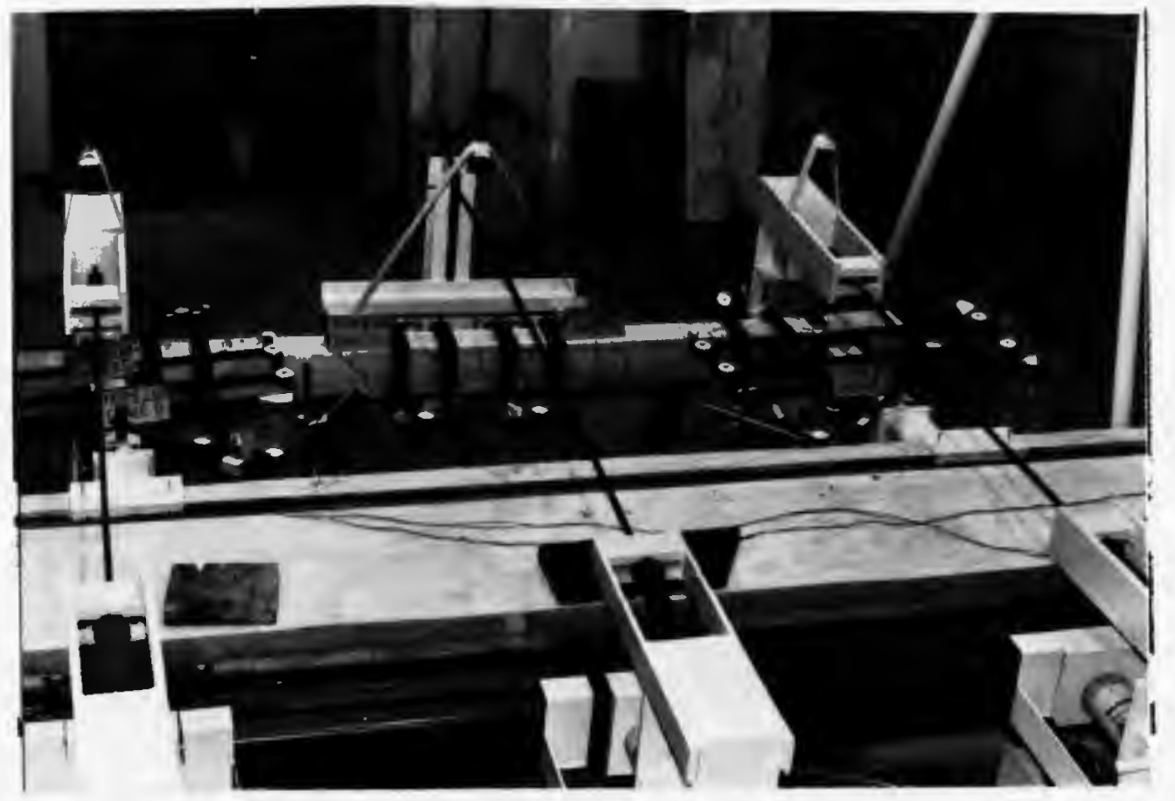

Figure 3.9. Curvature meters in position 

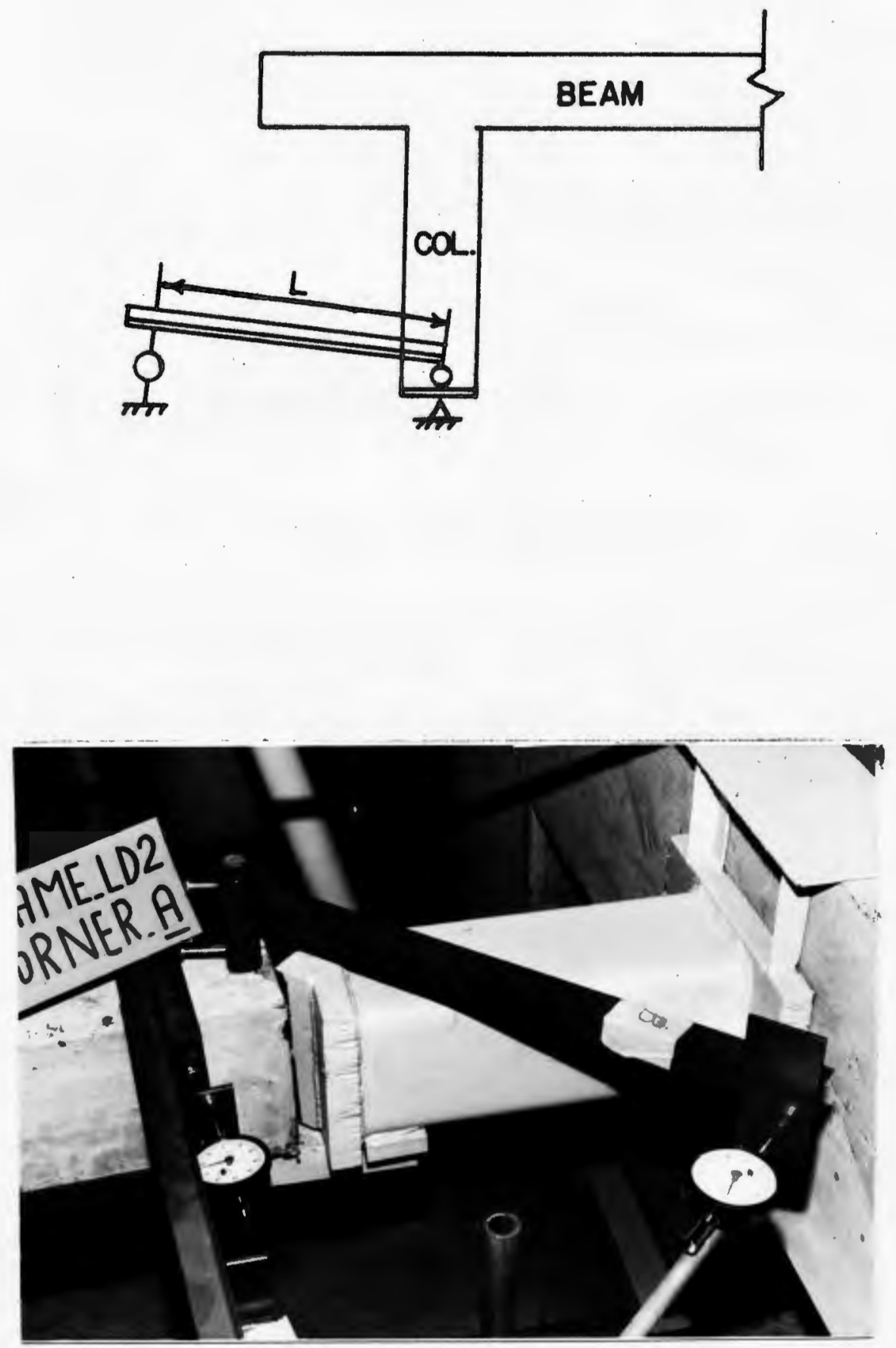

Figure 3.10. Corner rotation measurement system 
only for corners that rotate without translation.

e) Lateral deflection measurement - Lateral deflection of the frame was measured at corner $B$, using a 2-inch travel dial gage $(\mathrm{LC}-10)$. Dial gage was attached to a pipe cast in a concrete block as shown in Fig. 3.11. Since frames were symmetrical with respect to both the loading and geometry no lateral deflection under gravity loads was theoretically expected. In actual testing, there were slight lateral deflections, which could be due to imperfection of both frame geometry and the loading system.

\subsection{LOADING SYSTEM COMPONENTS}

a) General - The general test set up as shown schematically in Fig. 3.12 basically consists of a concrete reaction beam (A), movable steel load beam (b), bearing heads and column heads. The detail of concrete reaction beam is shown in Fig. 3.13. Movable steel loading beam (B) is a 12-ft long structural steel tubing TS $1 / 4 \times 6 \times 6$ resting on wheels which bear against the concrete reaction beam through a set of roller nests. Three steel plates $1 / 2$ " $\times 6$ " $\times 14^{\prime \prime}$ welded to steel tubing at location of roller nests provide extra stiffness at these locations. Roller nests allow the steel beam to move laterally, so the ram axes (strands) remain parallel to the original column center lines during testing. An overall view of test set up is shown in Fig. 3.14. As shown in Fig. 3.15 and the schematic diagram on Fig. 3.16, each roller nest is fabricated by four $2^{\prime \prime} \emptyset \times 8^{\prime \prime}$ long solid bars connected to two steel angles by $1 / 2 " \emptyset$ pins through ball bearings on top and bottom. Roller nests are suspended from a steel angle welded on top of steel beam (B) when no load is applied. During loading 


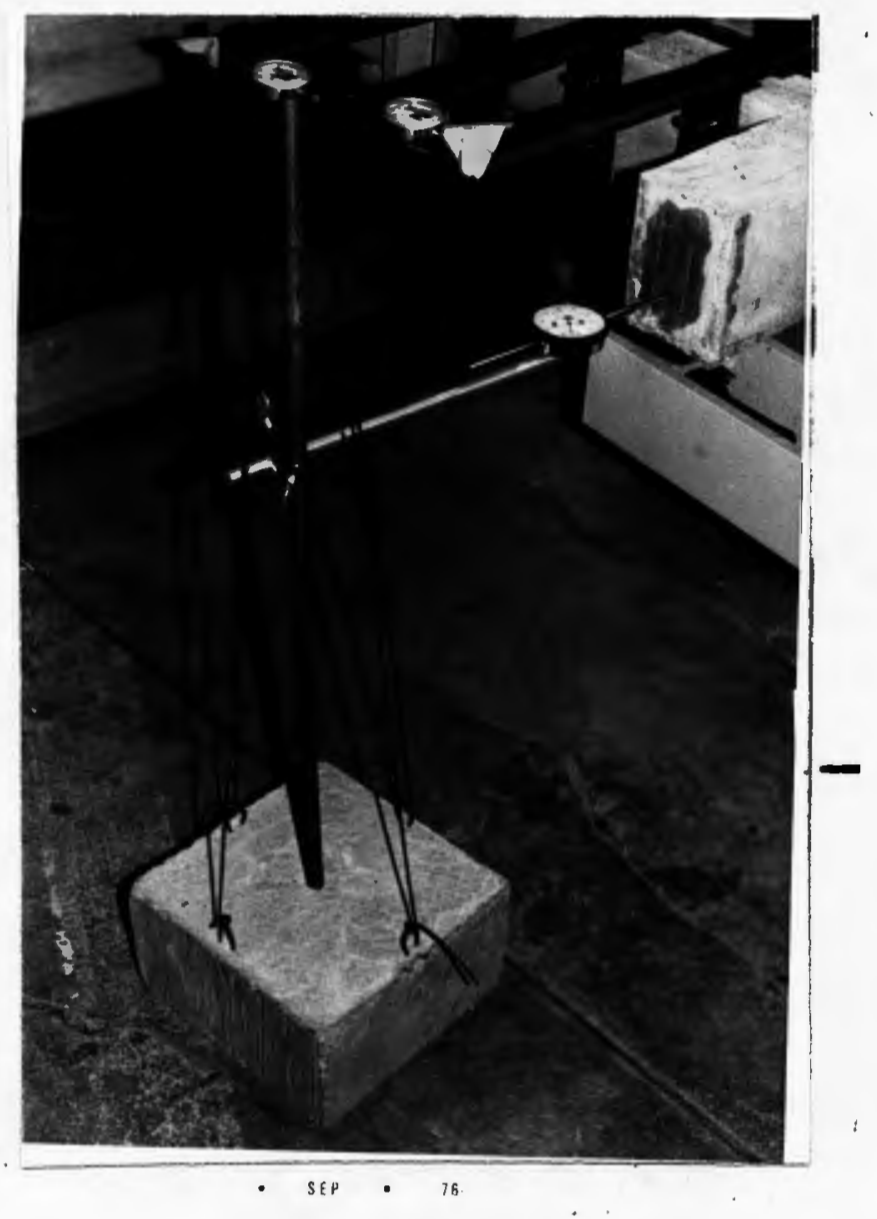

Figure 3.11. Lateral deflection measuring device 


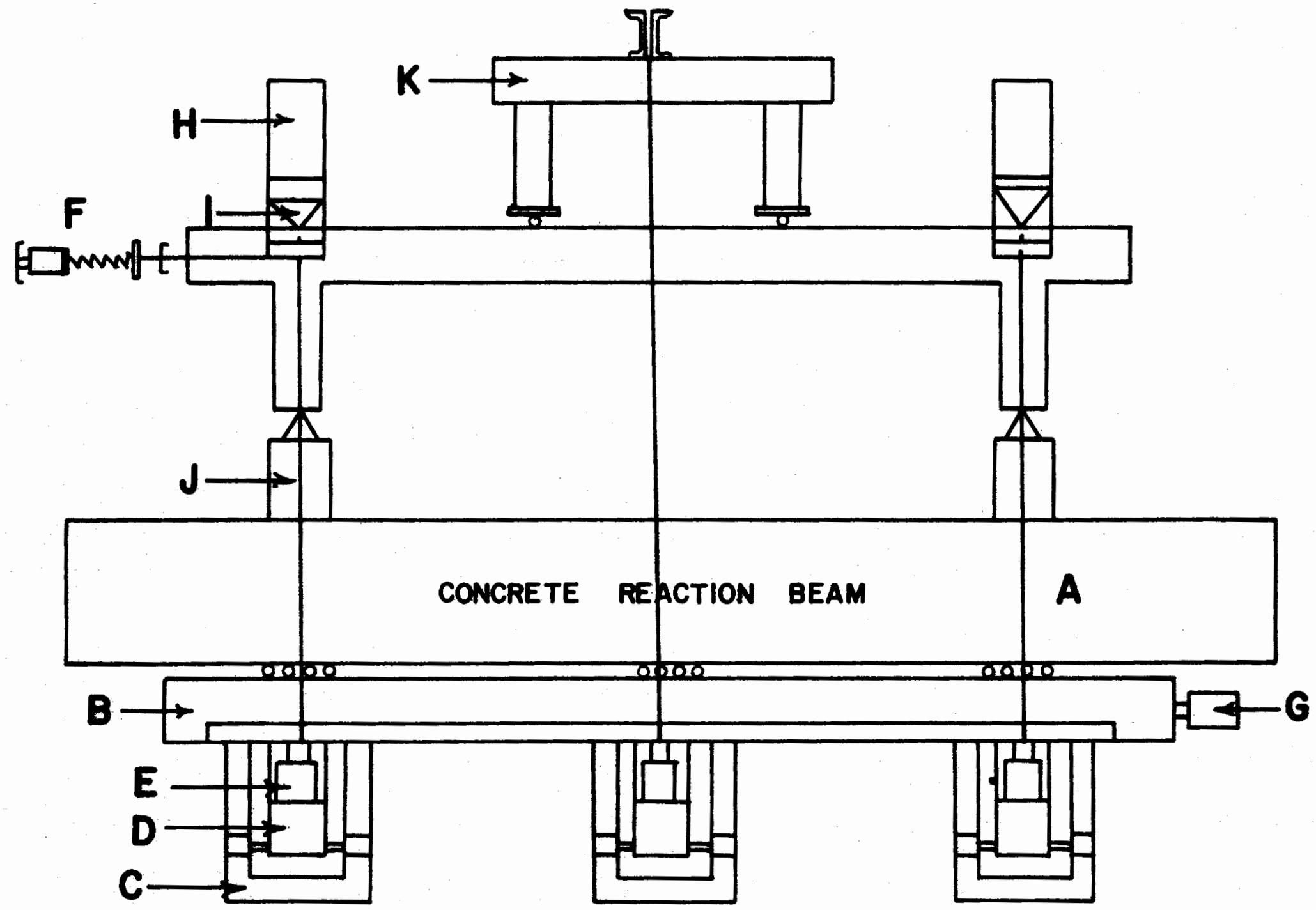

Figure 3.12. Schematic diagram of frame and loading system 


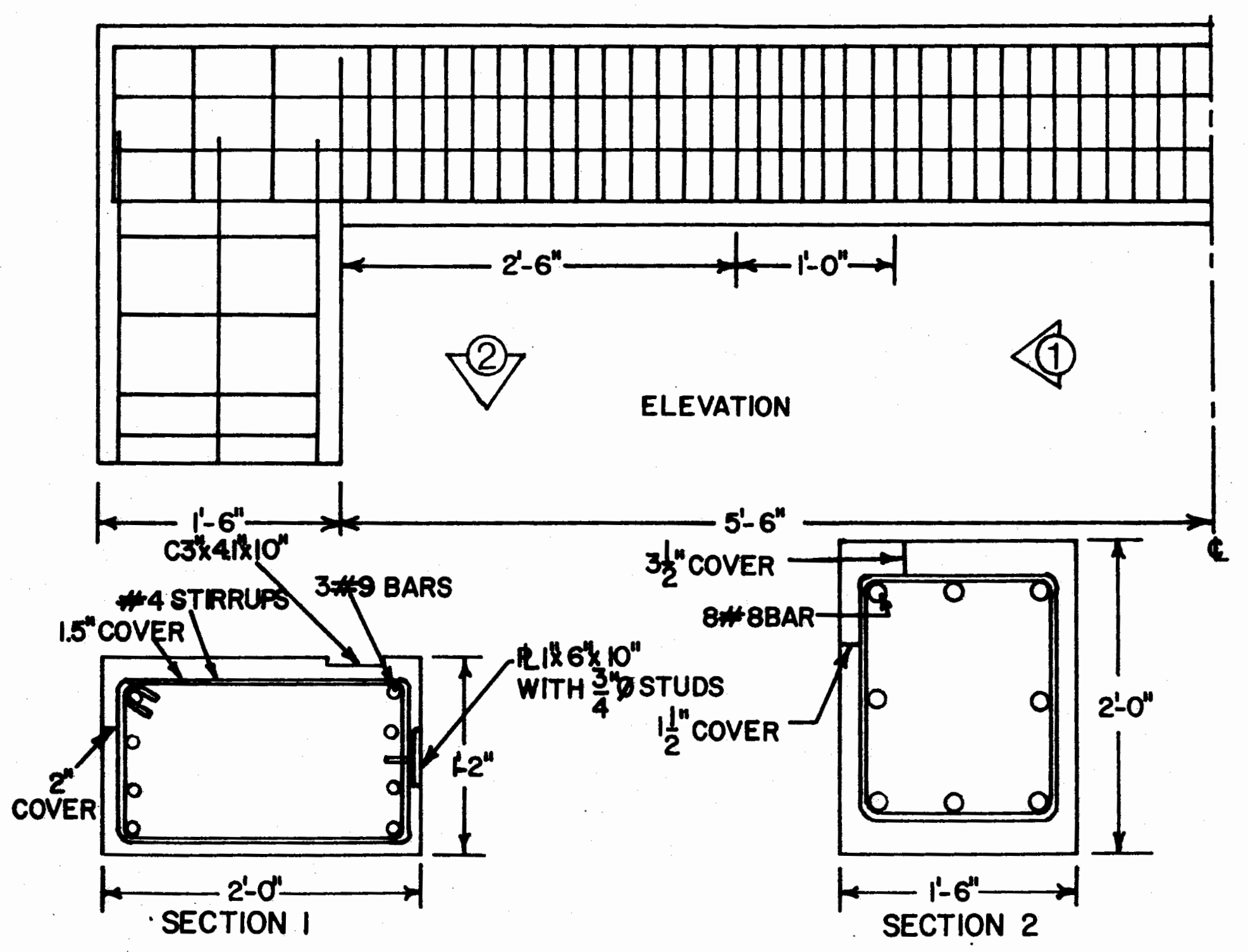

Figure 3.13. Detall of concrete reaction beam 


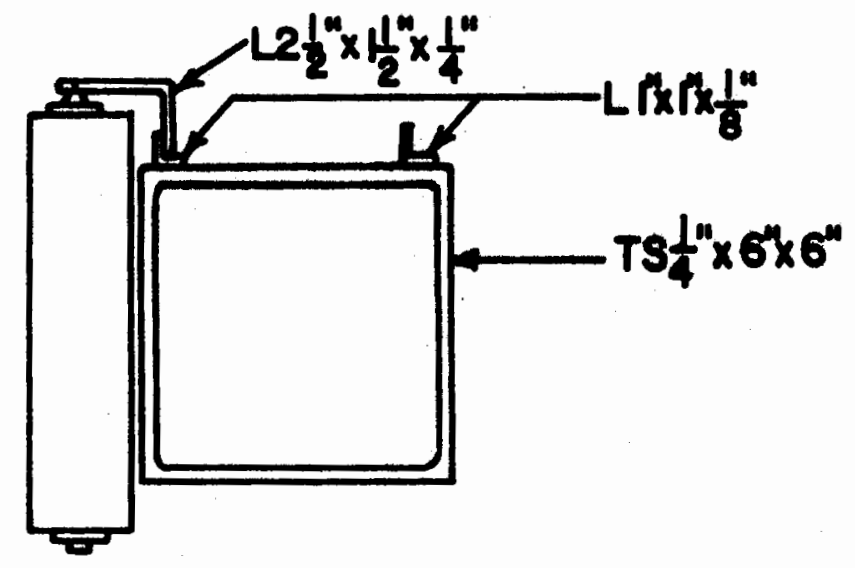

- CONNECTION OF MOVABLE STEEL BEAM AND ROLLER NEST

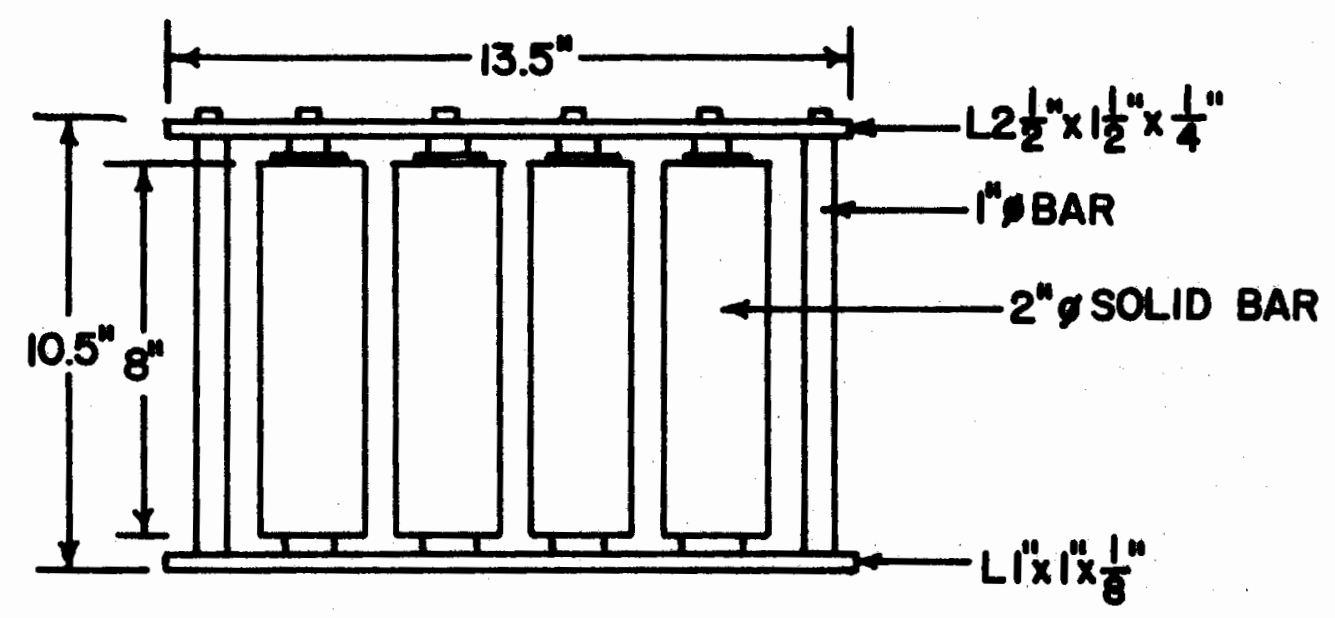

b) DETAIL OF ROLLER NEST

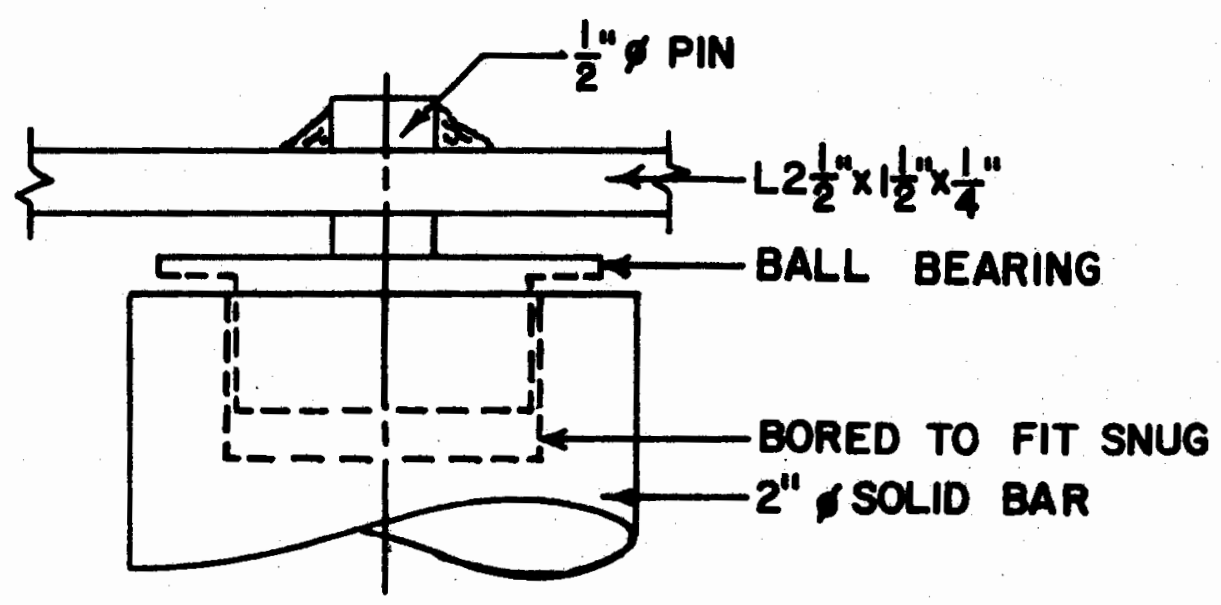

c) END DET.

Figure 3.16. Roller nest system 
relative displacement of steel beam and roller nests is free to occur.

b) Reaction devices and sway adjustment system - Reaction device $(\mathrm{J})$ was designed to transfer the loads from column to concrete reaction beam. A reaction device is shown in Fig. 3.17. The reaction device was suspended from concrete reaction beam.

The direction of the column load was one of the most influential components of the loading system on the frame response. The direction of column axial loads were set by aligning the column load strands using a transit. Since this condition must remain during testing, a sway adjustment system (G) was designed to move the steel beam (B) a distance equal to the lateral deflection. As shown in Fig. 3.18, it consists of a ram aperated by a pump. The ram is attached to an I-beam that is securely bolted to the concrete slab.

C) Column load devices - Bearing head (D) is designed for a maximum load of 200 kips. As shown in the schematic diagram of Fig. 3.19, it consists of a section of $\mathrm{S} 12 \times 31.8$ with four $\mathrm{PL} 3 / 4^{\prime \prime} \times 5^{\prime \prime} \times 28^{\prime \prime}$ welded on both sides at top and bottom. A 30-kips capacity ram is mounted at center of the flange. With wheels on both sides, the bearing head is able to move in a direction perpendicular to steel beam (B). A photograph of a column bearing head is shown in Fig. 3.20. Column heads $(\mathrm{H})$, shown in Fig. 3.21, were built similar to bearing heads. A point loading hinge was made by cutting a triangular piece from a PL $2^{\prime \prime} \times 4^{\prime \prime} \times 7^{\prime \prime}$. This piece was welded to the web at mid height of column heads. For each column the bearing head was interconnected to the column head by two $1 / 2 " D 270 \mathrm{~K}$ strands at top and bottom. Bearing heads rest on steel frames (C). The schematic diagram of wheel 


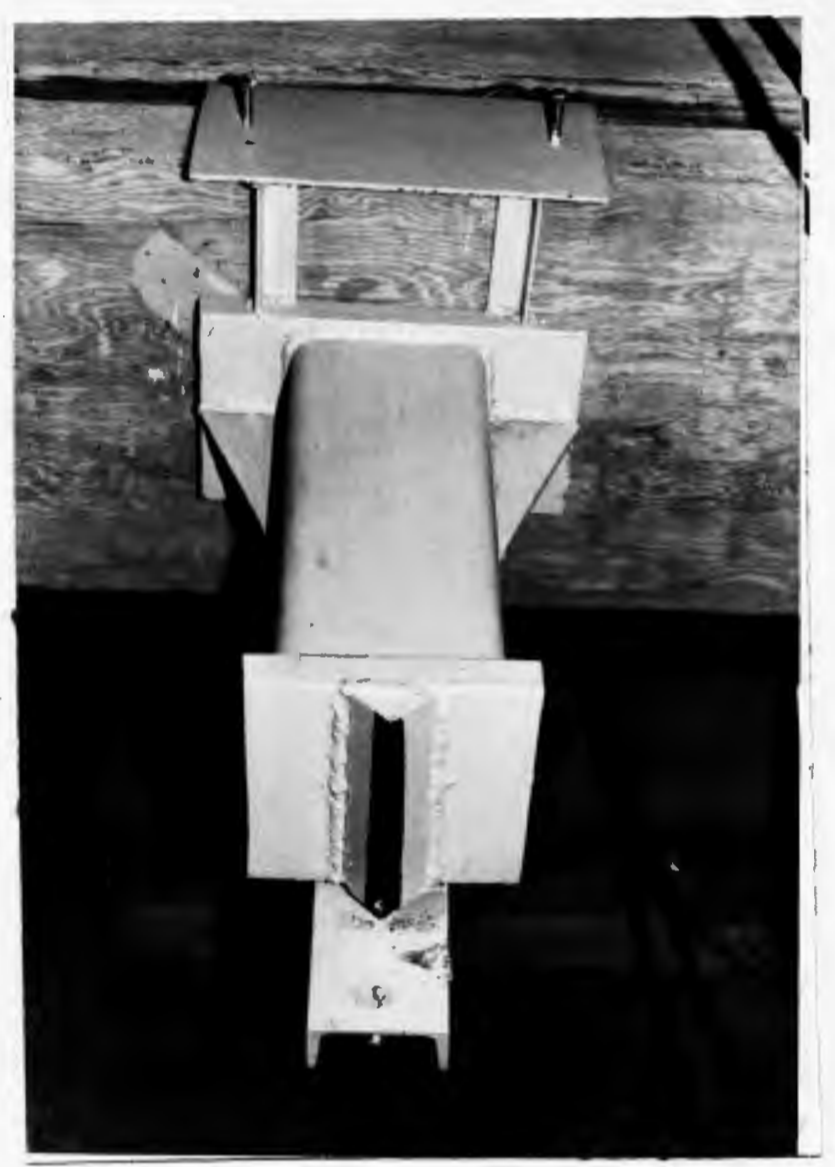

Figure 3.17 The reaction device

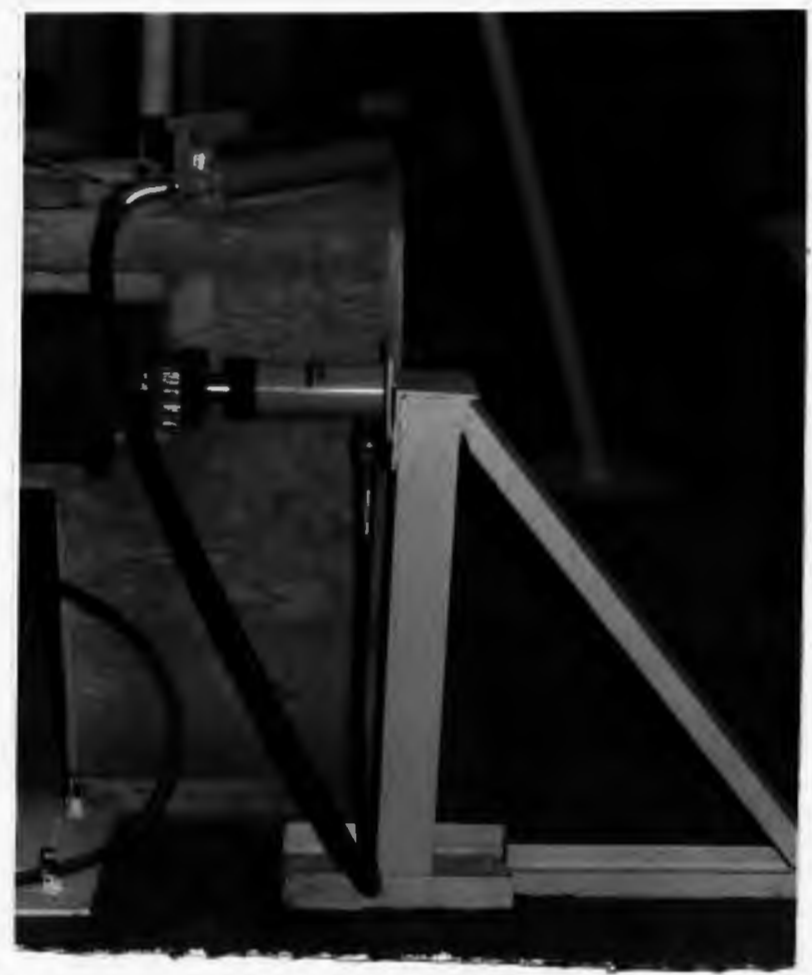

Figure 3.18. Sway adjustment system 


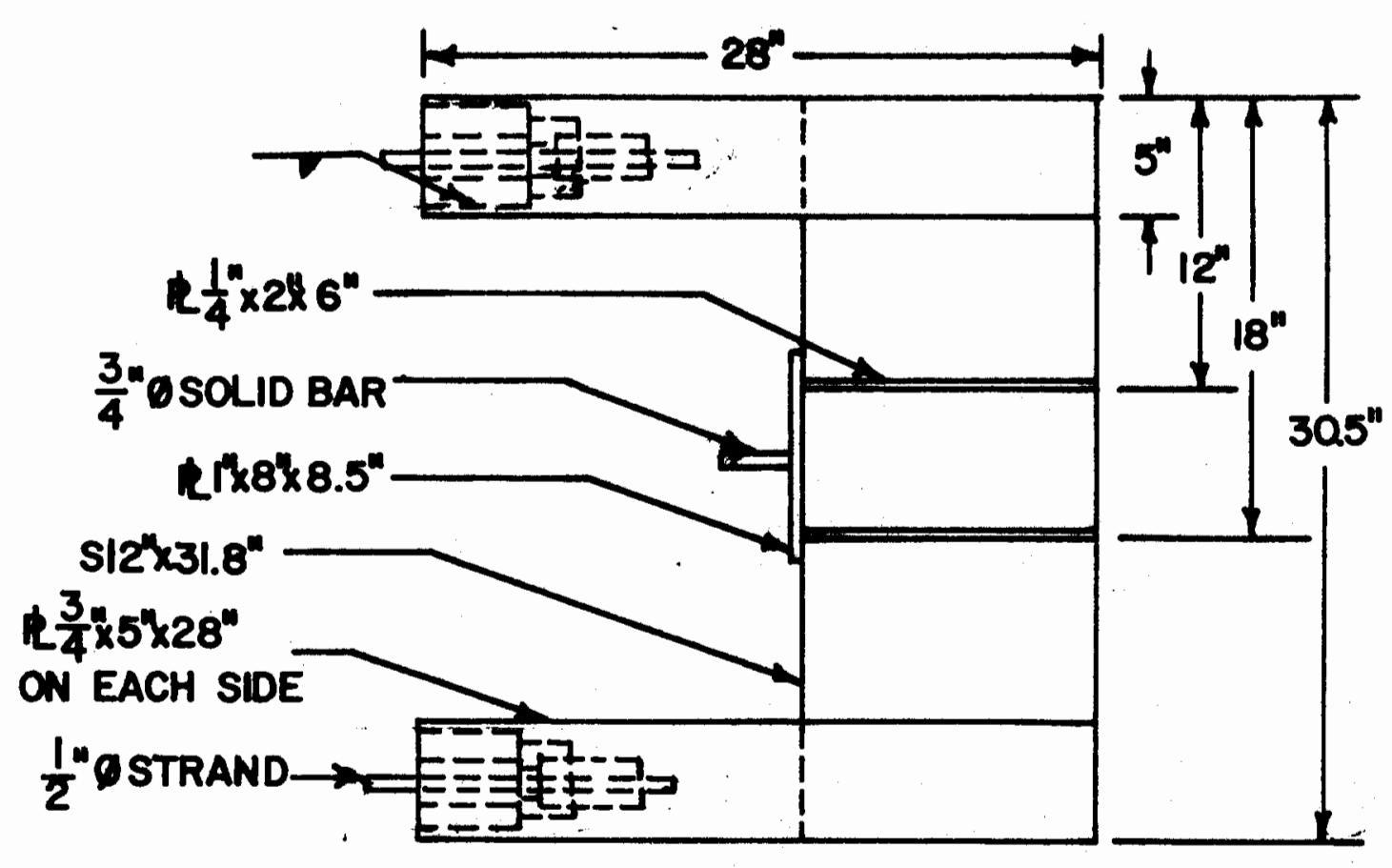

a) ELEVATION VIEW

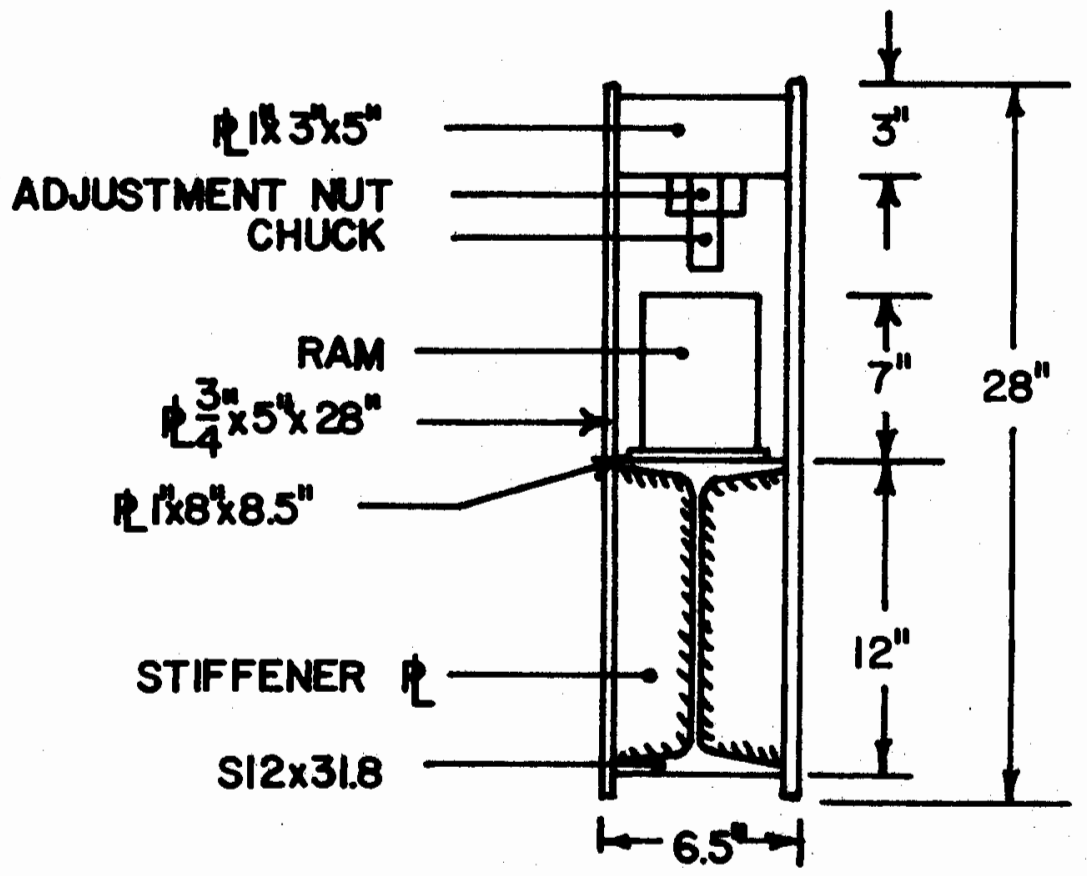

b) TOP VIEW

Figure 3.12 Hendrobed 


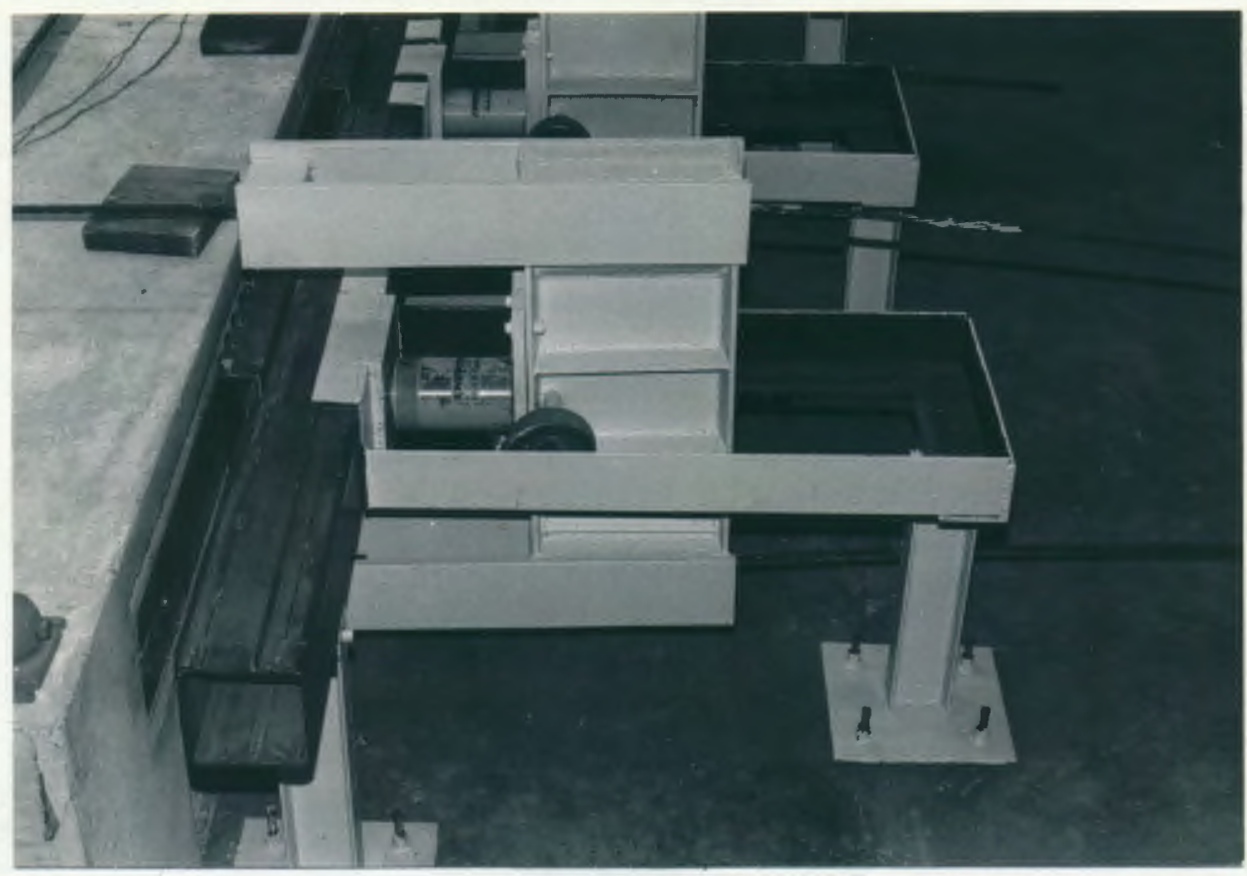

Figure 3.20. Column bearing head

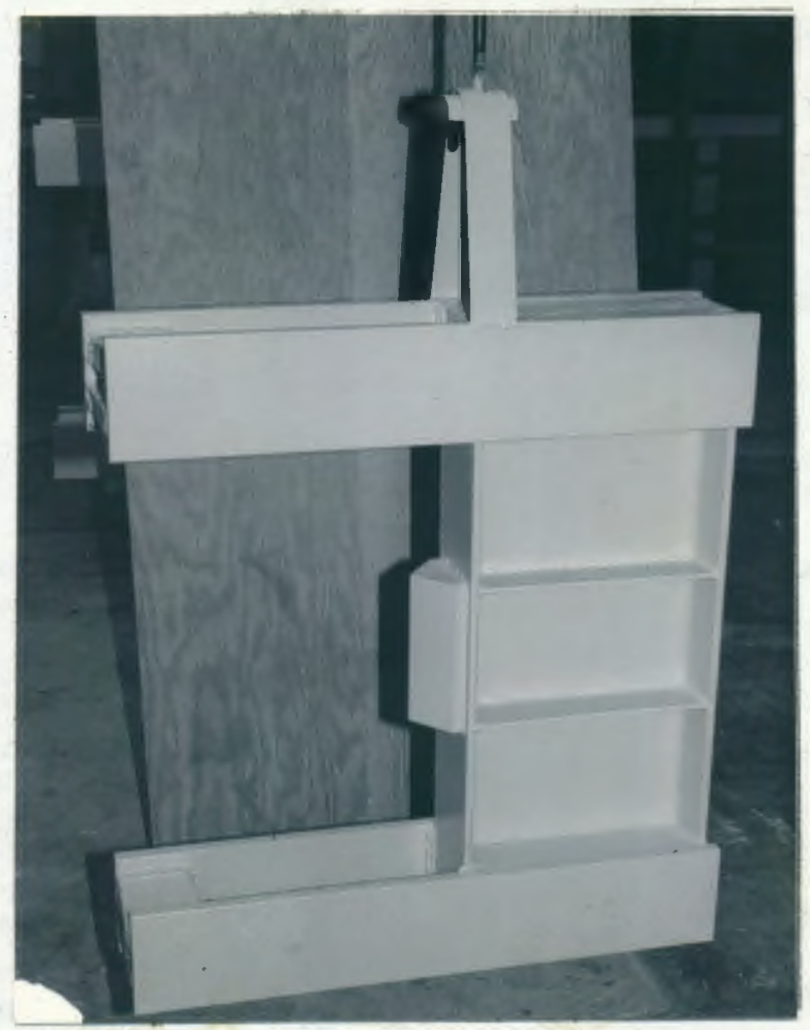

Figure 3.21. Column head 
stand which supports the steel frame (C) is shown in Fig. 3.22. Column heads were suspended from trolleys which were free to move along a level steel track, made of a S $4 \times 7.7 \times 12$ feet long, 9'-8" high above the floor. The overall dimensions of this support frame is shown in Fig. 3.23. Fig. 3.24 shows the trolley and tubular column supports of the suspension system.

d) Beam load device - The system used for applying the beam loads consisted of a bearing head similar to those used for column loads, and a beam head $(K)$ connected to the bearing head by two $1 / 2 " \emptyset$ strands at top and bottom. The beam bearing head was designed for a maximum load of 120 kips.

As shown in schematic diagram of Fig. 3.25a the beam head consisted of two $C 6 \times 8.2 \times 32$ " long standing vertically, back to back, one inch apart, and welded at midheight to two $\mathrm{C} 6 \times 8.2 \times 32^{\prime \prime}$ long back to back, $1 / 2$ inch apart. The beam head was suspended from the same track used for column heads. Fig. 3.25b shows the suspended beam head.

e) Lateral load system - The lateral load system used for applying the horizontal load $H$ was designed such that it would have sufficient strength and displacement capacity. To accomplish this purpose the following mechanism was used: A 3/4-in. diam. steel bar was inserted through the pipe cast at corner $C$. Two $1 / 4^{\prime \prime} \emptyset$ bars connected this $3 / 4-$ in bar to a steel channel section, as shown in schematic diagram of Fig. 3.26(a). A $1 / 2^{\prime \prime} \emptyset$ steel bar connected to the center of this channel and ran through a steel angle and a spring system whtch helps maintain the lateral load while the test specimen is creeping. The bar was 


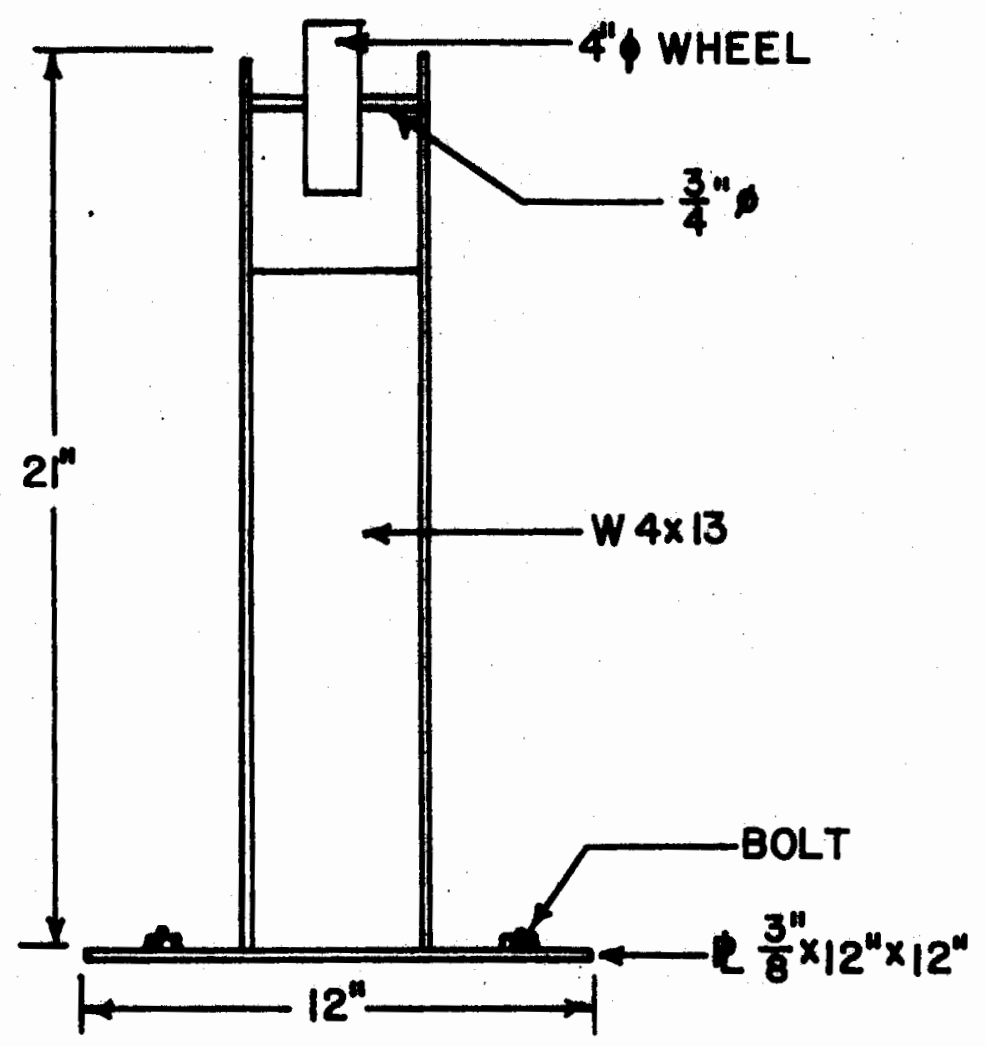

Figure 3.22 Detall of wheel stand

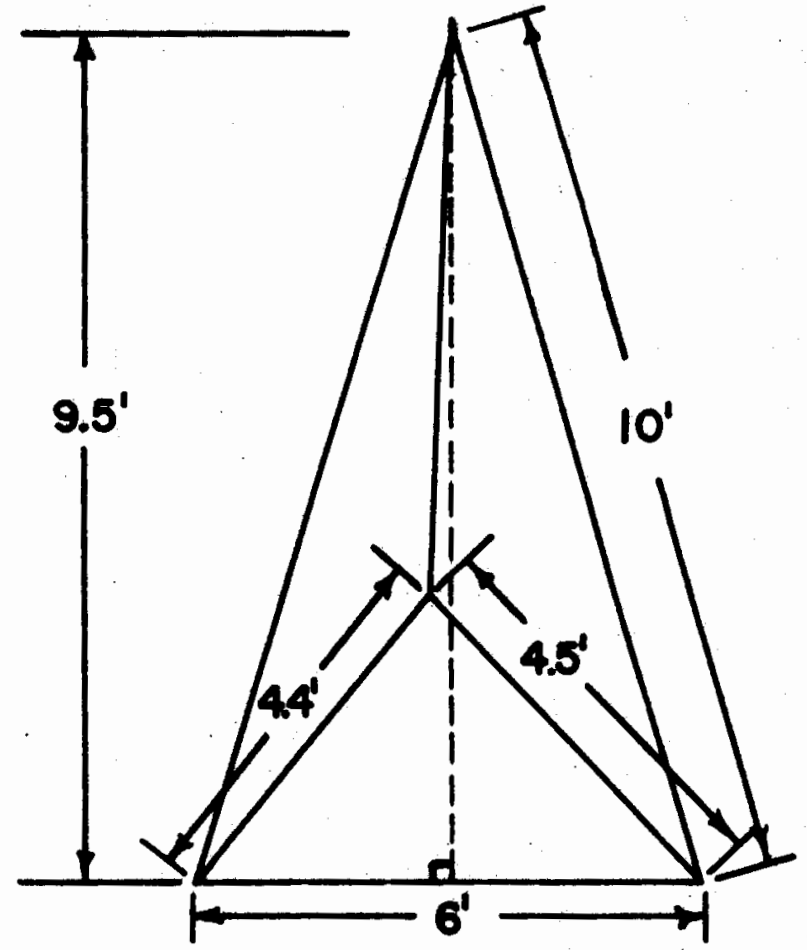

Figure 3.23 Elevation diagram of support frame 


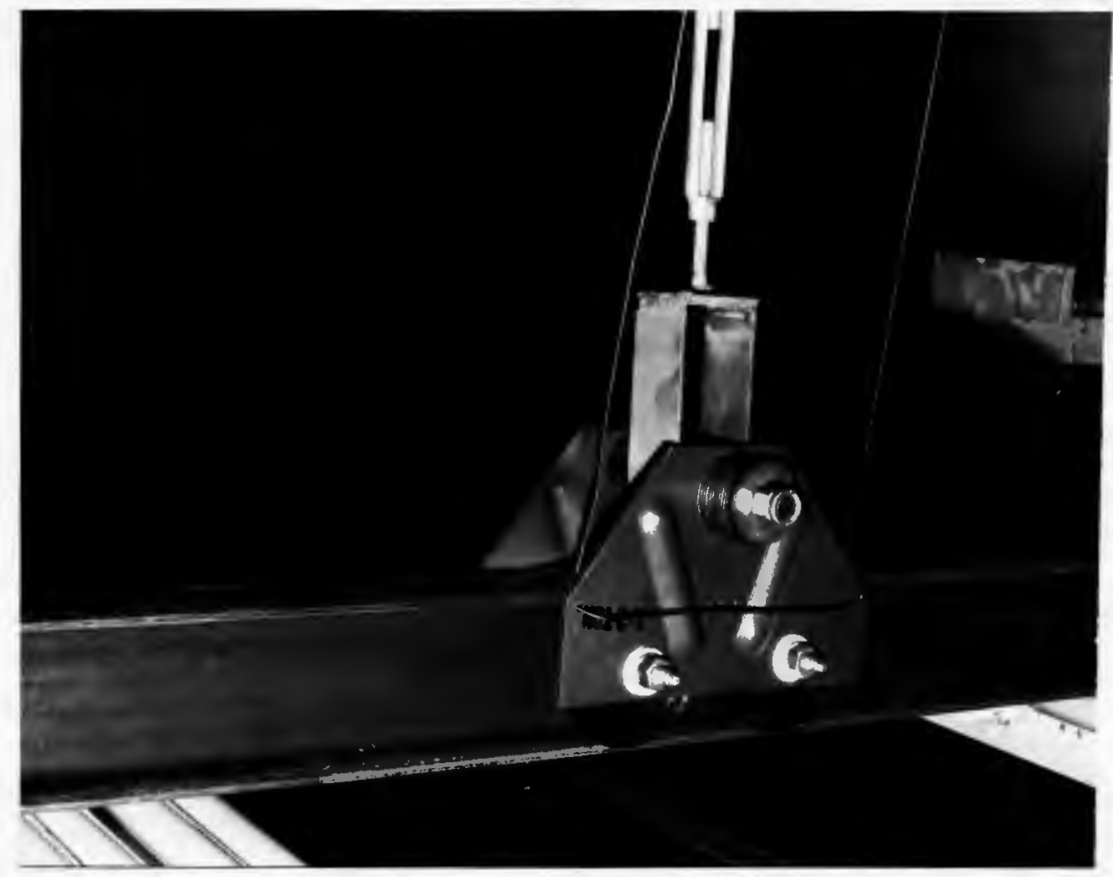

a) TROLLEY

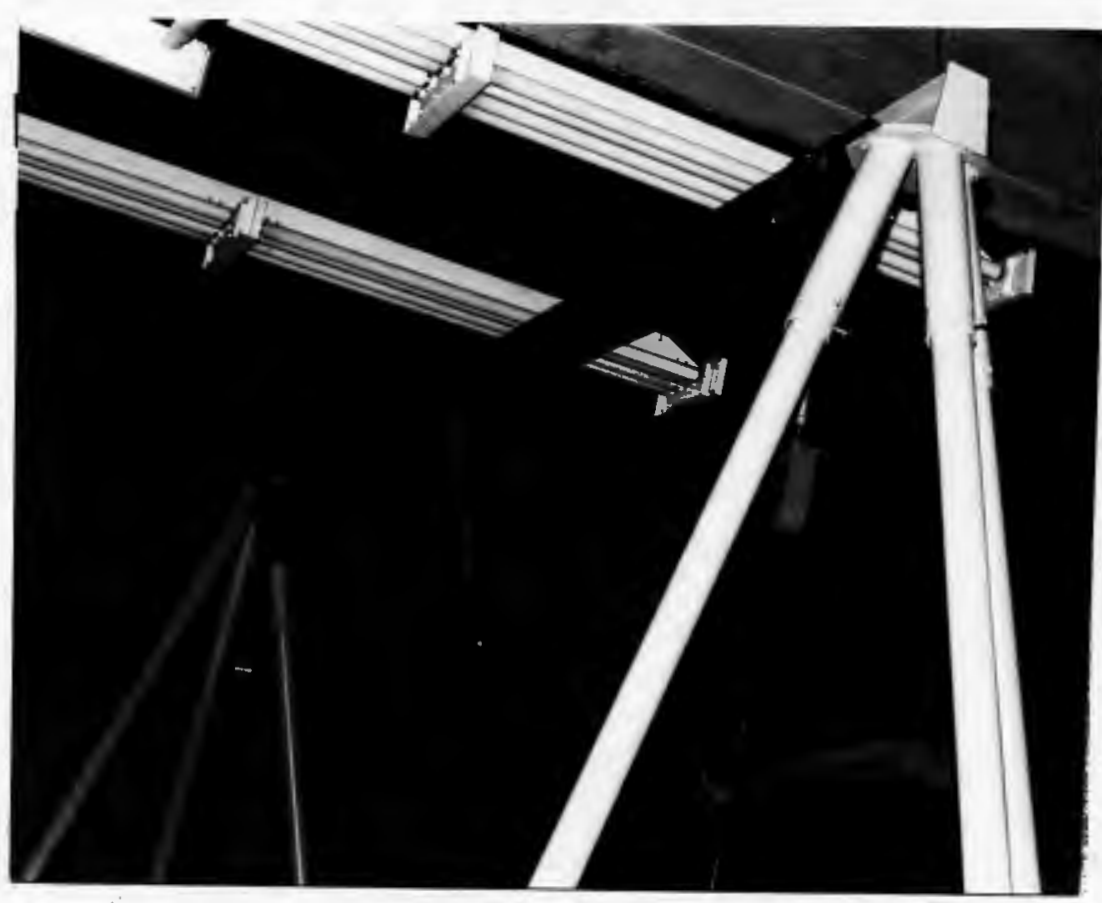

b) SUPPORTS

Figure 3.24 Column hears suspension system 


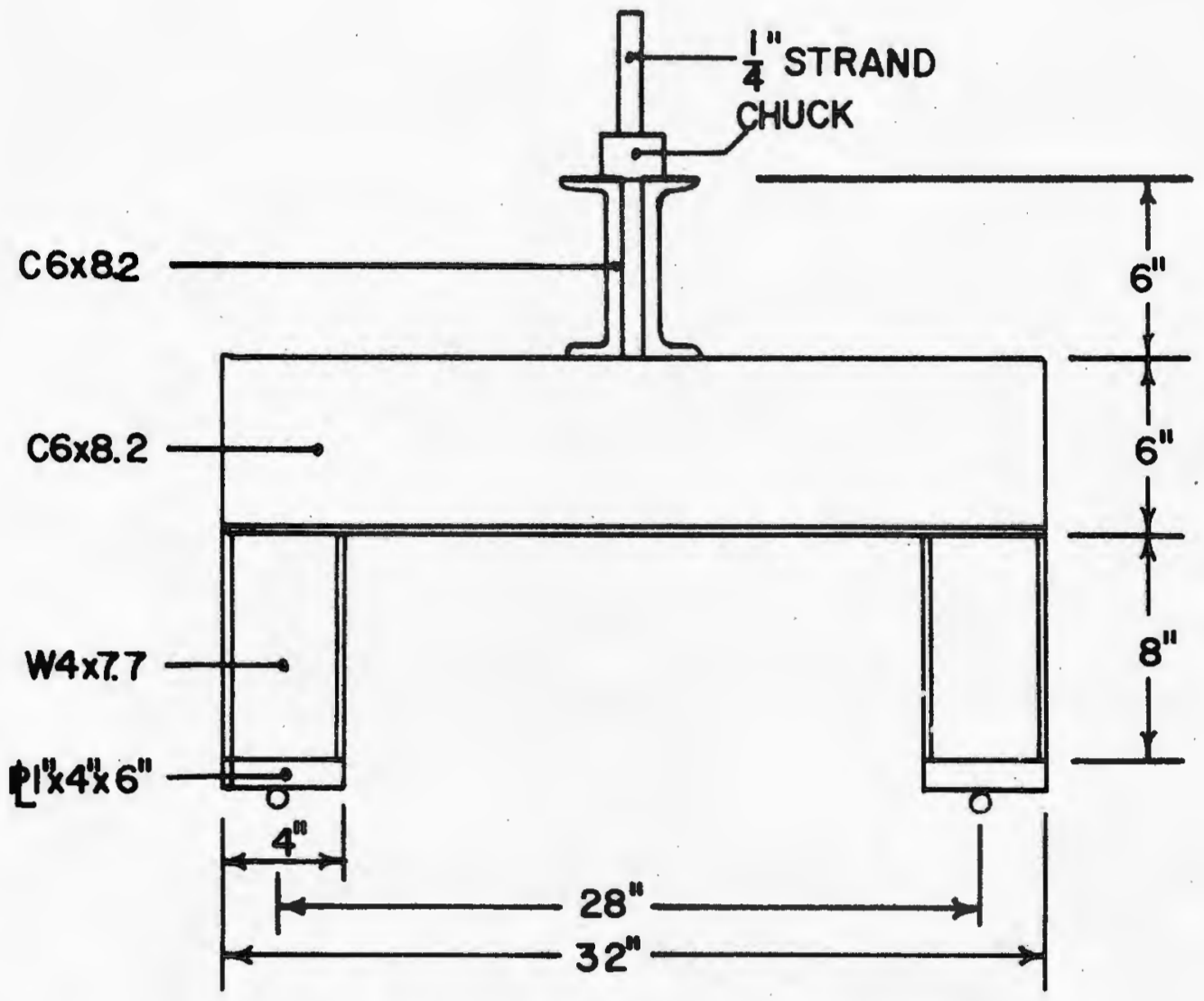

a) SCHEMATIC DIAGRAM OF BEAM HEAD

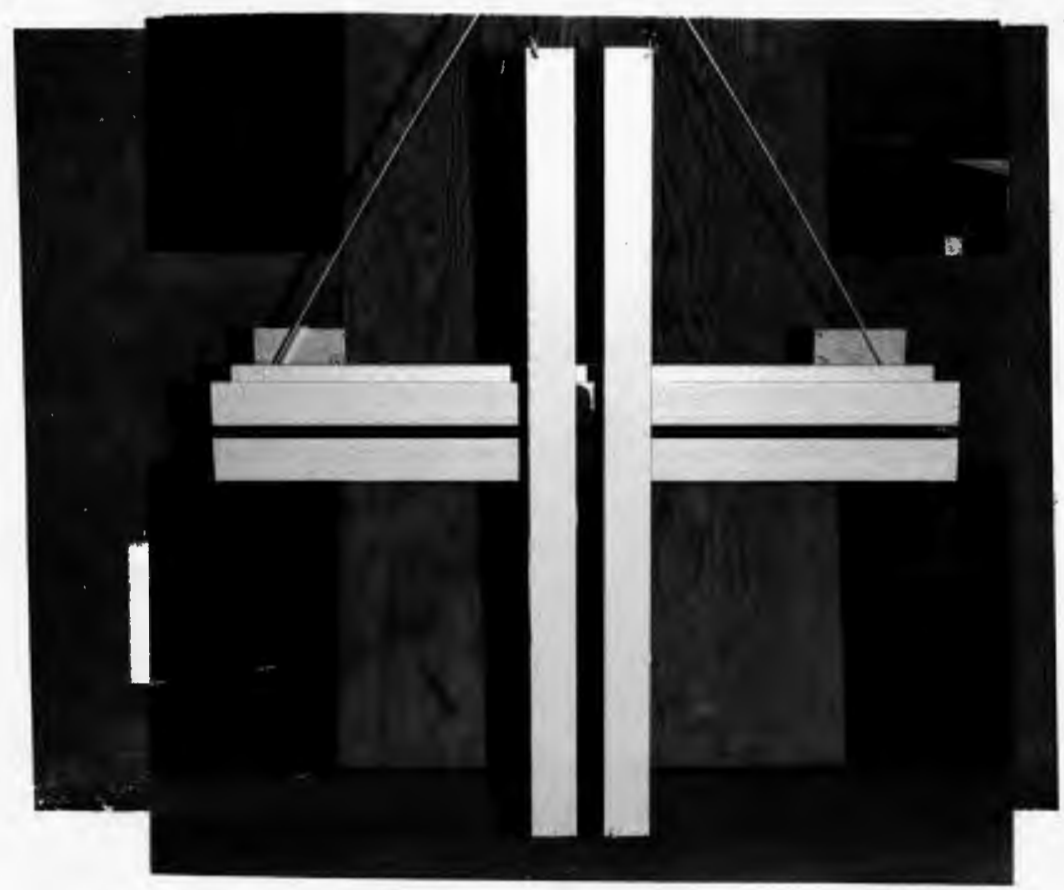

Figure 3.25 Beam head 


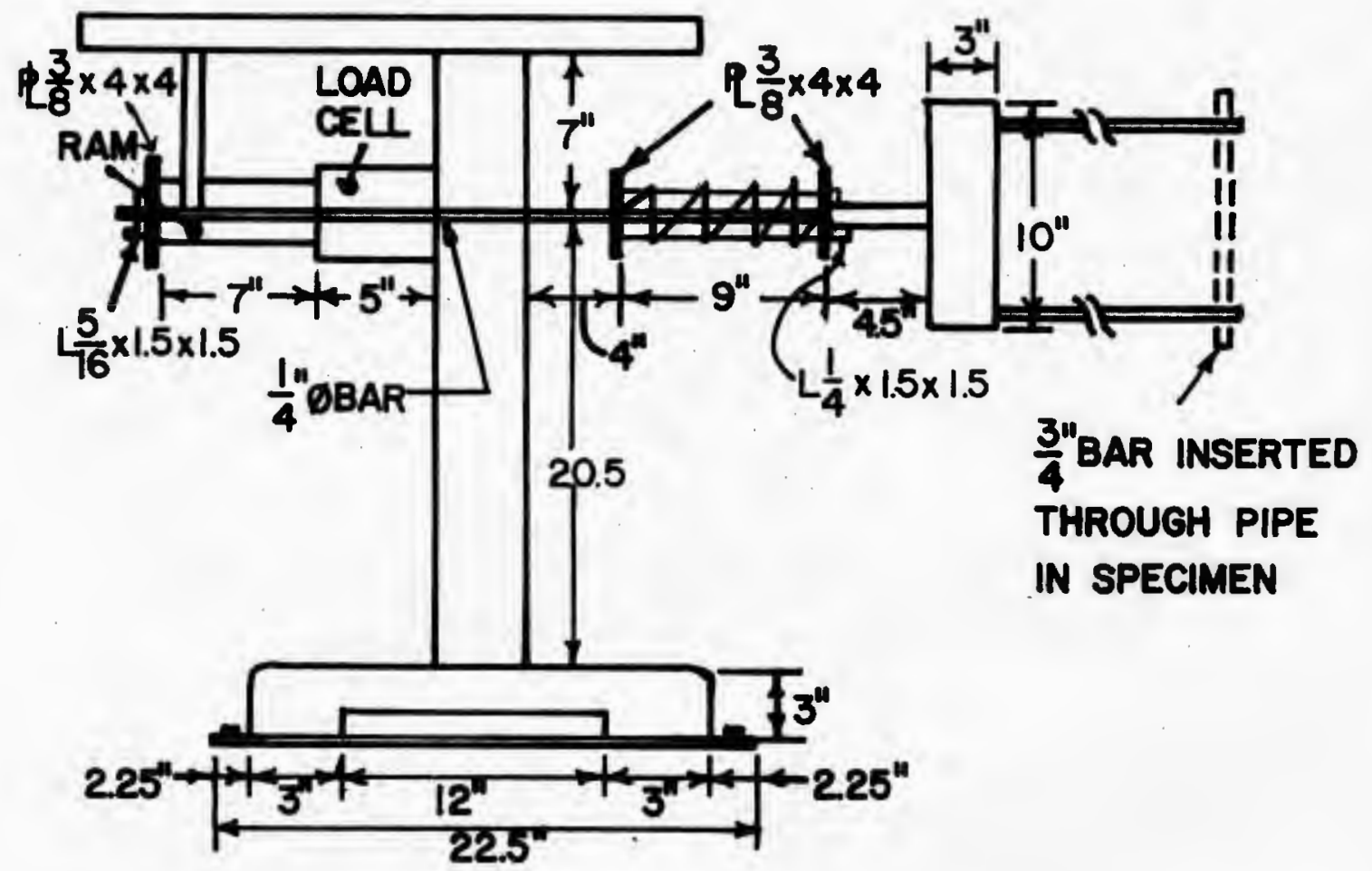

a) SCHEMATIC DIAGRAM

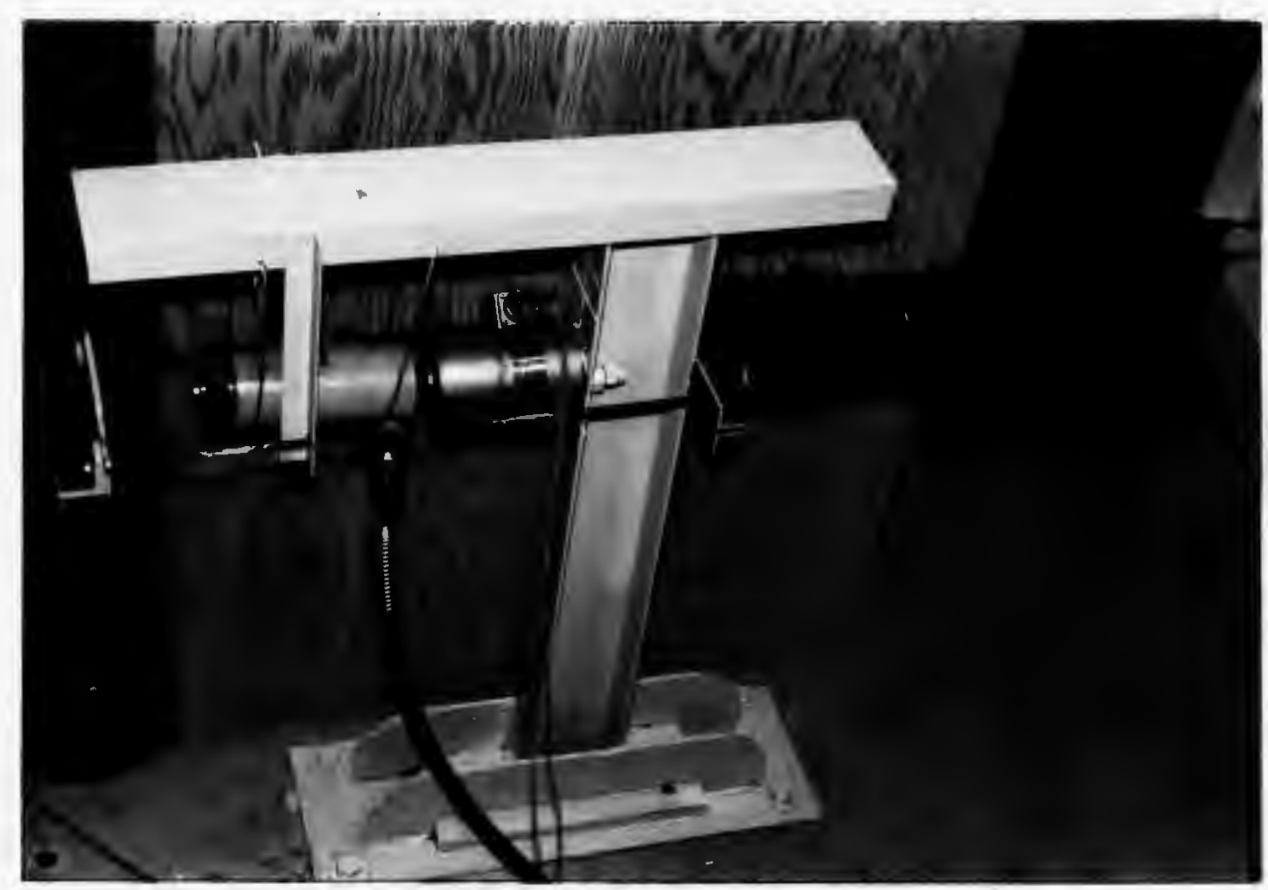

b) LATERA: LOAD SYSTEM

F1gure 3.26 Lateral load assembly 
welded to a steel plate PL $3 / 8^{\prime \prime} \times 4^{\prime \prime} \times 4^{\prime \prime}$. The lateral load ram assembly consisted of two steel angles connected together by two adjustable steel bars $\left(1 / 4^{\prime \prime} \emptyset\right)$, a 10-kip capacity load cell, and a 12kip capacity ram. This assembly was supported by a stand that is bolted to the concrete slab. A snapshot of lateral load assembly is shown in Fig. 3.26(b). 


\section{CHAPTER IV}

\section{TEST RESULTS AND PREDICTED BEHAVIOR}

\subsection{GENERAL}

As the experimental portion of this investigation, two rectangular reinforced concrete frames were designed based on two different methods, and tested to faflure. One frame was designed by the ultimate strength design method prescribed by ACI 318-71 (10), the other by a limit design method. These two frames are designated as USD-2 and $\mathrm{LD}-2$ respectively. The schematic diagram and principle properties of the frames are shown in Table 3.1.

For the reduction of all data, a computer program called "FRAG $\emptyset$ " was used. This program calculates the moment acting at a section for an applied axial load and measured concrete surface strain at that section. The input information for "FRAG $\emptyset$ " consists of section properties, the axial load on the section, the dial gage readings from curvature meters, and curvature meter arm lengths. The output includes the curvature, the axial load computed by integrating the concrete stress block over the cross section, the moment computed at the section corresponding to the input axial load and finally the moment computed by integration of stress block.

The experimental results for each frame are presented essentially in the form of six graphs as follows:

a) Load vs. Moment. These graphs show the axla1 column load and 
sway load vs. the indicated moments. The first graph shows the axial column load vs. the moments at corners $B$ and $C$ for the columns; and the second graph shows the lateral load vs. column and beam moments at corners B and C. Column axial loads and the lateral load were measured using pressure transducers and a load cell, respectively. From the dial readings of each pair of curvature meters at a station, the bending moments were computed at mid point of that station using program "FRAG $\emptyset "$. There were four stations along the beam and two stations along each column.

If the column axial loads had no accidental eccentricities, then the beam and column moments would be exactly the same at beam and column centerlines. However some inequality was observed which was partly due to the fact that cracked beam stiffness is assumed by "FRAG $\emptyset$ "; and partly due to the accidental eccentricity of the column axial loads.

b) Lateral Force vs. Components of Moment. This graph shows the measured lateral force vs. components of moment on the leeward column which are the moments due to beam loads $Q$, lateral force $H$, and sway deflection.

c) Lateral Force vs. $\delta$. This graph shows the measured lateral force vs. the moment magnification factor $\delta$ for the leeward column. The moment magnifications factor $\delta$ is obtained from the relationship $\delta=\mathrm{M}_{\mathrm{T}} /\left(\mathrm{M}_{\mathrm{T}}-\mathrm{M}_{\mathrm{P}-\Delta}\right)$; where $\mathrm{M}_{\mathrm{T}}$ is the total moment on the leeward column due to the beam loads $Q$, lateral force $H$, and sway deflection; and $M_{P-\triangle}$ is the moment due to sway deflection.

d) Load vs. Corner Rotations. This graph shows the measured column loads and sway load vs. colner rotations measured at corners A 
and D using dial gage systems.

e) Load vs. Lateral Deflection. These figures show the lateral deflection measured at corner $B$ vs. the axial loads and lateral load for each frame. Theoretically, no lateral deflection under gravity loads was expected. However, some deflection under gravity loads was observed which is due to imperfection in frame geometry or loading.

\section{$4.2 \quad$ FRAME USD-2}

a) General. Frame USD-2 was a symmetrical frame, designed by the U1timate Strength Design method. It represented the lower level of a seven-story unbraced frame with the beam to column load ratio of $\mathrm{Q} / \mathrm{P}=.083$ as discussed in Chapter 2. The columns were $4.00 \mathrm{in}$. deep by 6.00 in. wide; and the beam was 4.5 in. deep by 6.00 in. wide. Column reinforcements were 4-\#3 longitudinal bars and $\# 12$ gage wire ties at $4.00 \mathrm{in.}$ intervals. Concrete strength for columns was 4610 psi on the day of testing. The beam was also reinforced with 4-\#3 bars tailored according to the moment envelope and, tied with $⿰ ⿰ 三 丨 ⿰ 丨 三 12$ gage wire stirrups at 1.90 in. intervals. Compressive strength of the concrete for the beam was 4498 psi.

Frame USD-2 was designed such that the frame failure would occur as a result of hinges developing in the beam. The loading was based on the actual design loads. Column loads $P$ were applied at 2-kip increments, and $Q / P$ ratio of .083 was maintained all during the test. After reaching the maximum gravity loads, beam and column loads were held constant and sway load was applied at $200 \mathrm{lb}$. increments until failure. After frame failure, lateral load was taken of $f$, and the gravity loads were reduced by $25 \%$. Lateral load was reapplied incremen- 
tally and only the lateral deflection readings were recorded. Lateral load was increased again until frame became completely unstable.

b) Load vs. Moment. Axial thrust vs. the indicated column corner moments at corners $B$ and $C$ are shown in Fig. 4.1. The applied column loads $P$ were increased to $23.4 \mathrm{kips}$ and each beam 1 oad $Q$ to $1.93 \mathrm{kips}$, to result in total column thrusts of $25.33 \mathrm{kips}$. As shown in Fig. 4.1 , at maximum column thrust of 25.33 kips, column corner moments are 30 kip-in. The gravity loads were held constant during subsequent application of lateral load $\mathrm{H}$ which increased the moment at column corner $\mathrm{C}$ to $\mathrm{M}_{\mathrm{P}}=$ 58 kip-in.

Lateral force $\mathrm{H}$ vs. the indicated moments in the beam and columns are shown in Fig. 4.2. Theoretically the beam and column end moments would be exactly the same under gravity loads. However, as indicated in Fig. 4.2 some inequalities between the beam and column end moments were observed which are due to accidental eccentricities, difference in shear forces acting at two faces of the joint block, and cracked beam stiffness assumption by "FRAG $\emptyset$ ".

As indicated in Fig. 4.2 the beam and column moments at corner C were increased almost linearly up to $2400 \mathrm{lb}$. At this level excessive cracking was observed at corner C. It appears that at $25001 \mathrm{~b}$. the beam reached its maximum moment capacity at corner $\mathrm{C}$ and developed the first hinge. At the next increment large cracks appeared at poing $M^{\prime}$ (steel cut off point). The load increment was then decreased to $50 \mathrm{lb}$. It appears that at $2850 \mathrm{lb}$. point $\mathrm{M}^{\prime}$ is very close to its maximum capacity while corner $\mathrm{C}$ of beam was still resisting the constant hinge moment. Thus with two hinges in the beam, first hinge at corner $C$ and the second 
hinge at point $M^{\prime}$, the frame became unstable.

c) Lateral Load vs. Components of Moment. Lateral load vs. components of moment on leeward column is shown in Fig. 4.3. The moment induced on the leeward column comes from three sources; (1) moment from beam loads Q, (2) moment from the lateral load H, and (3) moment from the sway deflection. The value of $\mathrm{M}_{Q}$ using elastic analysis is $\mathrm{M}_{\mathrm{Q}}=$ $.19 Q \mathrm{Q}=0.19 \times 1.93 \times 84=30.8 \mathrm{k}$-in. at center of joint block; or $30.8 \times 18.75 / 21=27.5 \mathrm{k}-1 \mathrm{n}$ at the face of the beam; and $\mathrm{M}_{\mathrm{H}}=\mathrm{Hh} / 2$. The indicated $M_{Q}$ progressively decreases as the lateral force increases. This in part is due to the decreasing stiffness of the column as the moment increases. The lower stiffness of the column thus causes a smaller amount of beam load moment to be transferred to the column.

d) Lateral Load vs. $\delta$. As shown in Fig. 4.4, the moment magnification factor $\delta$ increases linearly up to $\mathrm{H}=24001 \mathrm{~b}$; but because of larger $\mathrm{M}_{\mathrm{P}-\Delta}$ at higher loads, the curve tends to become flatter at loads higher than $2400 \mathrm{lb}$. At $H=2850 \mathrm{lb}$, the $\mathrm{M}_{\mathrm{P}-\Delta}$ was 9.9 in-k, out of a total moment of $61.5 \mathrm{in-k}$; so the indicated magnification factor $\delta$ was $61.5 /(61.5-9.9)=1.19$

e) Corner Rotations. The axial load and lateral force vs. the measured rotations at corners $A$ and $D$ of the frame is shown in Fig. 4.5. Corner rotation increased almost linearly up to $2400 \mathrm{lb}$, and the curves became flatter at higher loads. Rotation of corner D was slightly higher than the rotation of corner A.

f) Load vs. Lateral Deflection. The measured and computed load deflection curves are shown in Fig. 4.6. As discussed earlier in section 4.1-e, since frame USD-2 was symmetrical no lateral deflection 
under gravity load was theoretically expected. However as indicated in Fig. 4.6, a lateral deflection of .002 in. (to the right) occured at maximum gravity loads. The measured initial stiffness of the frame was higher than the analytical curve. This might be expected since tensile strength of the concrete as it affects the beam stiffness was neglected in the analytical computer program. Computer results indicated that the frame failure would occur at $H=2400 \mathrm{lb}$. The actual frame withstood a maximum lateral force of $2850 \mathrm{lb}$. After reaching the maximum lateral force of 2850 the lateral load was released followed by decreasing the gravity loads by $25 \%$. Lateral load was applied again and the reloading response is also shown in Fig. 4.6. As indlcated, frame was capable of resisting a lateral load of $1800 \mathrm{lb}$. before becoming unstable. Figures 4.7 and 4.8 show four photographs of the frame after failure. 


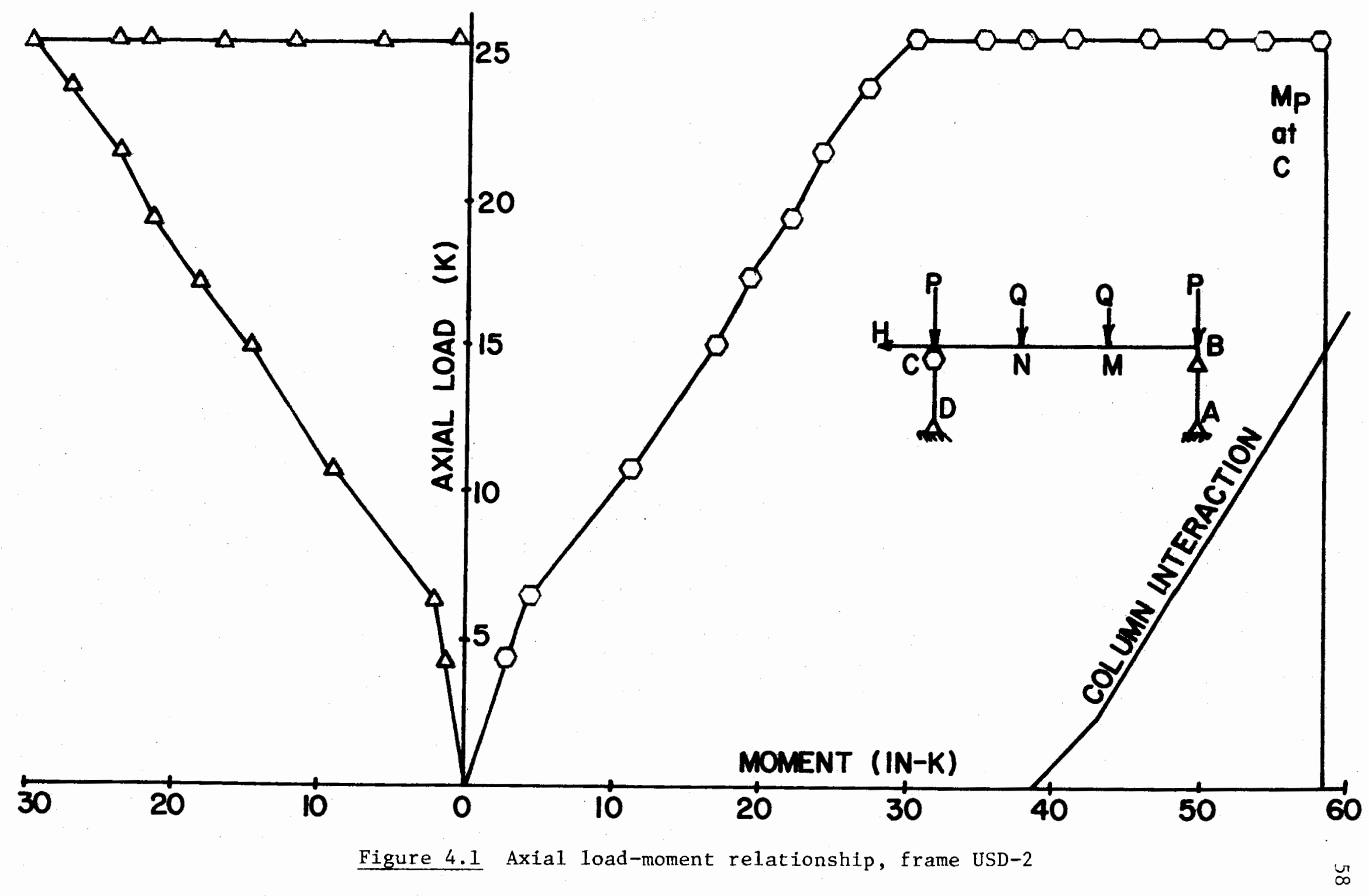




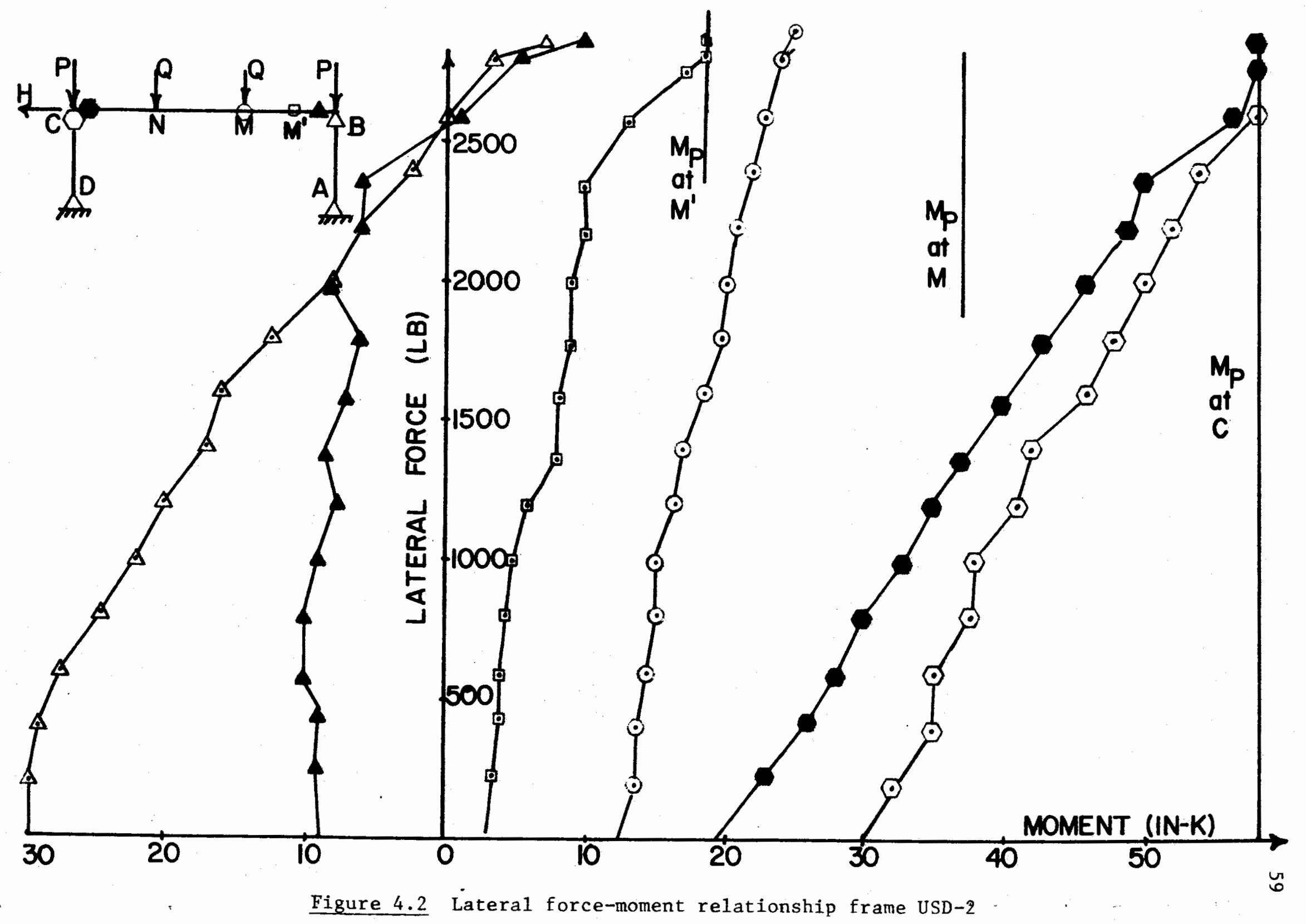




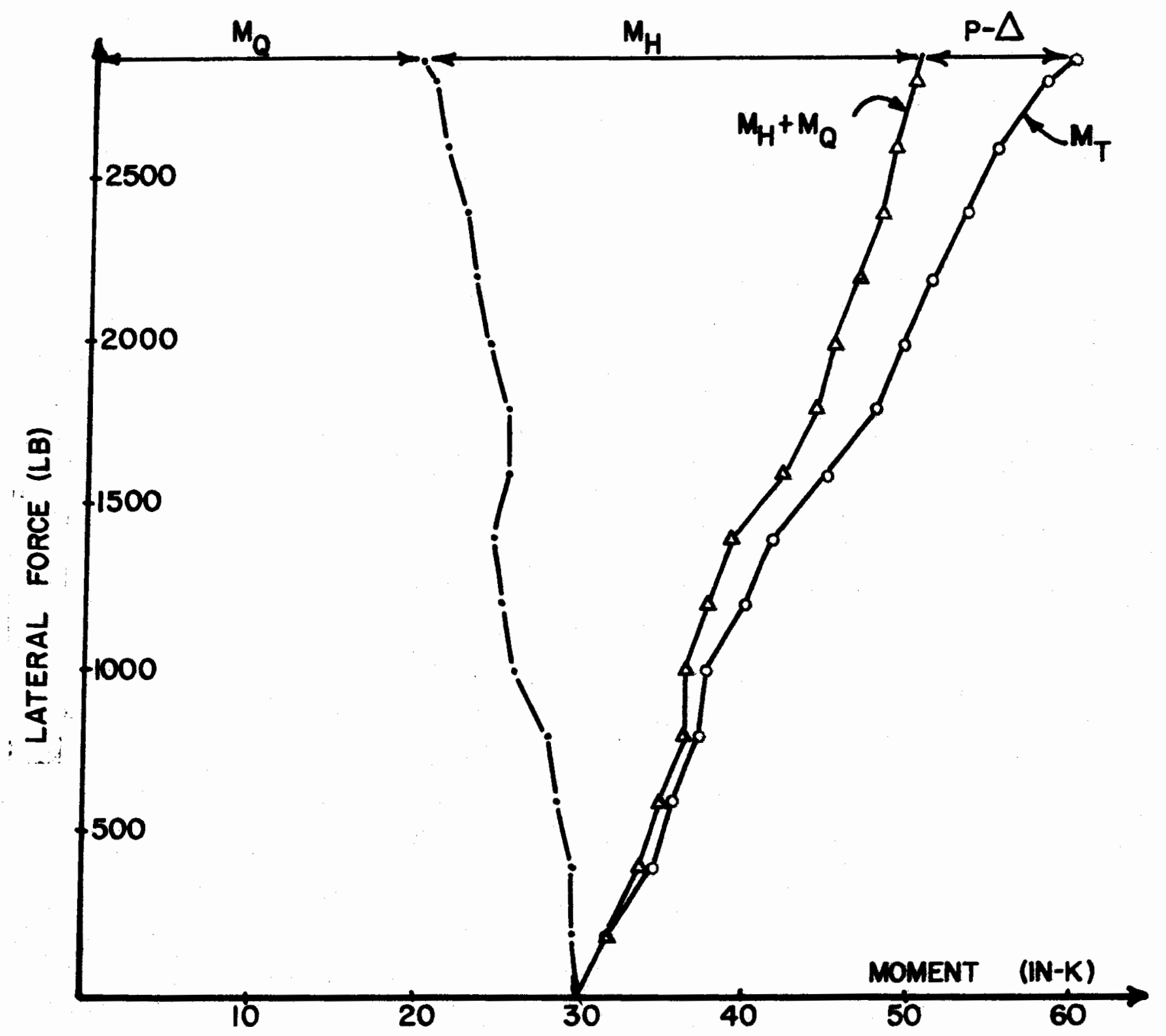

Figure 4.3 Components of moment in left column, frame USD-2 


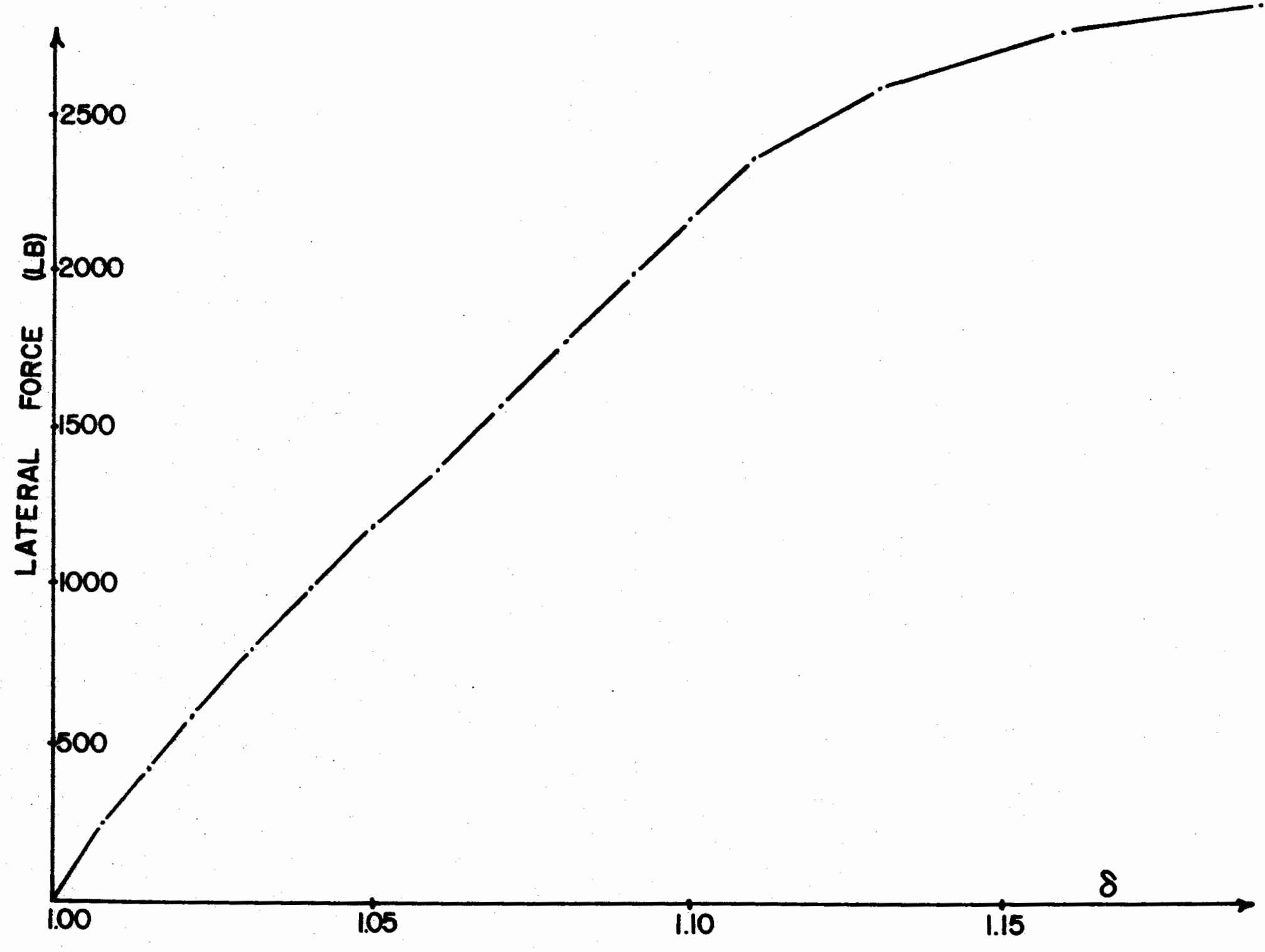

Figure 4.4 Lateral force- $\delta$ relationship, frame USD-2 


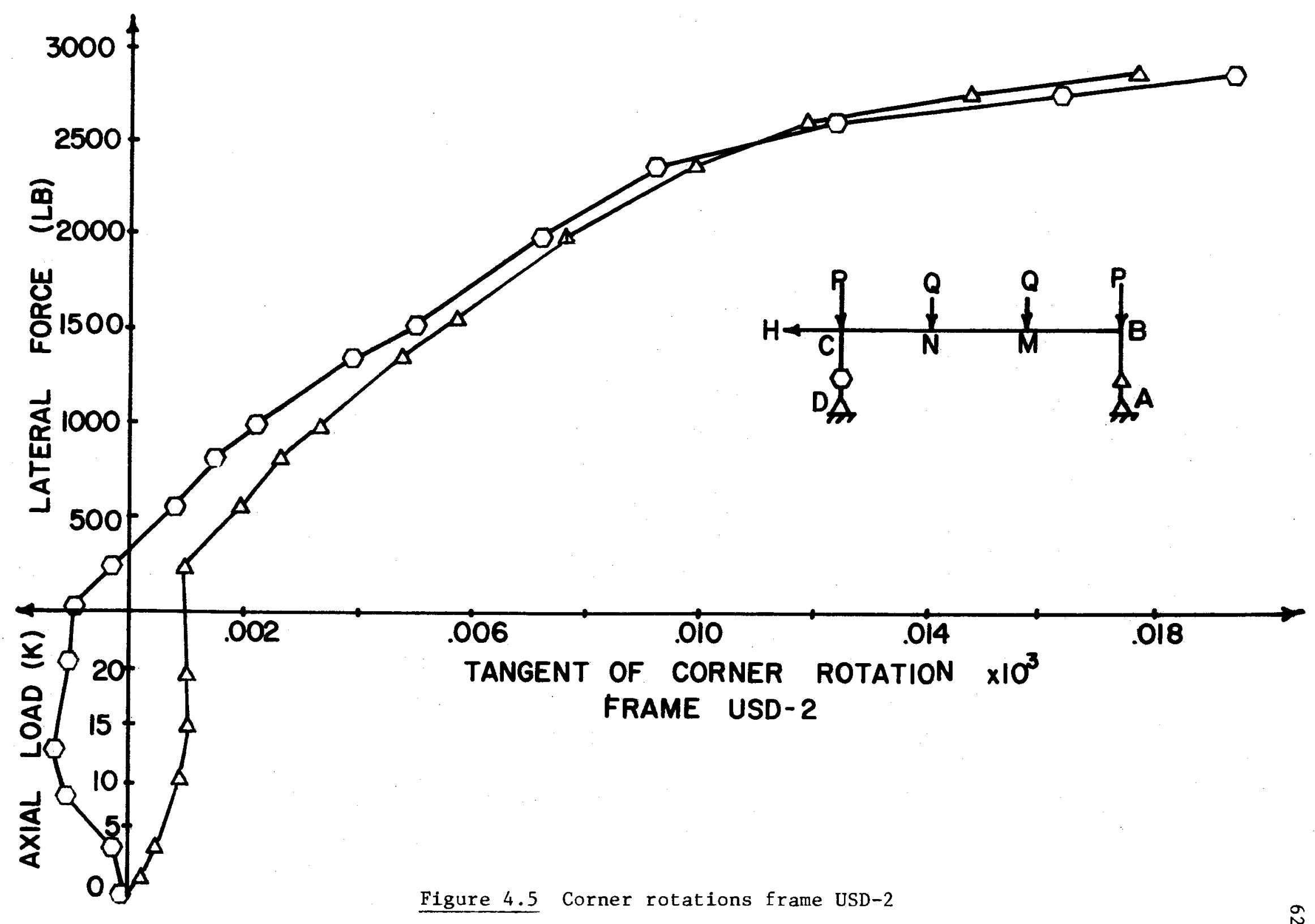




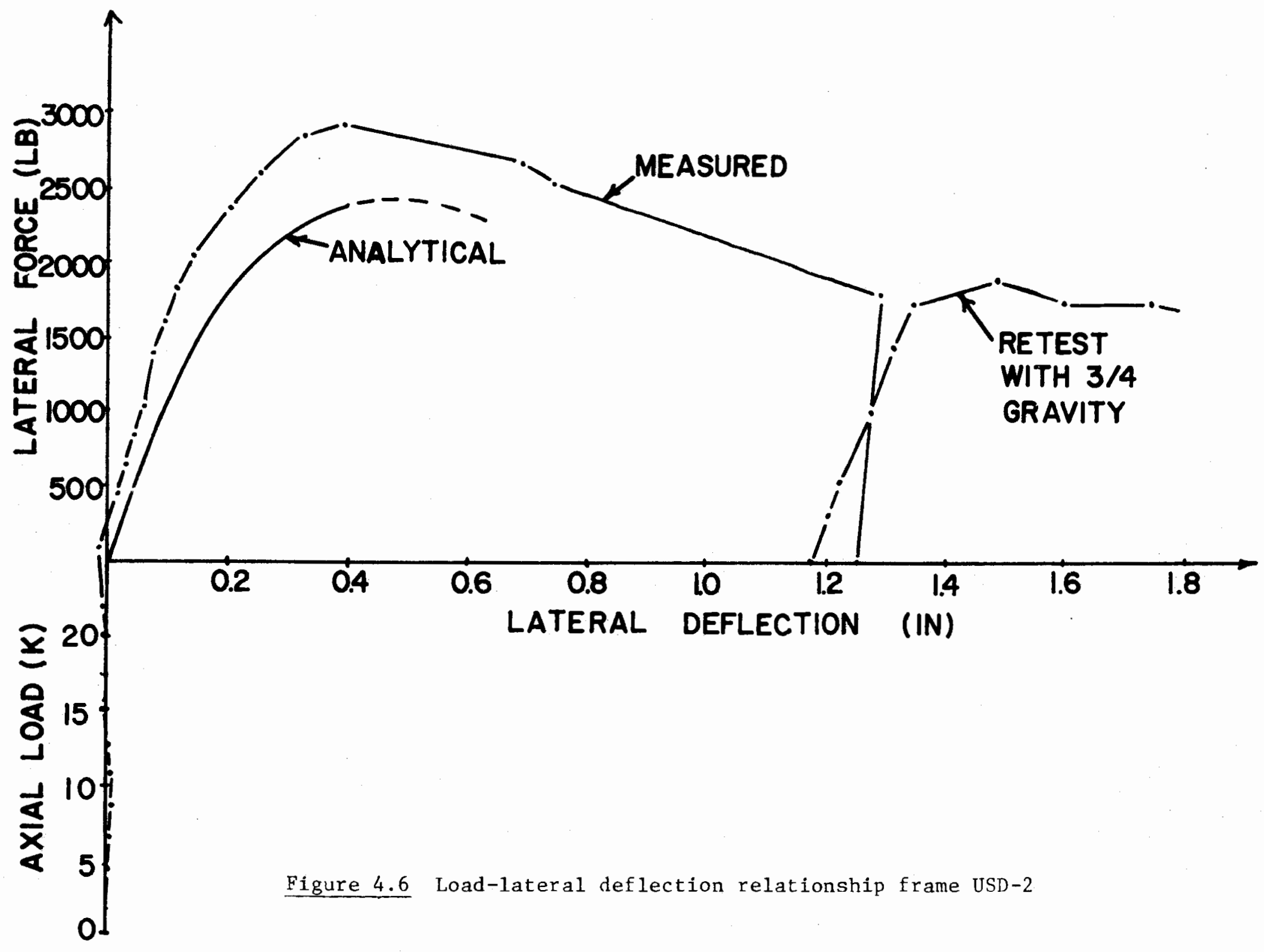




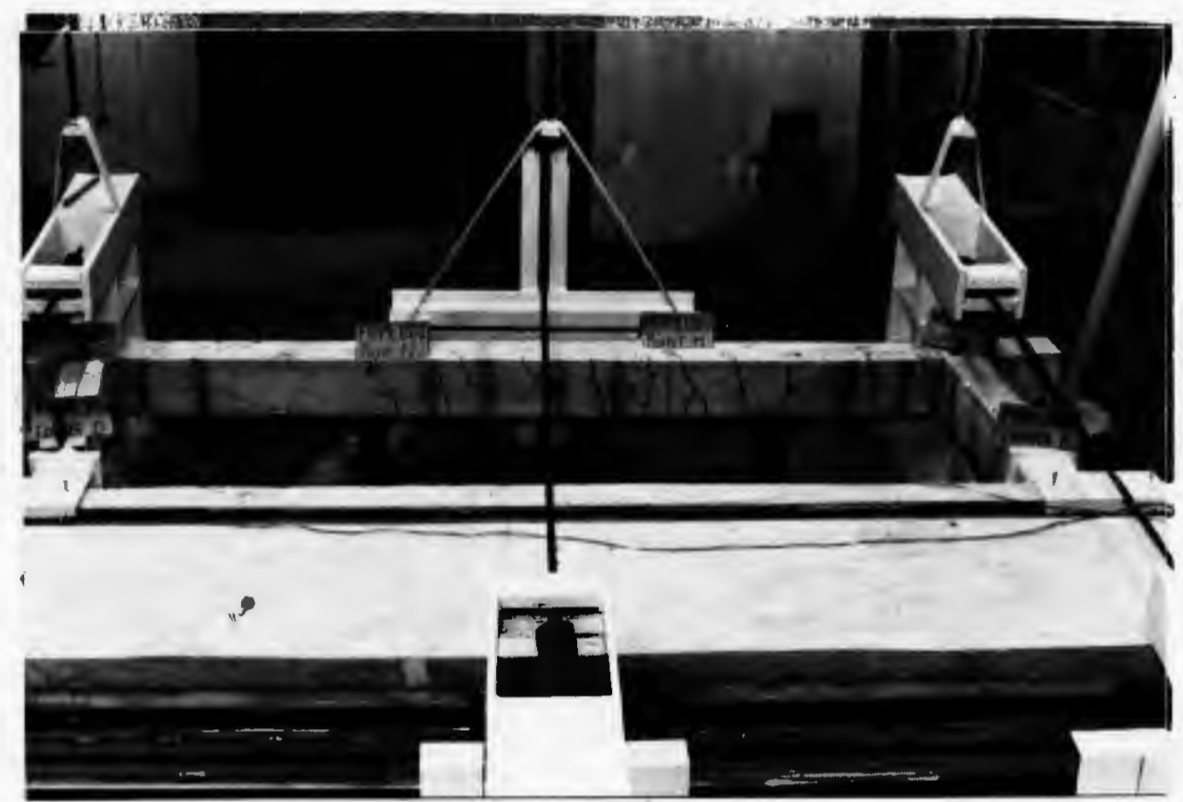

(a) OVERALL VIEW OF FRAME USD-2

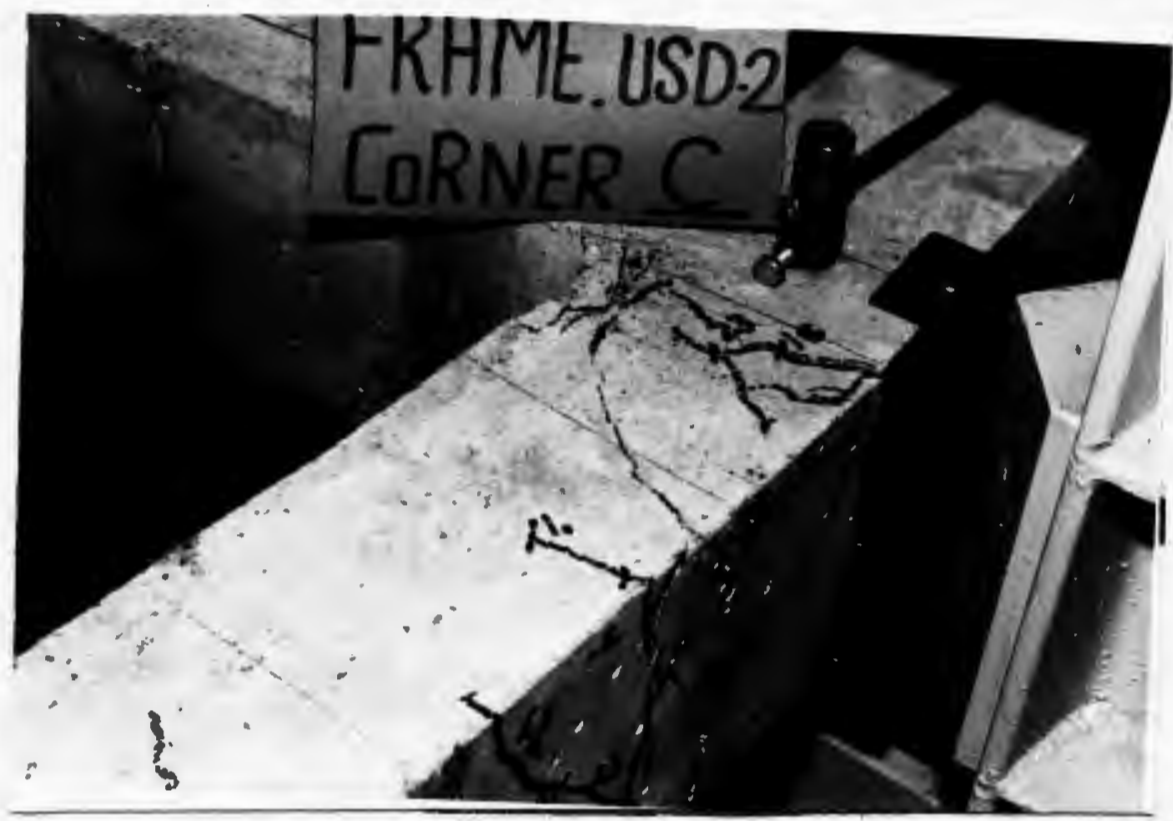

(b) CORNER $\mathrm{C}$

Figure 4.7 . Two views of frame USD-2 after testing 


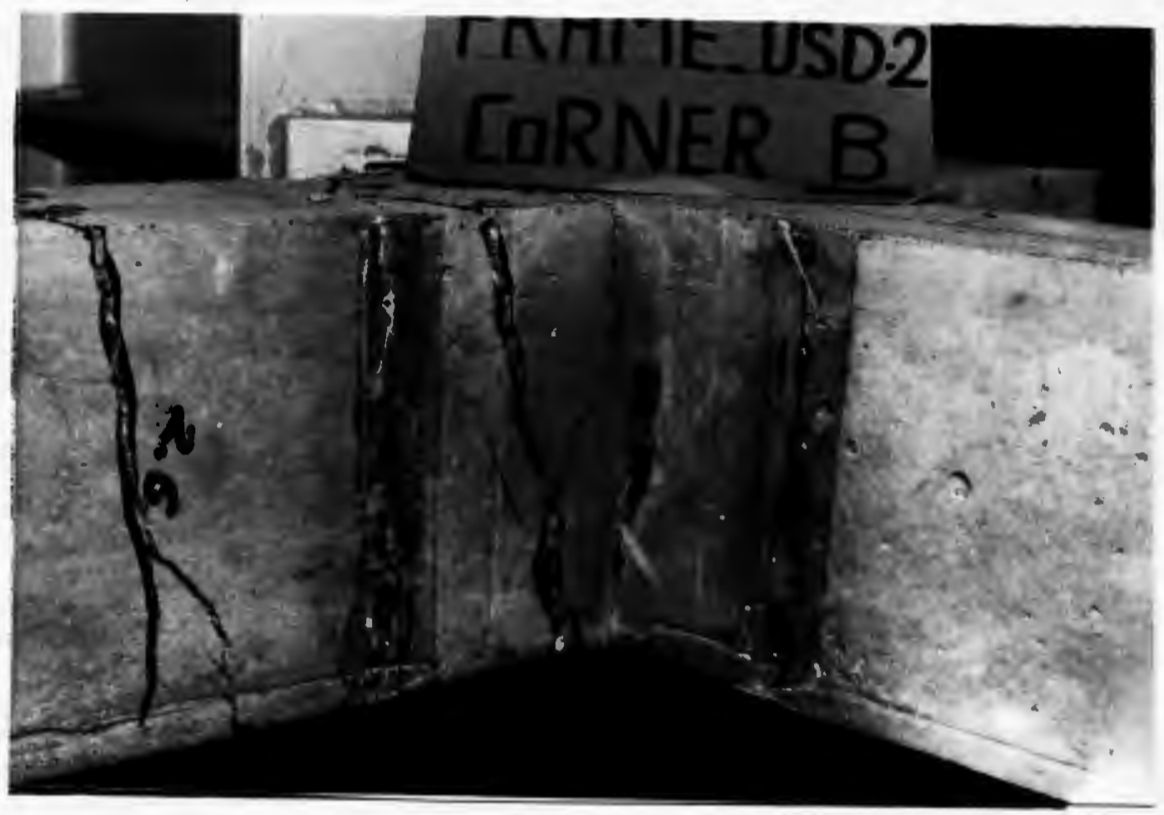

(a) CORNER B

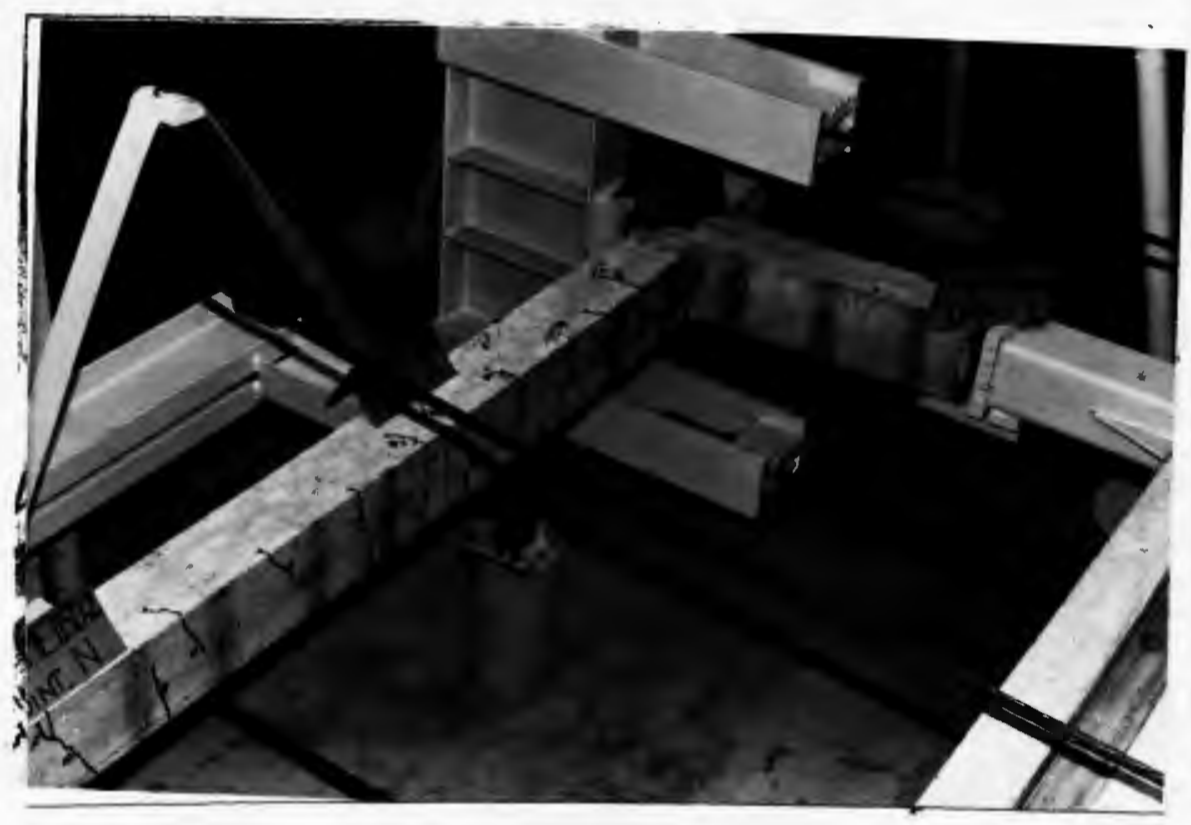

(b) CRACKS AT THE BEAM

Figure 4.8 Two views of frame USD-2 after testing 


\subsection{FRAME LD-2}

a) Genera1. Frame LD-2 was a symmetrical frame, designed by a limit design method. It represented the lower level of a seven-story unbraced frame with the beam to column load ratio of $Q / P=.083$. The columns were $3.50 \mathrm{in}$. deep by $6.00 \mathrm{in.} \mathrm{wide;} \mathrm{and} \mathrm{the} \mathrm{beam} \mathrm{was} 4.50 \mathrm{in}$. deep by 6.00 in. wide. Columns reinforcements were 4-\#3 longitudinal bars and 112 gage wire ties at 4.00 intervals. Concrete strength for column was $4372 \mathrm{psi}$ on the day of testing. The beam was also reinforced with 4-\#3 bars tailored according to the moment envelope and tied with \#12 gage wire stirrups at $1.87 \mathrm{in}$. intervals according to the shear requirements.

Frame LD-2 was designed such that the frame failure would occur as result of hinges developing in the beam. Column loads $\mathrm{P}$ were applied at 2-kips increments and $Q / P$ ratio of .083 was maintained al1 during the test. After reaching the maximum gravity loads, beam and column loads were held constant and sway load was applied at $2001 \mathrm{~b}$. increments until failure.

b) Load vs. Moment. Axial thrust vs. the indicated corners moments at corner $A$ and $B$ are shown in Fig. 4.9. The applied column load $P$ was increased to 23.57 kips and beam $10 a d s$ to $1.98 \mathrm{kips}$, to result in total column thrust of 25.57 kips. As shown in Fig. 4.9, column moments at corners $B$ and $C$ increase almost linearly with each load increment until the lateral load was applied. The gravity loads were held constant during subsequent application of lateral load $\mathrm{H}$, which increased the moment at column corner $C$ to $M_{P}=46$ in-k. 
Lateral force $H$ vs. the indicated moments in the beam and columns are shown in Fig. 4.10. The initial lateral load increment was $2001 \mathrm{~b}$. As shown in Fig. 4.10, the indicated moments at corner C for beam increased almost linearly until $\mathrm{H}=1800 \mathrm{1b}$. At this load the beam reached its maximum moment capacity at corner $C$, and excessive cracking for this region was observed. At $H=23001 \mathrm{~b}$, extensive cracks developed in the beam at the negative moment steel cut off point (point $N^{\prime}$ ) near corner C. Fig. 4.10 shows that at this load the beam moment at corner B started to increase more rapidly. At $H=24001 \mathrm{~b}$. a tension crack appeared in the beam at corner $B$ and the moment at this region appears to be close to its capacity. At $H=2430$ 1b. the frame became unstable, with vivid hinges at corner $C$ and load point $M$.

c) Lateral Load vs. Components of Moment. Lateral load vs. components of moment on leeward column is shown in Fig. 4.11. The indicated moment in the leeward column are decomposed Into three components: $M_{Q}, M_{H}$, and $M_{P-\Delta}$ following the procedure discussed in section 4.2(c). According to elastic analysis, $\mathrm{M}_{\mathrm{H}}=\mathrm{Hh} / 2: \mathrm{M}_{\mathrm{Q}}=.19 \mathrm{QL}=$ $.19 \times 1.98 \times 84=31.6$ in-k at center of joint block, or $31.6 \times 18.75 / 21=$ 28.2 at the face of the beam. The indicated $M_{Q}$ progressively decreases as the lateral force increases. This is due to the decreasing stiffness of the column as the moment increases.

d) Lateral Load vs. $\delta$. The moment magnification factor $\delta$ vs. the lateral load is shown in Fig. 4.12. The curve is almost linear up to $2300 \mathrm{1b}$, and becomes very flat at higher loads. At $\mathrm{H}=2430 \mathrm{lb}$, the $\mathrm{M}_{\mathrm{P}-\Delta}$ was $9.3 \mathrm{in}-\mathrm{k}$, out of a total moment of $50 \mathrm{in}-\mathrm{k}$; so the indicated magnification factor $\delta$ was $50 /(50-9.3)=1.23$. 
e) Corner Rotations. The axial load and lateral force vs. the measured rotations at corners $A$ and $D$ of the frame are shown in Fig. 4.13. The measured rotation of corner $D$ was larger than the rotation of corner $A$, under maximum gravity loads. Rotations of corners $A$ and $D$ were almost linearly increasing up to $2200 \mathrm{lb}$ of lateral load. The curve became much flatter at higher lateral loads, after the first hinge formation.

f) Load vs. Lateral Deflection. The measured and the computed load deflection curves are shown in Fig. 4.14. A lateral deflection of 0.03 in. was measured for this frame under maximum gravity loads. The measured initial stiffness of the frame appears to be higher than the analytical curve. The computer results (analytical curve) indicated that frame failure would occur at $H=1800 \mathrm{lb}$. The actual frame withstood a maximum lateral force of $2430 \mathrm{lb}$.

The frame was deflected under increasing lateral loads until a sway deflection of about 1 in. was obtained. Lateral load was then released followed by decreasing the gravity loads by $25 \%$. Lateral load was applied again and the reloading response is also shown in Fig. 4.13. The damaged frame was capable of resisting $1800 \mathrm{lb}$ before becoming unstable.

Fig. 4.14 and 4.15 show four photographs of the frame after failure. 


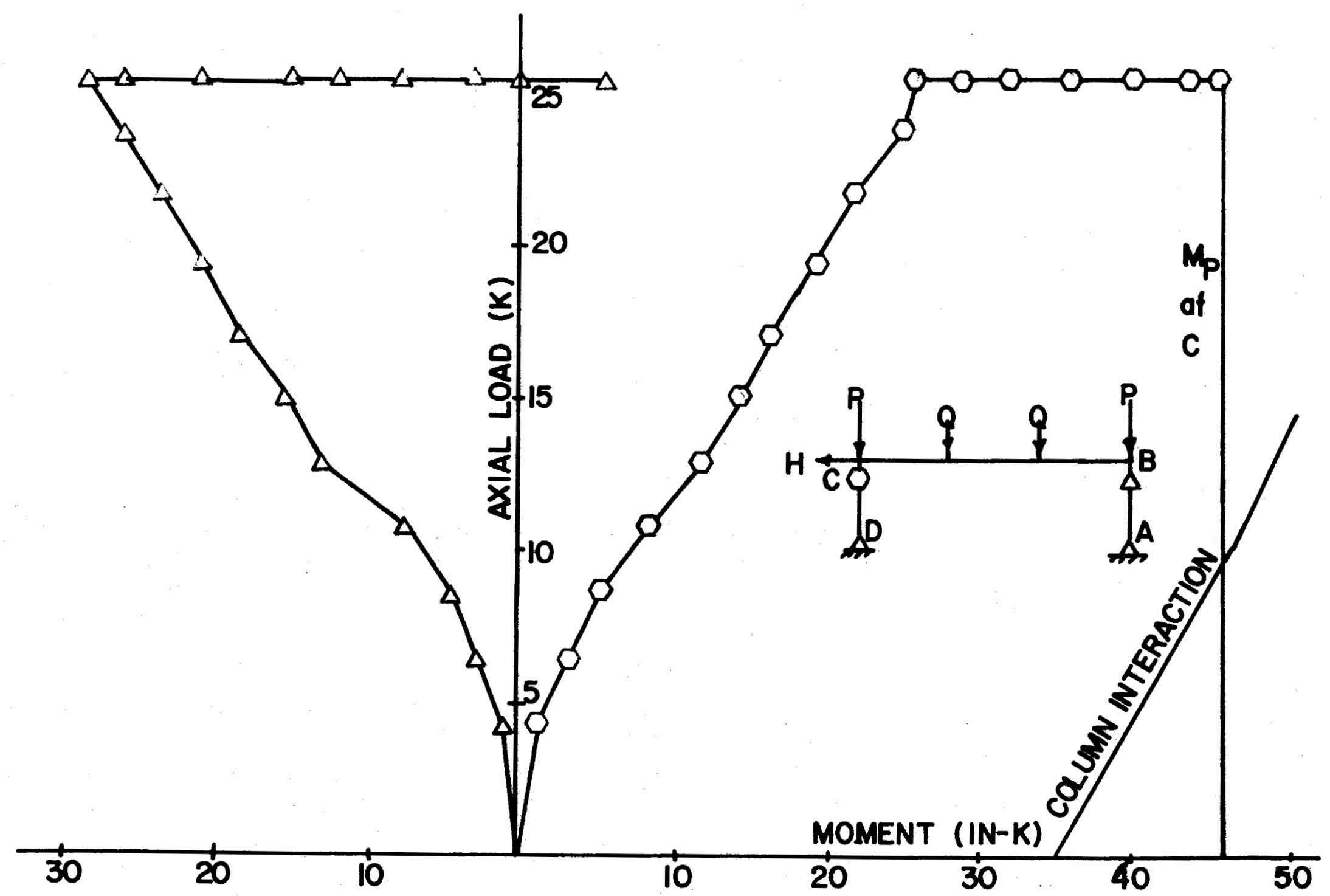

Figure 4.9 Axial load-moment relationship frame LD-2 


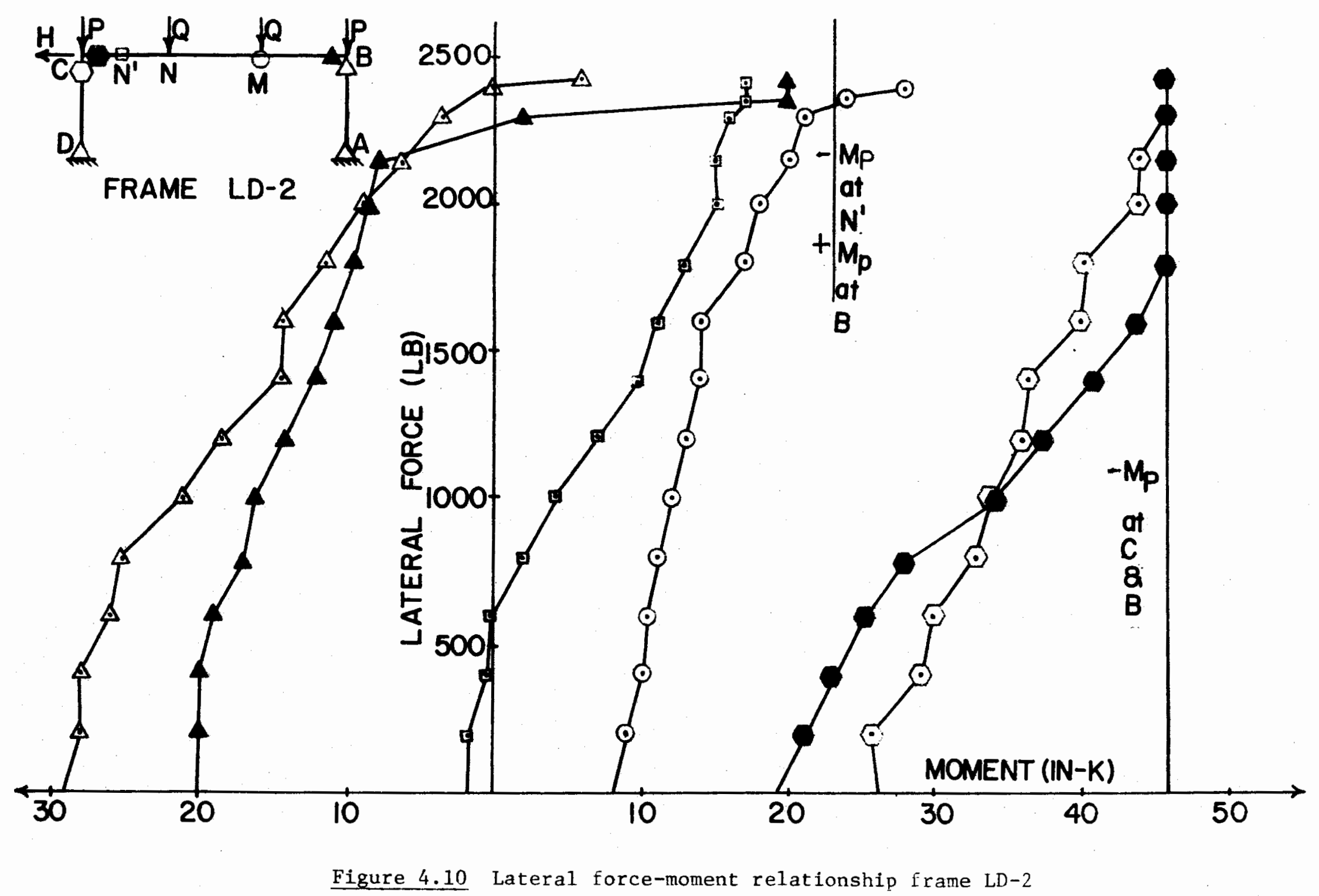




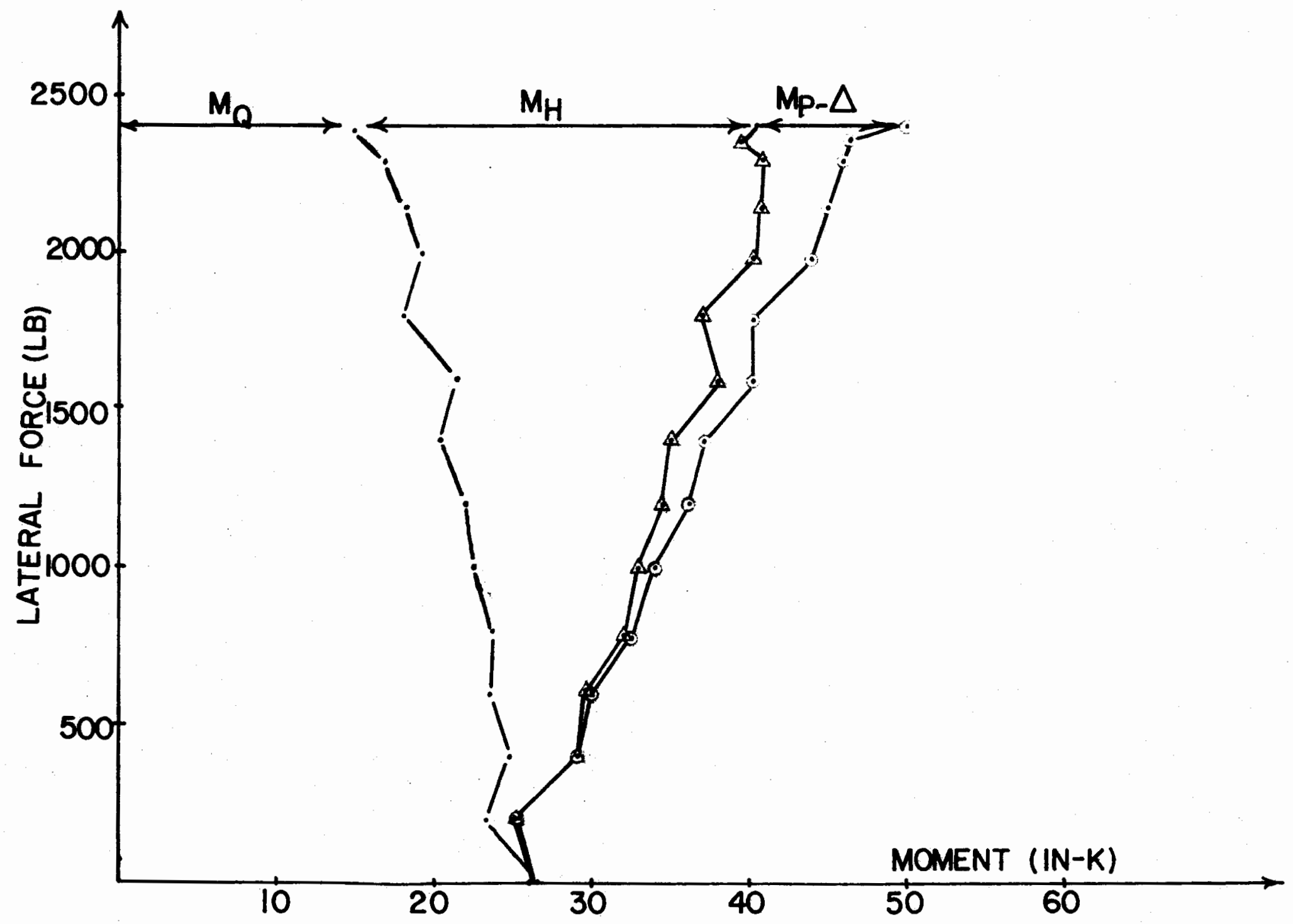

Figure 4.11 Components of the moment in left column irame LD-2 


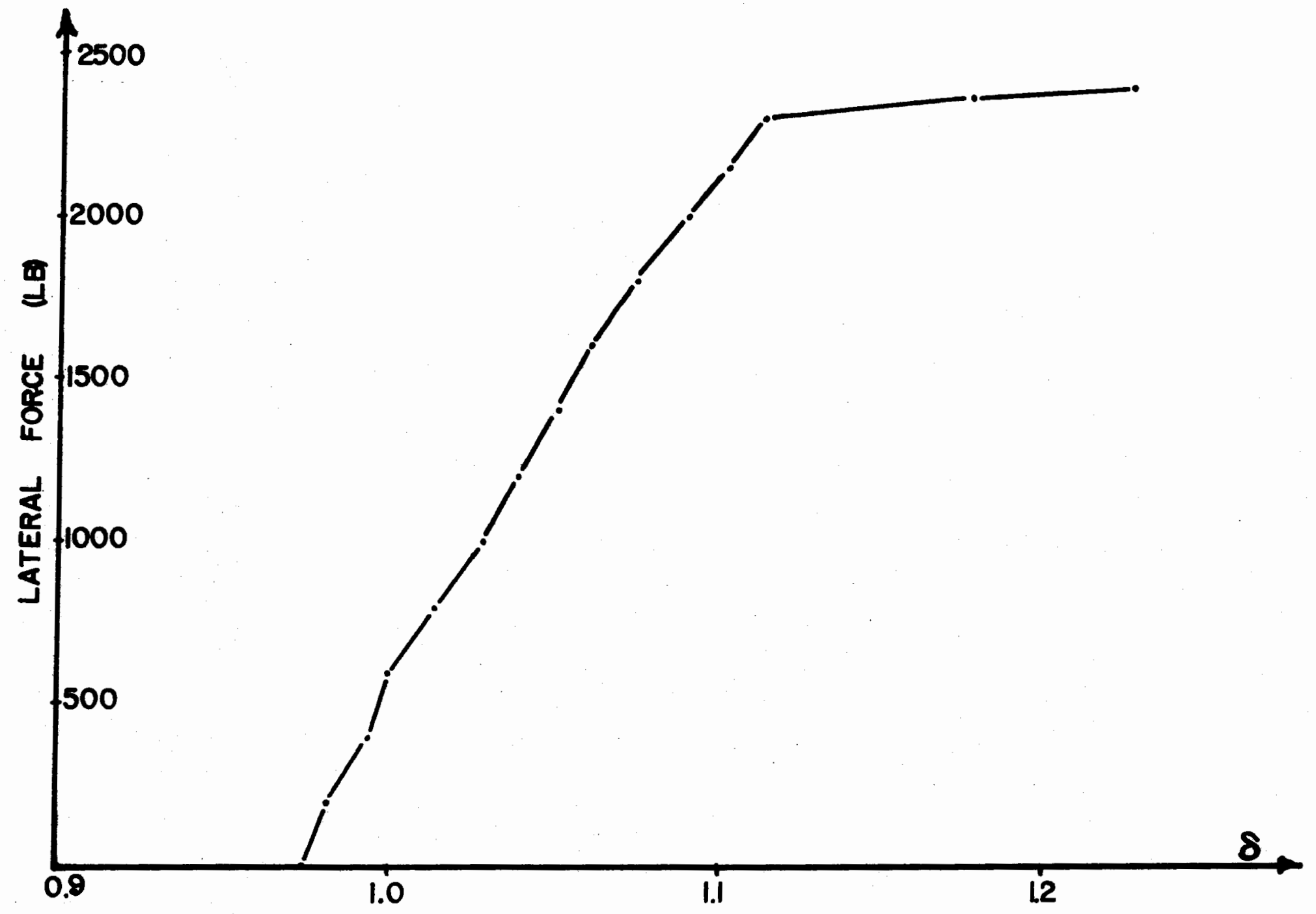

Figure 4.12 Lateral force- $\delta$ relationship frame LD-2 


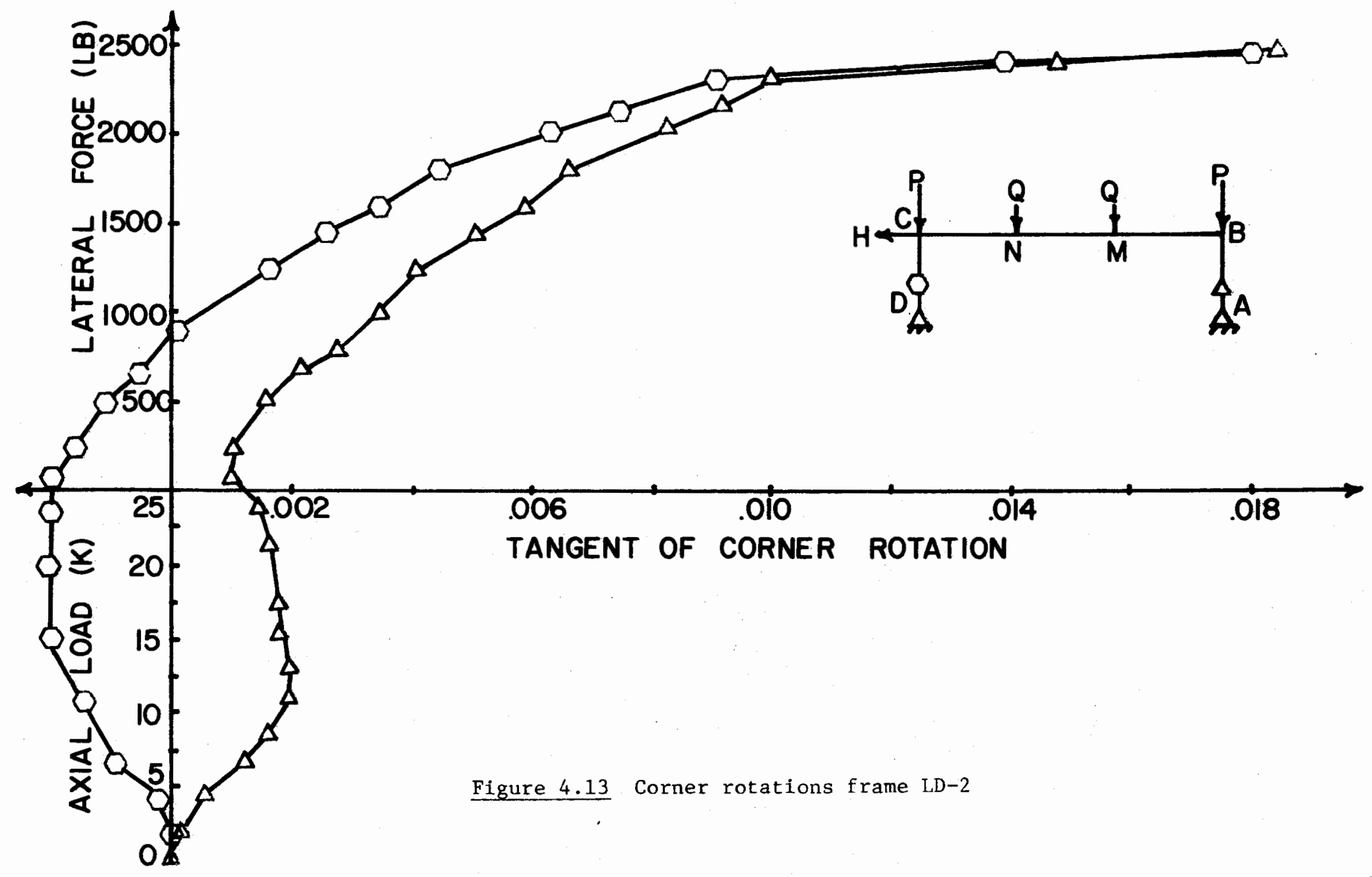




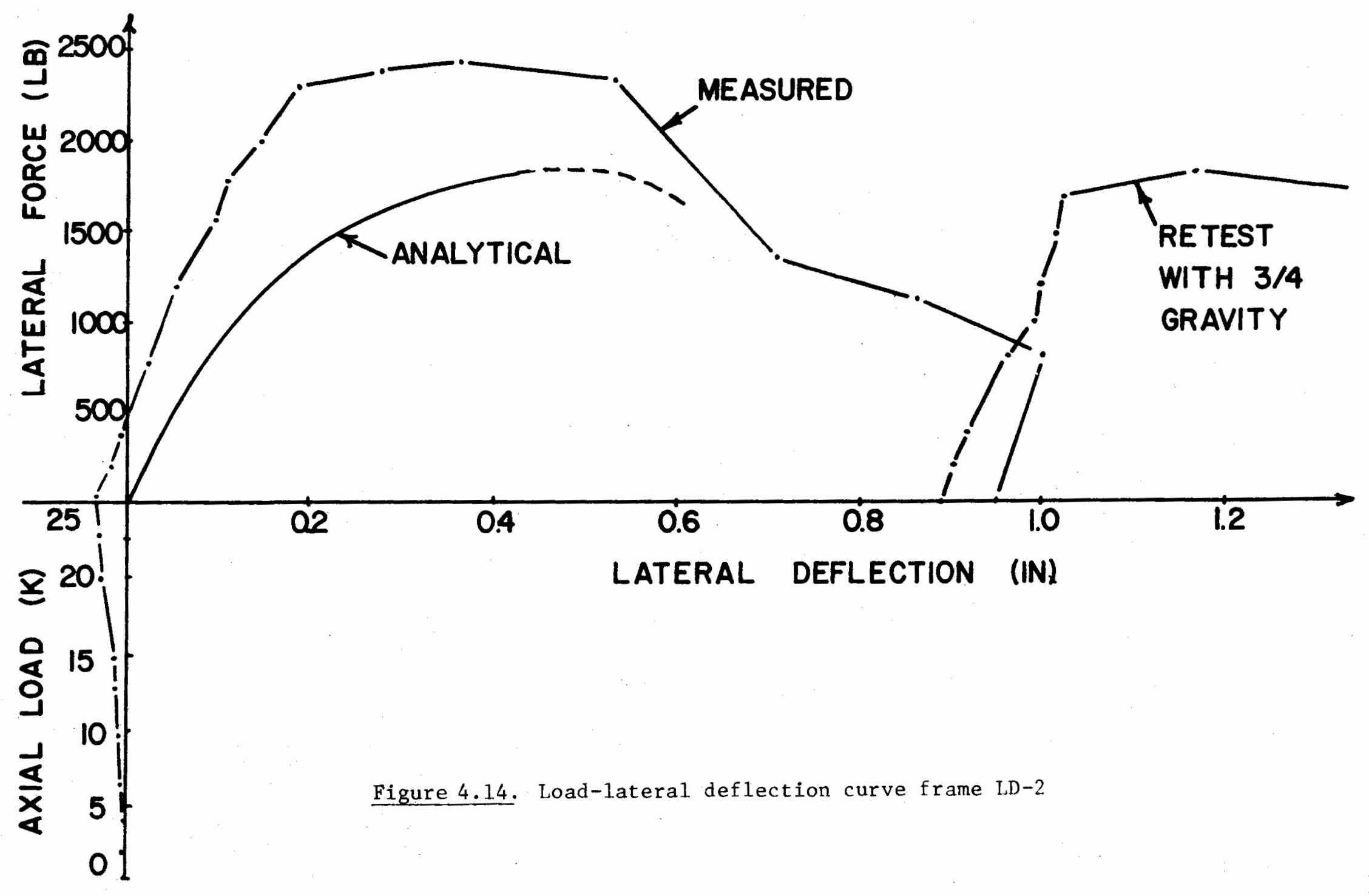




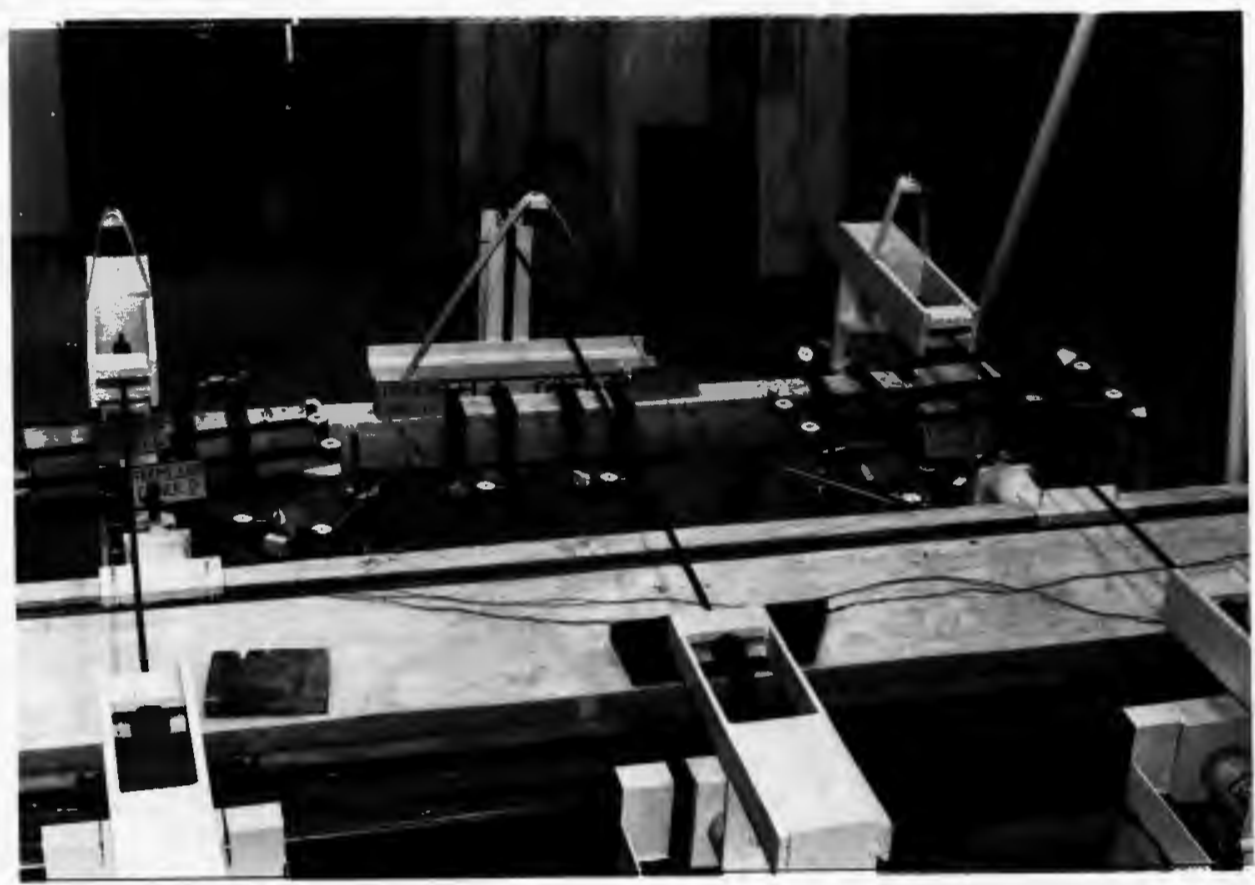

(a) OVERALL VIEW OF FRAME LD-2

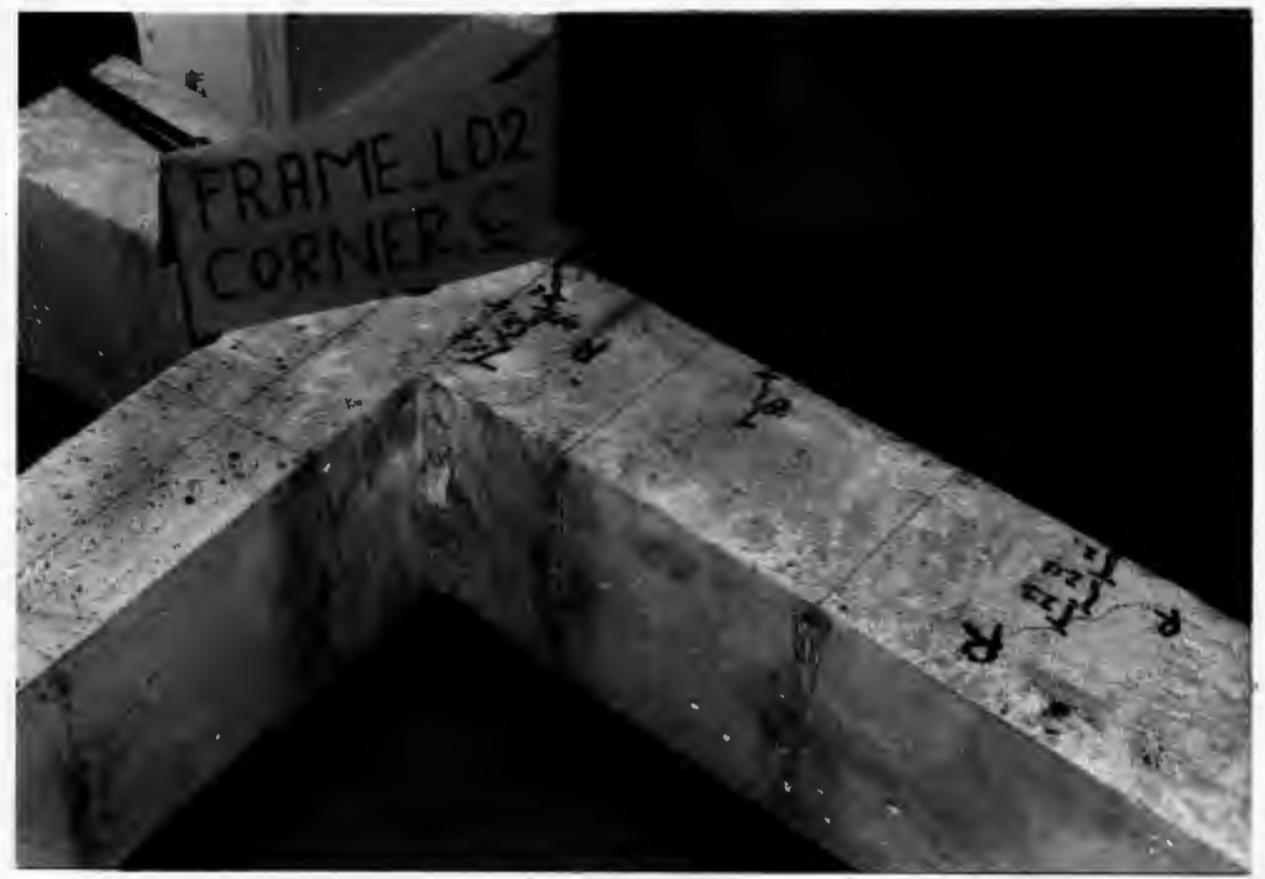

(b) CORNER C

Figure 4.15 Two views of frame LD-2 after failure 
4.4 COMPARISON OF FRAMES USD-2 AND LD-2

The lateral load vs. lateral deflection for frames USD-2 and LD-2 are shown in Fig. 4.17. As indicated in this figure, under service load $\mathrm{H}$ and factored load $\mathrm{H}$, the measured lateral deflections for frame USD-2 and LD-2 were $0.11 \mathrm{in.}$ and $.175 \mathrm{in}$. respectively. At $\mathrm{H}=2300 \mathrm{lb}$ frame LD-2 stiffness started to decrease rapidly, and at $H=24301 \mathrm{~b}$ this frame reached its maximum capacity and became unstable. Frame USD-2 reached its maximum capacity at $H=2850$; $1 . e .$, its capacity was $17 \%$ higher than LD-2. The measured lateral deflection for frames USD-2 and LD-2, under maximum lateral loads were .390 in. and .366 in. respectively. As shown in Fig. 4.17, both frames continued to deflect under rapidly decreasing lateral loads.

The reloading responses for both frames under $3 / 4$ of gravity loads are shown in Fig. 4.17. The damaged frames USD-2 and LD-2 were capable of resisting $1874 \mathrm{lb}$ and $1800 \mathrm{lb}$ of lateral load respectively before becoming unstable again. The reloading capacities were $66 \%$ and $74 \%$ of the original capacities respectively. 


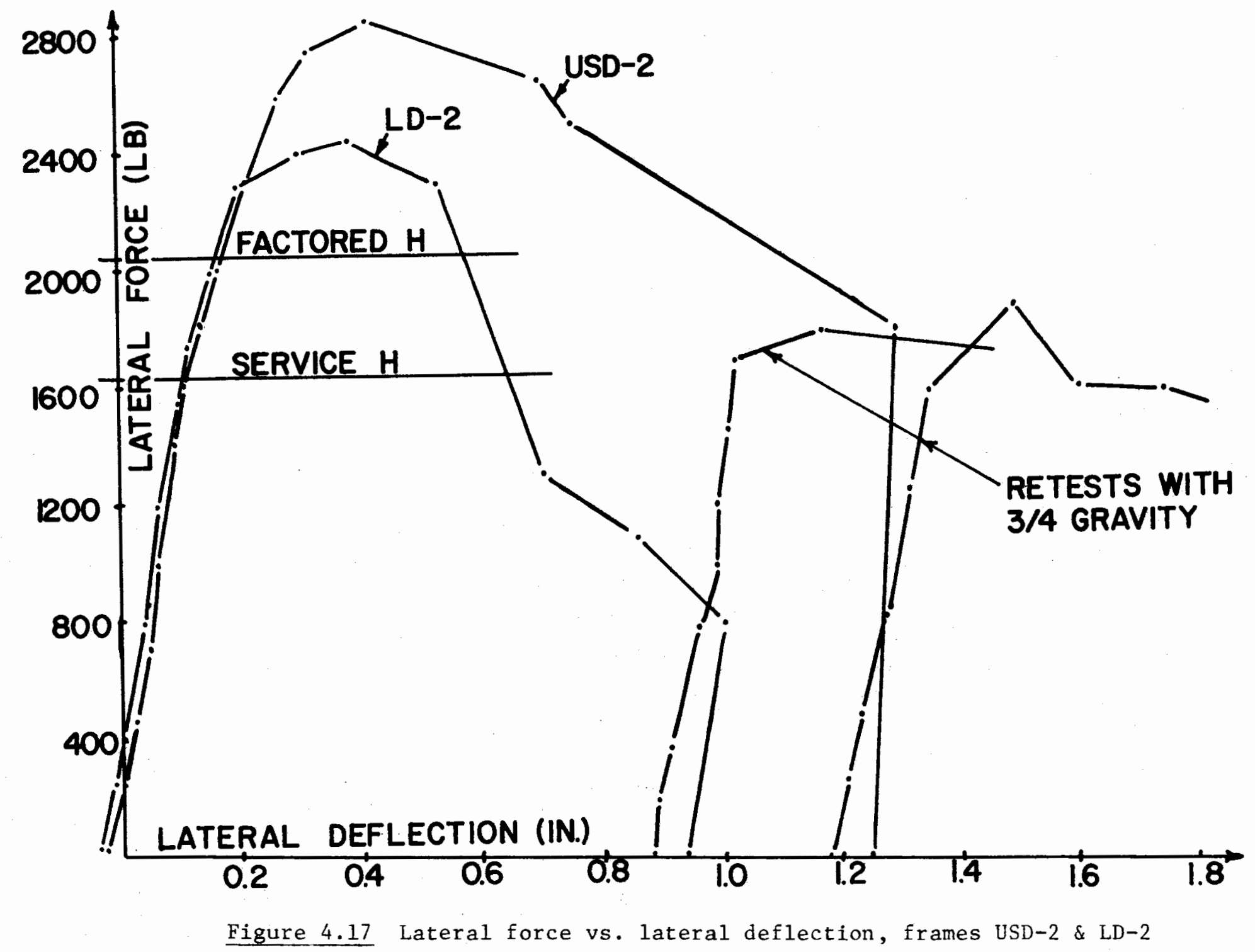




\section{CHAPTER V}

\section{SUMMARY, CONCLUSIONS, AND RECOMMENDATIONS}

The objective of this investigation was to determine the physical behavior of single story, single bay reinforced concrete frames under the action of low column axial loads, beam loads, and sway loads. The investigation was carried out both analytically and experimentally. The main analytical tool used in this investigation was the computer program "NONFIX7", which is a generalized computational method for nonlinear force deformation relationship and secondary forces due to displacement of the joints during loading.

In the experimental portion of this investigation, two rectangular frames, one designed by the Ultimate Strength Design method and the other by a Limit Design method were prepared and tested to fallure with short time loading. Beam and column lengths were 84.00 and 21.00 inches respectively. Frame loading consisted of column axial loads, beam loads applied at third points of beam span, and lateral load. Column and beam "gravity" loads were increased with constant beam to column load ratio until the maximum design loads were reached. These loads were then held constant while lateral load was applied until frame failure. Based on the work conducted in this investigation, the following conclusions are valid:

1) The loading system used in this investigation worked properly with no difficulty in operation and recording. 
2) Under gravity loads, both test frames continued to resist increading lateral load even after the formation of one hinge at the leeward corner of the beam. The frames were still stable under increasing lateral load until a second hinge formed at an intermediate point in the beam. The frames with two hinges then became unstable.

3) The nonlinear computer program used to describe the general behavior of the frames in this investigation provided a reasonable estimate of ultimate capacity, deflection and mode of failure.

4) The moment magnification factors based on computations using the 1971 ACI building code and Merchant-Rankin formula reasonably predicted the measured values.

5) Frame stiffnesses were about the same for both frames, but frame USD-2 was capable of resisting $17 \%$ more lateral load than frame LD-2.

6) The maximum lateral load taken by each frame during reloading was on the average, about $70 \%$ of the original capacity.

In order to obtain information on validity of limit design concepts for more realistic unbraced frames, tests on rectangular multi bay-multi column concrete frames are recommended. 
REFERENCES

1. Recommendation for an International Code of Practice for Reinforced Concrete, Committee European de Beton, Paris, 1964.

2. Baker, A. L. L., "Ultimate Load Design of Concrete Structures," Proc. Inst. Civil Engineers (London) 21 Feb 1962.

3. Mattock, A. H., "Rotational Capacity of Hinging Regions in Reinforced Concrete Beams," Flexural Mechanics of Reinforced Concrete, ACI SP-12, 1965, pp. 143-180.

4. Sawyer, H. A., "Comments on Model Code Clauses," ACI Journal, Sept. 1968, pp. 715-719.

5. Broms, B. and Viest, I. M., "Design of Long Reinforced Concrete Columns," ASCE Journal, Vo1. 84, No. ST4, July, 1958.

6. Ferguson, P. M., and Breen, J. E., "Investigation of the Long Concrete Column in a Frame Subject to Lateral Loads," Symposium of Reinforced Concrete Columns, ACI SP-12, 1966, pp. 75-118.

7. Rad, F. N., "Behavior of Single Story Two-Column Reinforced Concrete Frames Under Combined Loading," Ph.D. dissertation, University of Texas, 1972.

8. Gunnin, B. L., "Nonlinear Analysis of Planar Frames," Ph.D. dissertation, University of Texas, January, 1970.

9. Honnested, E., "A Study of Combined Bending and Axial Load in Reinforced Concrete Members," University of Illinois Bulletin, Engineering Experiment Station Bulletin Series No. 399, November, 1951.

10. ACI Committee 318, Building Code Requirements for Reinforced Concrete (ACI 318-71), American Concrete Institute, Detrolt, Michigan, 1971.

11. Gavin, T. G., "An Experimental Investigation of Unbraced Reinforced Concrete Frames," Thesis, Portland State University, May 1977.

12. Ferguson, P. M., Reinfroced Concrete Fundamentals, John Wiley \& Sons, Inc., New York 1973.

13. ACI Committee 340, U1timate Strength Design Handbook, SP. No. 17A, American Concrete Institute, Detroit, Michigan, 1968. 
14. Wood, H. R,, "Effective Lengths of Colums in Multi-story Buildings" Structural Engineering Journal, July 1974, No. 7, Volume 52, pp. 235-244. 